\title{
Coordination of Hours within the Firm
}

\author{
Labanca, Claudio; Pozzoli, Dario
}

Document Version

Final published version

DOI:

10.2139/ssrn.3230532

Publication date:

2018

License

CC BY-NC-ND

Citation for published version (APA):

Labanca, C., \& Pozzoli, D. (2018). Coordination of Hours within the Firm. Copenhagen Business School, CBS.

Working Paper / Department of Economics. Copenhagen Business School No. 7-2018TTPI - Working Paper /

Tax and Transfer Policy Institute No. 16/2018 https://doi.org/10.2139/ssrn.3230532

Link to publication in CBS Research Portal

\section{General rights}

Copyright and moral rights for the publications made accessible in the public portal are retained by the authors and/or other copyright owners and it is a condition of accessing publications that users recognise and abide by the legal requirements associated with these rights.

Take down policy

If you believe that this document breaches copyright please contact us (research.lib@cbs.dk) providing details, and we will remove access to the work immediately and investigate your claim. 
Copenhagen

Business School

HANDELSHøJSKOLEN

\section{Department of Economics}

Copenhagen Business School

Working paper 7-2018

Coordination of Hours within the
Firm
Claudio Labanca
Dario Pozzoli

Department of Economics - Porcelænshaven 16A, 1. DK-2000 Frederiksberg 


\title{
Coordination of Hours within the Firm
}

\author{
Claudio Labanca* \\ Dario Pozzoli \\ Monash University \\ Copenhagen Business School
}

July 26, 2018

\begin{abstract}
Although coworkers are spending an increasing share of their working time interacting with one another, little is known about how the coordination of hours among heterogenous coworkers affects pay, productivity and labor supply. In this paper, we use new linked employer-employee data on hours worked in Denmark to first document evidence of positive correlations between wages, productivity and the degree of hours coordination - measured as the dispersion of hours - within firms. We then estimate labor supply elasticities by exploiting changes made to the personal income tax schedule in 2010. We find that hours coordination is associated with attenuated labor supply elasticity and spillovers on coworkers not directly affected by the tax change. These spillovers led to a $15 \%$ increase in the marginal excess burden from the 2010 tax reform, and if ignored, they induce substantial downward bias in estimates of the labor supply elasticity. We explain these findings in a framework in which differently productive firms choose whether to coordinate hours in exchange for productivity gains, leading more productive firms to select into coordinating hours and to pay compensating wage differentials.
\end{abstract}

JEL Codes: J31, H20, J20

${ }^{*}$ We are extremely thankful to Julie Cullen, Gordon Dahl, Roger Gordon, Gordon Hanson, Marc Muendler, Sam Bazzi, Prashant Bharadwaj, Zach Breig, Giacomo De Giorgi, Itzik Fadlon, Michela Giorcelli, Daniel Hamermesh, Krislert Samphantharak, Esben Schultz and to the seminar participants at Bocconi University, Boston College, Collegio Carlo Alberto, Copenhagen Business School, Monash University, Scancor at Stanford, Stockholm School of Economics, UCD, UCSB, UCSC, UCSD, UCM, the 2016 SOLE meetings for the helpful comments. Funding provided by the Danish Council for Independent Research in Social Sciences, Grant no. DFF 6109-00007, and from the Carlsberg Foundation, Grant no.CF14-0031, is gratefully acknowledged. 


\section{Introduction}

In recent decades firms have become more collaborative, with coworkers spending a greater share of their working time interacting with one another (Delarue et al., 2008; Cross and Gray, 2013). One key aspect of the cooperation within firms is that it necessitates some degree of coordination of hours. Specifically, a greater need for interaction may require that coworkers work a more similar number of hours, despite possibly different labor supply preferences. While existing studies suggest that greater cooperation is associated with improved worker productivity (e.g., Hamilton et al., 2003; Chan, 2016), little is known about how hours coordination affects worker behavior or firm performance.

However, a better understanding of hours coordination is important for at least two reasons. First, coordination ties together the hours supplied by heterogeneous coworkers and, in doing so, it distorts the effects of policies that only affect the labor supply of a group of workers in a firm. In fact, coordination restrains the ability of the workers who are targeted by a policy to change their supply of hours. At the same time it generates labor supply spillovers from changes in the hours of targeted workers to other coworkers. In the specific case of tax reforms, these distortions result in higher tax efficiency costs and provide a new explanation for the low elasticity of labor supply found in several other studies (e.g., Chetty, 2012). Second, to the extent that hours coordination improves productivity but requires that firms pay compensating wage differentials for offering a limited choice of hours, the study of coordination may help explain the observed link between productivity and wages in a firm (e.g., Card et al., 2018).

In this paper, we first document the features of coordinated firms. We use unique linked employer-employee data from Denmark to measure hours coordination and to shed light on how this correlates with other firm characteristics, including wages and productivity. Next, we explore how coordination distorts the effects of a policy intervention by studying the labor supply response to a Danish tax reform that predominantly affected high-income workers. The specific features of this reform combined with the richness of the Danish data provide a rare opportunity to quantify the effects of hours coordination on the labor supply and on the efficiency costs of a tax reform. 
We conceptualize the link between firm profitability, coordination of hours, wages and labor supply elasticities in a framework where firms with different productivity employ workers with heterogeneous desired work hours. In this framework, firms can choose whether to coordinate hours. Coordination enhances productivity but entails fixed costs and requires the hours worked to be the same across heterogeneous coworkers. We derive four main predictions. (1) Firms that coordinate hours pay compensating wage differentials for imposing sub-optimal hours. (2) Firms that are ex ante more productive, which gain the most from coordination, choose to coordinate hours and thus incur higher labor costs. (3) Coordination attenuates the labor supply responses of workers targeted by a tax change. (4) In coordinated firms, a tax change that affects one type of workers has spillovers on the hours worked by other coworkers.

We investigate these predictions using linked employer-employee registers of the Danish population. Denmark is a particularly fitting setting for our study. The unique features of the Danish data allow us to link the number of hours worked to individual and firm characteristics. Additionally, in 2010, the government mandated a personal income tax reform that substantially lowered the marginal tax rates on high incomes while leaving almost unchanged the marginal tax rates of low-income workers. Furthermore, compared to other European countries, Denmark has a relatively flexible labor market in which employers have considerable discretion in setting wages and hours (Botero et al., 2004; Hummels et al., 2014). In particular, there are two institutional features that allow for discretion in the provision of hours by salaried and hourly workers: overtime hours and the possibility to convert paid vacation in working time.

We measure coordination using the standard deviation of average hours worked across skill groups in a firm. In doing so, we assume - consistent with survey data on desired working hours in Denmark - that workers in different skill groups have different labor supply preferences. Thus, we interpret a lower dispersion of hours as implying a greater overlap of workers at the workplace and, therefore, higher coordination. ${ }^{1}$ In line with this interpretation, we find that alternative measures of the interaction among coworkers from O*NET, the Survey of Adult Skills, and the Danish Time Use Survey strongly correlate with our measure of hours coordination.

\footnotetext{
${ }^{1}$ Ideally, we would measure coordination based on the degree to which coworkers with different labor supply preferences work at the same time of the day or interact with one another. Unfortunately, data of this type do not exist on such a large scale. We focus on full-time workers because Danish Time Use Survey data reveal that part-timers are more likely to start working later during the day or to work over weekends.
} 
With this measure of coordination in hand, we first document the features of coordinated firms. This analysis reveals that more-coordinated firms are more productive, larger in size, more likely to export and less likely to employ part-time, hourly and female workers. Next, we turn to a more systematic analysis of how the degree of coordination at a firm relates to the wage premium paid to workers. We estimate the premium as the firm fixed effect from a regression of hourly wages on individual, firm fixed effects and time-varying characteristics (Abowd et al., 1999). Then, we regress this premium on our measure of coordination. In line with the theory (Prediction 1), we find a strong and positive association between the firm component of wages and hours coordination across and within sectors. This correlation is robust to a number of firm characteristics that are known to affect wage inequality across firms. ${ }^{2}$ In the same specification, exporter status has a similar predictive power while firm size is not as predictive as coordination.

After controlling for measures of firm productivity, the correlation between wages and coordination is insignificant. In line with the theory (Prediction 2), this suggests that only highly productive firms can afford to pay higher wages to achieve greater coordination. Specifically, we estimate that coordination can explain between $4 \%$ and $12 \%$ of the wage inequality due to productivity across firms within the same sector. While descriptive, these findings suggest that a relevant part of the documented correlation between the firm component of wages and productivity may reflect wage differentials for greater coordination in more productive firms.

In the second part of the paper, we analyze the effects of a tax reform that abolished the middle bracket of a 3-bracket progressive tax schedule and lowered the top tax rates. This resulted in a sizable reduction of the marginal tax rates of workers who were formerly in the top and middle tax brackets prior to the reform (henceforth, high-skilled workers).

To identify the attenuating effects of coordination, we estimate the elasticity of hours worked by high-skilled workers in high- versus low-coordination firms. In doing so, we use the tax reform as an instrument for the observed changes in after-tax earnings (Gruber and Saez, 2002). In line with the model (Prediction 3), we find an elasticity that is close to zero and insignificant

\footnotetext{
${ }^{2}$ For instance, we control for firm size (Mueller et al., 2015), exporter status (e.g., Helpman et al., 2016), the skill and gender composition of the workforce (Card et al., 2016, Song et al., 2016), the average number of hours, the unionization rate (e.g., Dickens, 1986), and overtime premiums (Cardoso et al., 2012).
} 
in high-coordination firms and a significant elasticity of -0.1 in low-coordination firms.

Next, we test for the existence of labor supply spillovers by estimating the elasticity of hours worked by low-skilled workers to the tax-driven change in average hours worked by high-skilled coworkers. We find an elasticity of 0.88 , which implies an increase of 0.85 hours worked by lowskilled workers for each additional hour provided by high-skilled coworkers. Consistent with our framework (Prediction 4) we find lower spillover effects among workers in low-coordination firms. Importantly, the effects of coordination are robust to an extensive set of other firm controls such as firm productivity, size or workforce unionization.

Our findings of attenuating and spillover effects of coordination have multiple implications. First, they show that the elasticity of labor supply captures only part of the burden associated with a tax change (Feldstein, 1999) since it neglects the indirect effects on untargeted coworkers. By including spillovers, we estimate a $15 \%$ increase in the marginal excess burden from the 2010 Danish tax reform. Second, due to hours coordination, using workers who are not directly targeted by a tax change as a control group produces downward-biased estimates of the labor supply elasticity. We estimate that in our setting, the elasticity obtained using low-skilled workers as a control group would capture only $20 \%$ of the high-skilled response. More generally, our study suggests that hours coordination is important for policy evaluation, and it should be taken into account in the analysis of any intervention that affects the labor supply of one group of workers in a firm (e.g., older workers, parents).

This study relates to multiple strands of the literature. First, it relates to the literature on the effects of labor market frictions on labor supply responses to taxation (e.g., Kleven and Waseem, 2013). Within this literature, constraints on hours imposed at the firm level are usually viewed as a leading explanation for small labor supply responses to tax changes (Chetty et al., 2011; Best, 2014; Battisti et al., 2015). However, due to the lack of information on hours worked within firms, little is known about the source of these constraints or the magnitude of their effects. Using newly available data on hours and the quasi-experimental variation derived from a tax reform, we provide the first firm-level evidence quantifying the magnitude of a mechanism - coordination of hours - through which hours constraints attenuate the labor 
supply responses to taxation. ${ }^{3}$

Second, we contribute to the extensive literature on wage and productivity differentials across firms (e.g., Syverson, 2011; Card et al., 2018). Specifically, we offer a look inside firms by modeling, and empirically quantifying, the importance of coordination of hours as a rationale that leads more-productive firms to pay higher wages. In this respect, our results document a specific mechanism that can explain recent findings on compensating differentials as an important source of wage inequality across firms (Lavetti and Schmutte, 2016; Sorkin, 2018). ${ }^{4}$ Relative to the literature on compensating differentials from less-desirable hours, our results emphasize the importance of considering hours worked relative to those of other workers in the firm as a way to measure dis-amenities from hours at the workplace (e.g., Rosen, 1986; Abowd and Ashenfelter, 1981; Card et al., 2016; Goldin and Katz, 2016; Mas and Pallais, 2017).

The remainder of the paper is organized as follows. Section 2 presents the conceptual framework, Section 3 describes the data and the institutional setting. Section 4 presents the empirical relationships between coordination, wages and firm productivity. Section 5 quantifies the effects of coordination on the elasticity of labor supply. Finally, Section 6 concludes.

\section{Conceptual framework}

The standard labor supply model is based on the assumption that employers are indifferent to the hours supplied by their employees. However, hours worked vary across sectors and, most notably, across firms within a sector. Figure 1 shows the distribution of weekly hours worked across six major sectors in Denmark. The distribution is considerably more concentrated in

\footnotetext{
${ }^{3}$ Battisti et al. (2015) present evidence of reduced intertemporal elasticities from structural simulations of a policy that only affects a fraction of a firm's workforce. This evidence is consistent with the attenuating effects of coordination on steady-state elasticities that we document. We complement their analysis by being able to measure coordination using firm-level data on hours and an actual preference shock deriving from a tax reform. Our results also help to shed light on existing evidence at more aggregate levels. Kahn and Lang (1991) finds the elasticity of actual hours to be lower than the elasticity of desired hours. Our findings suggest that this difference may be linked to firm-level coordination. Hamermesh et al. (2008) documents synchronization of working schedules across US states. Our results indicate that coordination among coworkers is associated with co-movement of hours.

${ }^{4}$ Siow (1987) found higher wages in industry-occupations with less-volatile hours. Our research complements these findings with results from the linked employer-employee level. This allows us to measure the dispersion of hours between coworkers and examine how this relates to wage inequality across firms.
} 
the service sector than in agriculture, manufacturing or construction, despite that the latter sectors are more unionized than services.

The variation in hours worked across sectors, however, accounts only for a small part of the overall variation in hours. A decomposition of the variance of total annual hours worked in Denmark into between- and within-sector variability first, and then into cross- and withinfirm variability shows that cross-firm variation explains more than $35 \%$ of the overall variance, whereas merely $4 \%$ of the overall variation occurs between 1-digit sectors (Figure 2). ${ }^{5}$ This descriptive evidence suggests that employers may not be indifferent to their workers' supply of hours. Motivated by this evidence, in this section, we propose a model in which firms endogenously choose whether to restrict the range of hours available to their employees. Then, we examine how this affects wages and labor supply elasticities.

\subsection{Workers}

There are two types $i$ of workers, $N_{H}$ workers with high skill $(i=H)$ and $N_{L}$ workers with low skill $(i=L)$. Workers have preferences over a continuum of consumption goods $\omega \in \Omega$ and leisure $\ell_{i}$ of the following type (Dixit and Stiglitz, 1977; Prescott, 2004):

$$
U\left(Q_{i}, \ell_{i}\right)=\log \left[\int_{\omega \in \Omega} q(\omega)^{\frac{\sigma-1}{\sigma}} d \omega\right]^{\frac{\sigma}{\sigma-1}}+\eta v\left(\ell_{i}\right),
$$

where $\left(Q_{i}\right)^{(\sigma-1) / \sigma} \equiv \int_{\omega \in \boldsymbol{\Omega}} q_{i}(\omega)^{(\sigma-1) / \sigma} \mathrm{d} \omega$ is the (exponentiated) consumption index for a worker of skill $i$, and $\sigma>1$ is the elasticity of substitution between any two goods. We assume that the taste parameter $\eta$ is positive and that the utility of leisure $v\left(\ell_{i}\right)$ is increasing and concave with $v^{\prime}\left(\ell_{i}\right)>0$ and $v^{\prime \prime}\left(\ell_{i}\right)<0$.

Workers can take employment either in the non-coordinated or in the coordinated labor

5 The variance of hours is decomposed into between- and within-group components as follows:

$$
\frac{1}{N_{t}} \sum_{i}\left(h_{i t}-\overline{h_{t}}\right)=\frac{1}{N_{t}} \sum_{g} \sum_{i \in g}\left(h_{i t}-\overline{h_{g t}}\right)+\frac{1}{N_{t}} \sum_{g} N_{g t}\left(\overline{h_{g t}}-\overline{h_{t}}\right)
$$

Where workers are indexed by $i$ and years by $t, g$ denotes groups (i.e., firms or sectors), while $N_{g t}$ and $N_{t}$ denote the number of groups and the number of workers, respectively. $h_{i t}, \overline{h_{g t}}$ and $\overline{h_{t}}$ are the worker hours, the average hours within each group and the average hours across all workers, respectively. The variance is decomposed for each year between 2003 and 2008. Figure 2 shows the average shares across all years. To the extent that hours are measured with errors, the within-firm component of the variance may be overestimated, which means that hours may vary between firms even more than our measure indicates. 
market. In the non-coordinated labor market, workers face equilibrium wages $\mathrm{w}_{i}^{*}$ and pick their optimal hours $h_{i}^{*}=1-\ell_{i}^{*}$, allowing for an optimal consumption level $Q_{i}^{*}$ with individual product demand $q_{i}^{*}(\omega)$, and resulting in a utility level $U_{i}^{*} \equiv U\left(Q_{i}^{*}, h_{i}^{*}\right)$ (see details in the online Appendix A.1).

In contrast, workers employed in the coordinated labor market must work for a prescribed number of hours $\hat{h}$ regardless of their skill level. In the coordinated market, firms offer skillspecific hourly wages $\hat{\mathrm{w}}_{H}$ and $\hat{\mathrm{w}}_{L}$ that are discussed in the next subsection. Workers in this segment consume $\hat{Q}_{i}$ and $\hat{q}_{i}(\omega)$, resulting in utility $\hat{U}_{i} \equiv U\left(\hat{Q}_{i}, \hat{h}_{i}\right)$.

Workers face a skill-specific tax rate $t_{i}$ that generates tax revenues distributed through a lump-sum transfer $T$ that balances the government's budget. The overall labor market for each skill group clears such that $N_{i}^{*}+\hat{N}_{i}=N_{i}$ for equilibrium wages $\mathrm{w}_{i}^{*}$ and $\hat{\mathrm{w}}_{i}$.

\subsection{The wage-hour function}

We assume perfect worker mobility between firms in the non-coordinated and coordinated segments of the labor market. One implication of this assumption is that, in equilibrium, a coordinated labor market can only co-exist with a non-coordinated labor market if workers are indifferent between employment in the two market segments. The indifference condition for each type- $i$ worker between coordinated and non-coordinated labor market segments is:

$$
U\left(\frac{\hat{\mathrm{w}}_{\mathrm{i}}}{P} \hat{h}\left(1-t_{i}\right)+\frac{T+\bar{\pi}}{P}, \hat{h}\right)=U\left(\frac{\mathrm{w}_{\mathrm{i}}^{*}}{P} h_{i}^{*}\left(1-t_{i}\right)+\frac{T+\bar{\pi}}{P}, h_{i}^{*}\right),
$$

where $P^{\sigma-1} \equiv \int_{\omega \in \boldsymbol{\Omega}} p(\omega)^{-(\sigma-1)} \mathrm{d} \omega$ is the (exponentiated) price index, and $\bar{\pi} \equiv \int_{\omega \in \boldsymbol{\Omega}} \pi(\omega) \mathrm{d} \omega /\left(N_{H}+\right.$ $N_{L}$ ) represents the equal distribution of firm profits as dividends. This condition implicitly defines the wage rates $\hat{\mathrm{w}}_{i}$ for each type- $i$ worker as a function of the hours worked $\hat{h}$. To illustrate this, in Figure 3, we assume that $\hat{h}>h_{i}^{*}$. For the sake of clarity in the figure, we ignore $T$ and $\bar{\pi}$ and assume $t_{i}=0, P=1$. Figure 3 shows that the wage rate $\hat{\mathrm{w}}_{\mathrm{i}}$ that makes the worker indifferent between working $h_{i}^{*}$ at rate $\mathrm{w}_{\mathrm{i}}{ }^{*}$ and working $\hat{h}$ is greater than the equilibrium wage $\mathrm{w}_{\mathrm{i}}{ }^{*}$. Since this applies to any hours choice $\hat{h} \neq h_{i}^{*}$, condition $(2)$ defines a function $\hat{\mathrm{w}}_{i}(\hat{h})$, which has $\mathrm{w}_{\mathrm{i}}^{*}$ as parameter, and that we refer to as the wage-hour function.

Regarding the properties of this function, under standard regularity conditions on the shape 
of the utility function, it can be shown that $\hat{\mathrm{w}}_{i}^{\prime}(\hat{h})<0$ if $\hat{h}<h_{i}^{*}$. In this case, a marginal increase in $\hat{h}$ shortens the distance between $\hat{h}$ and $h_{i}^{*}$, thus requiring less extra compensation to make the worker indifferent between working $\hat{h}$ and working $h_{i}^{*}$. Similarly, $\hat{\mathrm{w}}_{i}^{\prime}(\hat{h})>0$ if $\hat{h}>h_{i}^{*}$, whereas if $\hat{h}=h_{i}^{*}$, no extra compensation is needed, and thus, $\hat{\mathrm{w}}_{i}^{\prime}(\hat{h})=0$. Additionally, it can be shown that $\hat{\mathrm{w}}^{\prime \prime}(\hat{h})>0$ (online Appendix A.2). ${ }^{6}$ Therefore, the resulting wage-hour function is U-shaped with its minimum at the equilibrium wage $\mathrm{w}_{i}^{*}$, where hours $\hat{h}=h_{i}^{*}$.

The economic insight behind this function is that firms in the coordinated market need to offer higher wages to both skill groups when the coordinated hours differ from optimal hours. ${ }^{7}$

\subsection{Firms}

There is a continuum of firms, each producing a different variety $\omega$ of consumption goods under monopolistic competition. Every firm produces with a constant-returns-to-scale technology $q(\omega)=\gamma \phi G\left(n_{H} h_{H}, n_{L} h_{L}\right)$, where $\phi$ is a productivity parameter that differs from firm to firm under some probability distribution (similar to Melitz, 2003), $\gamma$ is a Hicks neutral productivity shifter that varies with hours coordination, and $G(\cdot, \cdot)$ is the production function. The firm employs $n_{H}$ high-skilled and $n_{L}$ low-skilled workers. In what follows, we denote by $G_{H}(\cdot, \cdot)$ the first derivative of $G(\cdot, \cdot)$ with respect to its argument $\left(n_{H} h_{H}\right)$ and by $G_{L}(\cdot, \cdot)$ the first derivative with respect to $\left(n_{L} h_{L}\right)$. For simplicity, we do not allow for market entry (Chaney, 2008). However, firms can choose whether to operate in the non-coordinated or in the coordinated labor market. In the non-coordinated labor market, $\gamma=1$, such that firms produce with productivity $\phi$. In the coordinated labor market, $\gamma=\hat{\gamma}>1$, meaning that firms can raise their productivity to $\hat{\gamma} \phi$ but must pay a fixed cost $\hat{F}$ to achieve hours coordination. ${ }^{8}$

\footnotetext{
${ }^{6}$ As we show in the online Appendix A.2, there are conditions on the curvature of the leisure preferences or economy-wide productivity that ensure that $\hat{\mathrm{w}}^{\prime \prime}(\hat{h})$ is positive.

${ }^{7}$ In the presence of search frictions, coordinated firms would still pay higher wages compared to their noncoordinated peers as long as search costs do not exceed the utility losses from accepting standardized hours $\hat{h}$.

${ }^{8}$ The fixed costs of coordination can be thought of as the infrastructure needed to sustain coordinated production such as office space, conference rooms, scheduling software, and the like.
} 


\subsubsection{Non-coordinated labor market}

In the non-coordinated labor market, firms take equilibrium wages $\mathrm{w}_{\mathrm{i}}^{*}$ and workers' preferred hours $h_{i}^{*}$ as given. Thus, they choose the number of high- and low-skilled workers that minimize costs:

$$
C^{*}(\omega) \equiv \min _{n_{H}, n_{L}} \mathrm{w}_{\mathrm{H}}^{*} n_{H} h_{H}^{*}+\mathrm{w}_{\mathrm{L}}^{*} n_{L} h_{L}^{*} \quad \text { s.t. } \quad G\left(n_{H} h_{H}^{*}, n_{L} h_{L}^{*}\right) \geq q^{*}(\omega) / \phi .
$$

The first-order conditions imply that

$$
\frac{G_{H}\left(n_{H}^{*} h_{H}^{*}, n_{L}^{*} h_{L}^{*}\right)}{G_{L}\left(n_{H}^{*} h_{H}^{*}, n_{L}^{*} h_{L}^{*}\right)}=\frac{\mathrm{w}_{\mathrm{H}}^{*}}{\mathrm{w}_{\mathrm{L}}^{*}} .
$$

We assume that $G_{H}(\cdot, \cdot)>G_{L}(\cdot, \cdot)$, such that $\mathrm{w}_{\mathrm{H}}^{*}>\mathrm{w}_{\mathrm{L}}^{*}$ and $h_{L}^{*} \neq h_{H}^{*}$, with $h_{L}^{*}<h_{H}^{*}$ if the substitution effect prevails and the opposite if the income effect prevails.

\subsubsection{Coordinated labor market}

Firms in the coordinated labor market offer contracts for a single number of hours $\hat{h}$ that workers of all skill levels must accept but offer skill-specific wages along the wage-hours function $\hat{\mathrm{w}}_{i}(\hat{h})$ such that each type- $i$ worker is indifferent between employment in the coordinated or non-coordinated labor market. This results in the following cost minimization problem:

$$
\begin{aligned}
& \hat{C}(\omega) \equiv \min _{n_{H}, n_{L}, h} \hat{\mathrm{w}}_{\mathrm{H}} n_{H} h+\hat{\mathrm{w}}_{\mathrm{L}} n_{L} h \quad \text { s.t. } \quad h G\left(n_{H}, n_{L}\right) \geq q^{*}(\omega) /(\hat{\gamma} \phi) \\
& \text { and } U\left(h \frac{\hat{\mathrm{w}}_{i}}{P}\left(1-t_{i}\right)+\frac{T+\bar{\pi}}{P}, h\right)=U\left(Q_{i}^{*}, h_{i}^{*}\right) \\
& \text { for } i=H, L .
\end{aligned}
$$

From which the first-order condition that implicitly defines $\hat{h}$ is (see online Appendix A.3):

$$
\hat{n}_{H} \hat{\mathrm{w}}_{\mathrm{H}}^{\prime}(\hat{h})=-\hat{n}_{L} \hat{\mathrm{w}}_{\mathrm{L}}^{\prime}(\hat{h}) \text {. }
$$

Condition (4) has several implications. First, it implies that optimal hours $\hat{h}$ are between $h_{L}^{*}$ and $h_{H}^{*}$. In fact, since $h_{H}^{*} \neq h_{L}^{*}, \hat{h}$ cannot be equal to either $h_{L}^{*}$ or $h_{H}^{*}$. Furthermore, if $\hat{h}$ is greater than $h_{L}^{*}$ and $h_{H}^{*}$, then $\hat{\mathrm{w}}_{H}^{\prime}>0$ and $\hat{\mathrm{w}}_{L}^{\prime}>0$, and thus, (4) cannot be satisfied. For

a similar reason, $\hat{h}$ cannot be smaller than $h_{L}^{*}$ or $h_{H}^{*}$ to satisfy (4). Second, (4) establishes that optimal hours are such that the marginal costs of increasing hours in coordinated firms equal the marginal benefits. To understand this, let us consider the case in which high-skilled 
workers desire to work more than low-skilled workers $\left(h_{H}^{*}>h_{L}^{*}\right)$. For any choice of coordinated hours $h_{L}^{*}<\hat{h}<h_{H}^{*}$, a marginal increase in $\hat{h}$ moves them closer to $h_{H}^{*}$. Therefore, it results in lower wage premiums paid to high-skilled workers and thus in wage bill savings in the amount of $\hat{n}_{H} \hat{\mathrm{w}}_{\mathrm{H}}^{\prime}$. However, the same increase in hours moves $\hat{h}$ further away from $h_{L}^{*}$. Thus, it results in higher wages paid to low-skilled workers and therefore in a higher wage bill in the amount of $\hat{n}_{L} \hat{\mathrm{w}}_{\mathrm{L}}^{\prime}$. At the optimum, the savings from marginally higher hours equal the costs. Finally, (4) implies that $\hat{h}$ is set closer to the desired hours of the larger group of workers in the firm. ${ }^{9}$

Based on (4), both high- and low-skilled workers in coordinated firms work suboptimal hours and are therefore compensated with wage premiums. We thus have the following:

Prediction 1 Firms that coordinate work time at a common number of hours for both skill groups pay higher hourly wages than non-coordinated firms, which take the supply of work hours as given.

\subsubsection{Endogenous market segmentation}

We now establish the conditions for the existence of the coordinated labor market segment in equilibrium. A firm producing variety $\omega$ maximizes its profits by setting the variety-specific price $p(\omega)$ given total demand. Maximized profits in the two segments are (online Appendix A.4):

$$
\begin{aligned}
\pi^{*}(\phi) & =\left(\frac{\sigma-1}{\sigma}\right)^{\sigma-1}\left(\frac{P}{\mu^{*}}\right)^{\sigma-1} \frac{E}{\sigma} \phi^{\sigma-1} \\
\hat{\pi}(\phi) & =\left(\frac{\sigma-1}{\sigma}\right)^{\sigma-1}\left(\frac{\hat{\gamma} P}{\hat{\mu}}\right)^{\sigma-1} \frac{E}{\sigma} \phi^{\sigma-1}-\hat{F}
\end{aligned}
$$

where $E=P Q$ are economy-wide expenditures, and $\mu^{*}, \hat{\mu}$ are minimized marginal production costs in the uncoordinated and coordinated segment, respectively. Based on this, a firm with productivity $\phi$ will choose to enter the coordinated labor market if and only if

$$
\hat{\pi}(\phi)>\pi^{*}(\phi)
$$

\footnotetext{
${ }^{9}$ A greater $\hat{n}_{i}$ in (4) raises the marginal costs of increasing $\hat{h}$ if $\hat{h}>h_{i}^{*}$ or decreases the marginal benefits of increasing $\hat{h}$ if $\hat{h}<h_{i}^{*}$. This implies that $\hat{h}$ moves closer to $h_{i}^{*}$ as $\hat{n}_{i}$ increases.
} 
If $\hat{\gamma}>\hat{\mu} / \mu^{*}$, this inequality can be rewritten in terms of a firm's productivity $\phi$ :

$$
\phi>\frac{\sigma}{\sigma-1} \frac{\hat{F}^{1 /(\sigma-1)}}{E^{1 /(\sigma-1)} P} \frac{\hat{\mu}}{\hat{\gamma}-\hat{\mu} / \mu^{*}} \equiv \hat{\phi},
$$

where $\hat{\phi}$ is the productivity threshold above which firms select into the coordinated segment. Intuitively, the higher the fixed cost $\hat{F}$ of coordinating or the higher the marginal cost $\hat{\mu}$ of producing in the coordinated market, the more elevated the entry threshold would be. Conversely, a less competitive market with a high overall price level $P$ and a larger aggregate economy with higher $E$ facilitates entry and therefore reduces the entry threshold. The inequality would be reversed if $\hat{\gamma}<\hat{\mu} / \mu^{*}$, and a coordinated labor market would not exist. Therefore, we can state the following:

Prediction 2 If a firm's productivity premium resulting from coordinating work hours is sufficiently large, $\hat{\gamma}>\hat{\mu} / \mu^{*}$, a coordinated labor market co-exists with a non-coordinated labor market. Firms with productivity above a unique threshold $\hat{\phi}$ coordinate work time, whereas firms with productivity weakly below that threshold remain non-coordinated.

Assuming that $\hat{\gamma}>\hat{\mu} / \mu^{*}$, we indicate with $\hat{M}$ and $M^{*}$ the total mass of non-coordinated and coordinated firms in equilibrium, respectively. It follows that the total number of each type- $i$ worker in the two labor market segments is $\hat{N}_{i}=\hat{M} \cdot \hat{n}_{i}$ and $N_{i}^{*}=M^{*} \cdot n_{i}^{*}$.

\subsection{The effect of a tax rate change on hours worked}

In this section, we explore the consequences of a change in the tax rate faced by high-skilled workers $t_{H}$ on optimal hours in the coordinated sector of the economy. Based on (4), one can derive the following expression (see online Appendix A.3):

$$
\frac{d \hat{h}}{d t_{H}}=-\left[\hat{\mathrm{w}}_{\mathrm{H}} \frac{U_{c c, H} U_{\ell, H}}{U_{c, H}^{2}\left(1-t_{H}\right)}+\frac{P U_{\ell, H}}{U_{c, H} \hat{h}\left(1-t_{H}\right)^{2}}\right] \times\left[\hat{\mathrm{w}}_{H}^{\prime \prime}(\hat{h})+\alpha \hat{\mathrm{w}}_{L}^{\prime \prime}(\hat{h})\right]^{-1},
$$

where $U_{c c, H}(<0), U_{c, H}(>0)$ and $U_{\ell, H}(>0)$ are the second derivative of the utility function relative to consumption, the marginal utility of consumption and the marginal utility of leisure for high-skilled workers, respectively, whereas $\alpha=\hat{n}_{L} / \hat{n}_{H} \cdot{ }^{10}$

\footnotetext{
${ }^{10}$ Here, we consider the case of a generic additively separable utility function of which (1) is an example. Since firms simultaneously optimize hours worked and the number of workers of each type, the envelope theorem implies that $\alpha=\hat{n}_{L} / \hat{n}_{H}$ is not affected by changes in $t_{H}$.
} 
Since $\hat{\mathrm{w}}_{i}^{\prime \prime}(\hat{h})>0$ (Section 2.2 ), the sign in (6) depends on the first term in brackets that consists of two terms. Starting from the left, the first term captures the income effect, while the second term is the substitution effect. If the income effect prevails over the substitution effect, the derivative is positive. In that case, the desired hours of high-skilled workers increase when $t_{H}$ increases, and so do the hours worked in the coordinated sector. Conversely, the derivative is negative if the substitution effect prevails over the income effects.

Hours worked by high-skilled workers in coordinated firms, however, are less elastic to the tax change than high-skilled workers' hours in uncoordinated firms. To visualize this, in Figure 4, we plot the case, consistent with our empirical findings, in which high-skilled workers desire to work more hours than low-skilled workers, the tax rate on high-skilled workers declines, and the income effect from the tax change prevails. In this case, as $t_{H}$ declines, desired hours decrease from $h_{0 H}^{*}$ to $h_{1 H}^{*}$, and thus, optimal hours in coordinated firms shift down from $\hat{h}_{0}$ to $\hat{h}_{1}$. If hours in the coordinated sector were to decline by as much as desired hours $\left(\left|\hat{h}_{1}-\hat{h}_{0}\right|=\left|h_{1 H}^{*}-h_{0 H}^{*}\right|\right)$, the benefits for coordinated firms from marginally increasing hours would remain unchanged relative to the pre-tax-change period. However, the marginal costs from increasing hours would be lower because coordinated hours after the tax change are closer to the desired hours of lowskilled workers. Therefore, due to the convexity of the wage-hours function, a marginal increase in hours would imply a smaller increase in the wage premiums paid to low-skilled workers than prior to the tax change. As a result, marginal benefits would exceed marginal costs, and hours would optimally increase. This implies that $\left|\hat{h}_{1}-\hat{h}_{0}\right|<\left|h_{1 H}^{*}-h_{0 H}^{*}\right|$.

Based on the discussion in the paragraph above, we can state the following two predictions: Prediction 3 (Attenuation): High-skilled workers in coordinated firms are less responsive to tax rate changes than are high-skilled workers in uncoordinated firms.

Prediction 4 (Spillovers) In firms that coordinate work hours, changes in tax rates that affect only high-skilled workers have spillover effects on the hours worked by low-skilled coworkers. Hours worked by high- and low-skilled workers move together.

In the empirical analysis that follows, Prediction 1 and 2 are discussed in Section 4, while the empirical analysis of Predictions 3 and 4 is presented in Section 5. ${ }^{11}$

\footnotetext{
${ }^{11}$ The algebra behind Prediction 4 remains difficult to treat even when assuming specific functional forms for
} 


\section{Institutional framework and data sources}

We base the empirical part of the study on a panel of Danish workers. In this section, we describe the main features of the Danish labor market and the main sources of our data.

\subsection{The Danish labor market}

Denmark is a particularly fitting setting for our study. In fact, a soft employment protection legislation combined with a generous social safety net makes the Danish labor market one of the most flexible in the world (Botero et al., 2004). In the past, wages and working time were set at the industry level through collective bargaining, but over time, the system has undergone a decentralization process that has made the negotiation much more firm-level based.

As an effect of this process and despite the fact that approximately $70 \%$ of the workers in the private sector are unionized, the wages of approximately $85 \%$ of them are negotiated directly at the worker-firm level (Hummels et al., 2014). The wage premium for workers who work overtime is usually equivalent to $50 \%$ of the normal wage for the first 3 hours and $100 \%$ of the normal wage for each hour of overtime that exceeds the first 3 hours.

Regarding working time regulation, sectoral agreements usually define the normal week to be composed of 37 hours on average and by not more than 8 hours of overtime work. Firms, however, have made increasing use of "opening clauses", which allow the union representatives at the company to develop local regulations that can deviate from sector-level agreements. In 2008, approximately $60 \%$ of full-time workers in the private sector were estimated to be covered by this type of local regulation (Dansk-Arbejdsgiverforening, 2012).

Further discretion in the choice of working hours comes from overtime work. Approximately $20 \%$ of the salaried workers and $60 \%$ of the hourly workers in our sample report at least one hour of paid overtime work. Finally, flexibility in the supply of hours derives from the possibility the utility function. Therefore, we only propose a graphical examination of this prediction. While our main analysis focuses on hours worked, a tax change that moves coordinated hours also affects wage rates. These effects are discussed in the online Appendix A.5. In the model in this section, we do not explicitly consider unions. As long as unions' preferences reflect workers' preferences, including unions would not change the main predictions. Moreover, in the empirical analysis, we do not find sizable differences in the magnitude of the effects between highly and less unionized firms. 
to convert hours of vacation into working hours at the contractual wage (online Appendix B.1). According to a survey of Danish private firms, $73 \%$ of $\mathrm{HR}$ managers report having employees who do not make full use of their vacation time (Bluegarden, 2014). In line with this, a decomposition of the variance of annual vacation hours into between- and within-firm variability reveals substantial variation in vacation time between firms, particularly among salaried workers (online Appendix Figure D.1). The relative flexibility that Danish firms have in setting hours is consistent with the substantial variation in hours worked across firms that we observe in the data (Figure 2).

\subsection{The data}

The empirical analysis is based on data from multiple sources (online Appendix Table D.2). We use data on individual socio-economic characteristics such as tax returns, earnings and education from the Integrated Database for Labor Market Research (IDA) that collects annual data on the entire Danish population. Data on annual hours of regular and overtime work are extracted from Lønstatistikken (LON). These are reported by employers whose contributions to the employees' pensions are based on hours worked. ${ }^{12}$ Unfortunately, not all workers in IDA can be matched to LON. For our study, however, it is particularly important to observe the hours of as many workers as possible within a firm. For this reason, we only consider firms in which the number of hours worked in a year are available for at least $95 \%$ of their workforce. Hourly wages are obtained as annual earnings over the sum of regular and overtime hours.

We use firm-level data from the Firm Statistics Register (Firmstat) and the Danish Foreign Trade Statistics Register that provide information on firm characteristics such as number of employees, industry affiliation, accounting and trade data. These registers cover the totality of private firms with more than 50 full-time equivalent employees and a representative sample of smaller private firms. We match each employee to the highest paying employer using the Firm-Integrated Database for Labor Market Research (FIDA) that links workers to firms in the employment spell of week 48 of each year only. For workers whose spell in week 48 lasted less

\footnotetext{
${ }^{12}$ Employers' pension contributions discontinuously jump at certain hours levels, and this may induce bouncing of reported hours. However, in the Danish setting, these discontinuities only affect part-time employees $(<27$ weekly hours) that are not included in the sample used for estimation.
} 
than 1 entire year, we use annualized hours and earnings.

We focus on full-time employees who were 15 to 65 years old in the period 2003-2011, when data are available from all sources. Following the official definition in place during that period, we define full-timers as those working more than an average of 26 weekly hours over a one-year period, which represent approximately $90 \%$ of the workers in the sample. We exclude parttimers for two main reasons: first, because they are more likely to work at unusual hours or fewer days in a week, and this can be problematic for measuring coordination (Section 4.3). The second reason is because focusing on full-timers makes our results more easily comparable to other studies, especially those on wage inequality across firms.

The final sample that we use includes more than 400,000 employees and approximately 8,300 firms. Table 1 reports descriptive statistics on the entire population (column 1), on the sample of the population that can be linked to data on firms and hours (column 2), and on our final sample that comprises firms for which data on hours are reported for $95 \%$ or more of the workforce (column 3). A comparison of columns 2 and 3 suggests that our final sample, while providing better information on hours worked, does not substantially distort the composition of the population for which records on individuals and firms are available.

\section{Coordination and wage differentials across firms}

\subsection{The empirical model}

In this section, we study the relationship between employer-specific wage premiums and the coordination of hours. To do so, we use an empirical model that relates the average wage premium paid by each firm $j$ to all its workers over the time period of the study $\left(\widehat{\psi_{j(i, t)}}\right)$ with a measure of the average coordination of hours over the same period $\left(\sigma_{j}\right)$ and a vector of average firm controls $\left(\bar{Z}_{j}\right)$. The equation to be estimated is as follows:

$$
\widehat{\psi_{j(i, t)}}=\delta_{0}+\delta_{1} \sigma_{j}+\delta_{2} \bar{Z}_{j}+v_{j}
$$

where $\widehat{\psi_{j(i, t)}}$ is the firm fixed effect from a firm-worker fixed effect model of the type described in Abowd, Kramatz and Margolis (1999) (henceforth, AKM) that we discuss in Section 4.2. The 
term $\sigma_{j}$ measures the average dispersion of hours worked across skill groups in a firm. Higher dispersion is interpreted as lower coordination. In Section 4.3, we discuss the details behind this variable. Based on Prediction 1 from the stylized model, we expect $\hat{\delta_{1}}$ to be negative.

Existing studies have shown that wage differentials across firms correlate with a number of other firm characteristics, some of which may confound the estimated correlation between the coordination of hours and wages. For this reason, in our empirical specifications, we include in $\bar{Z}_{j}$ an extensive set of controls intended to reduce these concerns. Among the controls, we include detailed geographic and industry fixed effects, controls for the composition of the workforce of a firm both in terms of gender and ability, as well as other firm characteristics such as firm size, exporter status or unionization rate, all of which have been found to correlate with wage differentials across firms.

Furthermore, one may worry that a negative correlation might be driven by institutional factors. In particular, workers in high-paying firms may work longer hours, and in doing so, they may bunch at 37 hours, which is the upper limit imposed on the average number of hours by most of the collective labor agreements. For a similar reason, if workers in high-paying firms are more likely to work overtime, higher wages may reflect statutory overtime premiums rather than compensating wage differentials. To take these factors into account, first, in all the specifications, we control for the average number of hours worked. Then, in a set of robustness checks, we explicitly explore these potential concerns by excluding firms that bunch at 37 hours and by considering only the earnings from regular hours.

While we control for a large number of confounding factors, in the absence of an exogenous change in coordination, the results of this analysis remain of a correlational nature. However, due to the limited evidence that exists on coordination of hours among coworkers, we regard this analysis as an important first step towards understanding a relevant economic phenomenon.

A growing number of studies have found evidence of a positive correlation between wage and productivity differentials across firms (e.g., Card et al., 2018). In the setting of our study, the coordination of hours can be regarded as a factor by which higher productivity in a firm translates into higher wages through compensating wage differentials. To measure the share of the correlation between wages and productivity in a firm that can be predicted by coordination, 
we first estimate equation (7) while omitting $\sigma_{j}$ and including measures of firm productivity such as value added and total factor productivity (TFP). From this alternative specification of equation (7), we obtain the partial R-squared associated with value added and TFP. Then, we measure the predictive power of hours coordination as the ratio of the partial R-squared associated with $\sigma_{j}$ from equation (7) and the partial R-squared associated with valued added and TFP. Henceforth, we refer to this ratio as the coordination share.

\subsection{The firm component of wages}

We estimate the average wage premium paid by a firm to all workers as the firm fixed effect in the following regression model:

$$
\ln \mathrm{w}_{\mathrm{ijt}}=\alpha_{i}+\psi_{j(i, t)}+\beta_{1} X_{i j t}+r_{i j t}
$$

where $\mathrm{w}_{\mathrm{ijt}}$ is the gross hourly wage earned by individual $i$ in firm $j$ in year $t . X_{i j t}$ is a vector of time-varying controls, while $\alpha_{i}$ controls for individual fixed effects. ${ }^{13}$ The variable of primary interest to us is the firm fixed effect $\psi_{j(i, t)}$ that measures the fixed component of the wage that is specific to firm $j$ once we control for individual fixed and time-varying characteristics.

Equation (8) is similar to the model used in AKM and several other studies. However, unlike most other studies, we use hourly wages rather than annual or monthly earnings as a dependent variable to better fit the theoretical model that refers to wage rates. Furthermore, we consider both male and female workers since coordination of hours involves all coworkers in a firm regardless of their gender. As in other studies, we focus on full-time workers only.

The AKM wage decomposition rests on the assumption of exogenous worker mobility conditional on observables. Following Card et al. (2013), in online Appendix C.1, we present a number of tests performed with the aim of investigating the plausibility of this assumption. The results of these tests suggest that endogenous mobility is unlikely to be an issue in our

\footnotetext{
${ }^{13}$ Following Card et al. (2013), we include in $X_{i j t}$ a set of interactions between year dummies and educational attainment, as well as interaction terms between quadratic and cubic terms in age and educational attainment. In addition, we also control for firm characteristics that change over time such as value added, sales, capital per employee, exporter status and the share of hourly workers. These additional firm controls isolate the average wage premium paid by a firm from temporary fluctuations due to firm-level shocks. The results obtained when we only include individual characteristics are noisier but still in line with the baseline regression and are shown in the robustness section. We estimate this regression on all workers and firms for which data on hourly wages, individual and firm characteristics are available (column 2 in Table 1).
} 
setting.

\subsection{Coordination of hours: measures and facts}

Ideally, we would measure coordination based on the degree to which coworkers with different labor supply preferences work at the same time of the day or interact with one another. Unfortunately, data of this type do not exist on a large scale. In what follows, we introduce an alternative measure of coordination based on the number of hours worked. Then, we use survey data to validate it, and finally, we discuss how this measure correlates with other firm characteristics.

Our measure of coordination is the standard deviation of hours worked across skill groups:

$$
\sigma_{j t}=\left[\frac{1}{S_{j t}} \sum_{s=1}^{S_{j t}}\left(\tilde{h}_{s j t}-\mu_{j t}\right)^{2}\right]^{1 / 2}, \tilde{h}_{s j t}=\frac{1}{N_{s j t}} \sum_{i=1}^{N_{s j t}} h_{i s j t}
$$

where $h_{i s j t}$ is the number of annual hours (regular and overtime) worked by employee $i$ in skill group $s$ in firm $j$ at time $t, \tilde{h}_{s j t}$ is the average of $h_{i s j t}$ across workers in $s j t$, and $\mu_{j t}$ is the average of $\tilde{h}_{s j t}$ across skill groups in firm-year $j t$. Finally, $N_{s j t}$ and $S_{j t}$ are the number of workers in $s j t$ and the number of skill groups in $j t$, respectively. We interpret a low value of this standard deviation as implying greater overlap of workers at the workplace and thus greater coordination. $\sigma_{j}$ in equation (7) is the average of $\sigma_{j t}$ over the years 2003-2011.

In measuring coordination, we use skill groups to proxy for differences in desired hours. Labor force survey data on desired hours support this assumption and indicate that desired hours increase with skills (online Appendix Table D.3). We use two alternative definitions of skill groups. First, starting from the estimated coefficients from equation (8), we measure skills as the sum of the fixed and the time-varying individual components of the hourly wages: $\widehat{s_{i j t}}=X_{i j t} \hat{\beta}_{1}+\hat{\alpha}_{i}$ (Iranzo et al., 2008 and Irarrazabal et al., 2014). We thus assign workers in each year to one of 10 skill groups defined as deciles of the distribution of $\widehat{s_{i j t}}$. As this measure of skills is based on individual fixed effects and observable time-varying characteristics, it might more closely reflect a worker's skills. In a setting where wages depend on hours, however, $\widehat{s_{i j t}}$ might still reflect compensating wage differentials to the extent that they are not fully captured by the firm component of wages in equation (8). For this reason, in online Appendix D.3, 
we present the results of a parallel analysis in which we define skills at the intersection of 3 educational groups (i.e., primary, secondary and tertiary education) and 3 broad occupational categories (i.e., manager, middle manager and blue collar). The results obtained from these two alternative definitions of skills do not differ in a meaningful way.

Since we do not observe the days and times when workers provided hours, our measure of coordination may be misleading if coworkers work a similar number of hours at different times of the day, on different days of the week or in different periods of the same year. For the latter case, since the vast majority of the workers in our sample work for the entire year, this is unlikely to play a major role. ${ }^{14}$ Furthermore, by focusing on full-time workers in private firms, we reduce concerns regarding whether they work on different days of the week or at different times of the working day. In fact, descriptive evidence from time use survey (TUS) data indicates that approximately $70 \%$ of full-time workers in Denmark start working between $7 \mathrm{am}$ and $9 \mathrm{am}$. Of the remaining 30\%, the vast majority are employed in either manufacturing or the health-care sector. However, the former sector emerges as one of the least coordinated from our analysis (Section 4.3.2), while most of the health-care sector is public and thus excluded from the analysis. Similarly, approximately $60 \%$ of full-time workers in the TUS do not work on weekends, and those that do work are mostly concentrated in the health-care sector (for further details see online Appendix C.2).

While focusing on full-timers reduces the concerns mentioned above, this may come at the cost of ignoring some of the variation that is of interest to us. In particular, firms with a low degree of coordination may hire relatively more part-timers. This concern, however, is mitigated by the fact that our measure of coordination strongly correlates with the share of part-timers, such that, based on $\sigma_{j t}$, more coordinated firms also hire fewer part-timers (Section 4.3.2).

\subsubsection{Validation exercises}

In this section, we use $\mathrm{O}^{*} \mathrm{NET}$ data to validate our measures of firm-level coordination. $\mathrm{O}^{*}$ Net is a survey that provides information on 277 occupation-specific descriptors such as work style, work content, interests and experience on 965 occupations. It is based on an ongoing survey of

\footnotetext{
${ }^{14}$ More than $75 \%$ of the workers in our sample have yearly employment spells that last more than 360 days.
} 
workers in the United States. We use the US survey because a similar survey is not available in Denmark. For each descriptor, $\mathrm{O}^{*}$ Net provides a measure of its importance in each of the occupations surveyed. We match this information to Danish registers based on occupation. We select the 3 descriptors in $\mathrm{O}^{*} \mathrm{NET}$ that capture aspects of a job that involve coordination of hours across skills. Similar descriptors are used in other studies to capture skill complementary (Bombardini et al., 2012). The descriptors are as follows: Contact: "How much does this job require the worker to be in contact with others (face-to-face, by telephone, or otherwise) in order to perform it?"; Teamwork: "How important is it to work with others in a group or team in this job?"; and Communication: "How important is communicating with supervisors, peers, or subordinates to the performance of your current job?".

The measure of the importance of these 3 descriptors ranges between 1 and 100. We take the median score across coworkers each year as a measure of the importance of each factor in a specific firm in that year. In Figure 5, we plot the standard deviation of hours versus the importance of the 3 descriptors across firm-year observations. A negative and statistically significant correlation emerges between each of the above descriptors and the standard deviation of hours across skill groups. That is, in firms where coordination of hours is low, the importance of aspects that involve coordination is also low.

In the online Appendix $\mathrm{C}$, we discuss an additional set of validation exercises based on the Survey of Adult Skills and the Danish Time Use Survey. The evidence emerging from these surveys is consistent with the evidence we found using $\mathrm{O}^{*} \mathrm{NET}$.

\subsubsection{Coordination and firm characteristics}

In this section, we document new facts that emerge when we examine the correlations between our measures of coordination and other firm characteristics.

Table 2 reports the standardized coefficients obtained from a set of regressions of coordination on a number of firm characteristics. A few interesting facts emerge from the table. First, firms that coordinate are more profitable: they have higher value added per employee and TFP. This evidence supports our theoretical framework in which more productive firms select into coordination. Moreover, firms that coordinate are more likely to be exporters and to employ 
a greater share of tertiary educated workers. Second, less coordinated firms employ relatively more hourly, part-time and female workers, which suggests that greater flexibility in these firms is achieved through the hiring of these workers. Third, conditional on industry fixed effects, the relationship between coordination and the share of unionized workers is insignificant. This suggests that a low dispersion of hours is not systematically linked to institutional constraints imposed by unions.

Existing studies document that managerial ability in a firm strongly correlates with the use of more advanced management practices and higher productivity (Ichniowski et al., 1997, Bloom et al., 2015). In a recent study by Bender et al. (2018), managerial ability is measured as the average individual fixed effect $\left(\hat{\alpha}_{i}\right)$ from an AKM model among the workers in the top quartile of the distribution of $\hat{\alpha}_{i}$ in each firm. In Table 2, we examine the correlation between this measure of managerial ability and hours coordination and find a strong positive association between the two. This suggests that hours are more coordinated in better managed firms.

Deming (2017) highlights the importance of social skills in reducing the costs of coordination among workers. To examine how coordination of hours correlates with social skills at the firm level, we construct 4 measures of social skill intensity within firms. These are based on the same O*NET descriptors used in Deming (2017) to measure the intensity of social skills at the occupational level (i.e.,Coordination, Negotiation, Persuasion and Social Perceptiveness). Consistent with Deming (2017), we find that hours coordination is stronger in firms where the social skill intensity is greater. In this respect, our empirical findings support the theoretical work that links synchronization of working schedules to the potential for better communication and cooperation (Lewis, 1969; Weiss, 1996).

If hours coordination is thought of as decreasing the costs of communication, then greater coordination may lead to more problems being solved at the top of the firm hierarchy, and thus to a decrease in wage inequality among blue collar workers and an increase in wage inequality among managers and between managers and blue collar workers (Garicano and Rossi-Hansberg, 2006). In line with this hypothesis, we find that high coordination in a firm is associated with a lower 90th-10th wage ratio among blue collar workers, a greater 90th-10th ratio among top managers, and a greater ratio between the average wage of managers and blue collar workers. 
Comparing the degree of coordination of firms in different sectors, we find that firms in the service industry coordinate more on average than those operating in the agriculture, manufacturing or construction sectors (online Appendix Table D.4). However, most of the correlations discussed in this section hold within narrowly defined sectors, which suggests that they are driven by differences across firms within sectors (see column 2 in Table 2). Reassuringly, when we use time use survey data to measure coordination based on the overlap of differently skilled workers at the workplace across hours of the day, we obtain a similar ranking of the sectors to that based on our measure of coordination (online Appendix C.2.2).

\subsection{Results}

In this section, we discuss the correlation between the firm component of wages and hours coordination. We begin by estimating this correlation across all firms and checking for the importance of other confounding factors. Then, we study how wages and coordination of hours correlate across firms within sectors, and finally, we assess the importance of coordination in linking productivity to wages in a firm.

Column 1 in Table 3 shows the standardized correlation between coordination and the firm component of wages. In line with Prediction 1 from the theory, higher coordination in a firm is associated with higher relative wage premiums. The magnitude of the coefficient is such that a one-standard-deviation (95 yearly hours) increase in hours coordination is associated with an increase equivalent to $0.9 \%$ of the average wage. ${ }^{15}$

However, from the discussion in the previous section, one may be concerned that this correlation may be driven by other firm characteristics. Thus, in column 2 , we control for firm size and exporter status to account for the fact that large firms and exporters pay higher wages (e.g., Mueller et al., 2015, Helpman et al., 2016, Macis and Schivardi, 2016). We also include region fixed effects to control for geographic differences in pay. In this last specification, we also control for the share of female workers in the firm because females are more likely to sort into low-paying firms or to bargain lower wages (Card et al., 2016). Finally, we control for the share

\footnotetext{
${ }^{15}$ This is obtained by multiplying the coefficient $(0.075)$ by the standard deviation of the firm component of wages $(0.26)$ that gives a $0.0195 \log$ wage increase, which is $0.9 \%$ of the average log wage $(2.26 \approx 183 \mathrm{DKK})$.
} 
of unionized workers as a way to capture rents from unions (Dickens, 1986), and the average number of hours worked to control for compensating differentials due to long hours.

In line with the literature, we find that firm size and export status are positively associated with wages and that better paying firms employ fewer female workers. Importantly, as in other recent studies, we find no evidence of compensating differentials due to long hours (Card et al., 2016). In contrast, we find that the magnitude, sign and significance of the correlation between wages and coordination is unaffected by these controls. This result highlights the importance of measuring relative hours in a firm to capture dis-amenities from working time.

In column 3, we add to the previous specification further controls for the skill composition of a firm's workforce. Recent studies show that the sorting of better able workers into better paying firms is important in determining wage inequality between firms (Card et al., 2013, Song et al., 2016). We control for the skill composition of the workforce in two ways. First, we include controls for the share of workers in each skill group. Then, to account for the fact that workers in the same skill group might differ across unobserved dimensions, we also control for the average values of the individual fixed effect $\left(\hat{\alpha}_{i}\right)$ in each quartile of the firm distribution of $\hat{\alpha}_{i}$. The average $\hat{\alpha_{i}}$ in the top quartile of the firm distribution has been found to correlate strongly with better managerial practices (Bender et al., 2018). Therefore, this additional set of controls also provides a way to proxy for differences in managerial practices across firms. The findings from this specification are reassuring because the coefficient attached to coordination retains its sign and significance while the magnitude increases.

The correlation remains negative and of similar magnitude when we exclude from the analysis firms that bunch at 37 hours (average hours between 36.5 and 37.5) or when we consider earnings and coordination from normal hours only, thus excluding overtime (columns 4 and 5). This suggests that the results are not affected substantially by these other institutional factors.

From the results of the previous section, we know that coordination positively correlates with the intensity of social skills in a firm. These skills have been associated with higher wages (Deming, 2017). In light of this, one possible reason for the higher returns associated with social skills may be that they allow for a greater degree of hours coordination that requires compensating wage differentials. However, to the extent that the returns to social skills are 
associated with other factors such as low substitutability with new production technologies, it is important to assess the extent to which the correlation between coordination of hours and wages can be linked to social skills. Thus, in column 6 , we add to the baseline specification the 4 measures of social skill intensity described in the previous section. We find that approximately $1 / 3$ of the correlation estimated in column 3 can be attributed to these skills, suggesting that most of the returns from coordination are not driven by social skills.

The strong correlation between the firm component of wages and coordination of hours persists within 1-, 2- or 3-digit sectors (columns 1 to 3 in Table 4), which suggests that coordination plays a non-negligible role in predicting wage inequality across firms within sectors. ${ }^{16}$

In most of the specifications, the magnitude of the correlation between wages and coordination is greater than the association between wages and firm size or capital per employee and of comparable magnitude to export status. These findings establish compensating differentials from hours coordination as an important predictor of between-firm wage inequality and are in line with other recent studies that, using a structural approach, identify compensating differentials as an important determinant of wage inequality across firms (Sorkin, 2018). ${ }^{17}$

In online Appendix C.3, we discuss a set of additional robustness checks to the results presented in this section, including a discussion of measurement errors in hours.

\subsubsection{Coordination of hours, wages and firm productivity}

Existing studies find that the firm component of wages strongly correlates with productivity in a firm (e.g., Card et al., 2018). In our theoretical model, more productive firms select into coordination and pay wage premiums (Predictions 1 and 2). Consistent with this, conditional on measures of firm productivity, such as value added per employee, the coefficient on the standard deviation of hours decreases and becomes insignificant, while value added per employee strongly

\footnotetext{
${ }^{16}$ The correlation within 2- or 3-digit industries is less precisely estimated. This is likely due to outliers. If coordination is measured through the median absolute deviation from the median hours, the coefficients are negative and strongly significant (columns 4 to 6 in Table 4).

${ }^{17}$ If we allow for mobility frictions, the wage differentials may also reflect rent sharing at better paying firms (Burdett and Mortensen, 1998). However, in a recent work, Lavetti and Schmutte (2016) propose an estimation procedure to identify compensating wage differentials using matched employer-employee data in the case of mobility under frictions. Following this procedure, we obtain estimates of similar magnitude (online Appendix Table D.5). This suggests that mobility frictions are unlikely to play a major role in our specific analysis.
} 
and positively correlates with wage premiums (column 8 in Table 4).

To measure the importance of hours coordination in explaining the wage inequality across firms that is due to productivity, we use the coordination share described in Section 4.1. In line with the evidence provided in the previous paragraph, this measure rests on the assumption that coordination only affects wages through productivity. We estimate a coordination share of $20 \%$ across all firms (column 3 in Table 3) and of 12\% (4\%) among firms in the same 1-digit (3-digit) industry (columns 1 and 3 in Table 4). This suggests that coordination predicts a non-negligible share of the variation of firm wages that is linked to productivity differentials and that cannot be explained by other factors that are known to affect wages and productivity.

\section{Coordination, labor supply and tax rate changes}

\subsection{The 2010 Danish tax reform}

We base the analysis presented in this section on the changes to the Danish personal tax schedule mandated by the 2010 tax reform. This reform led to a substantial decrease in the marginal tax rate on labor income faced by high income earners, while it left the tax rate of low-income workers almost unchanged. To the extent that low- and high-income workers differ in desired work hours, the reform provides an ideal setting to test for spillovers and attenuating effects from coordination.

The Danish income tax system is based on different types of income that are aggregated in multiple ways to form different tax bases that are taxed at different rates. A detailed description of the tax system can be found in online Appendix B.5. Relevant to our analysis, prior to the 2010 reform, income was taxed using a three-bracket progressive tax schedule. The 2010 reform abolished the middle tax bracket and decreased tax rates in the bottom and top brackets by 2 and 7 percentage points, respectively, between 2008 and 2011. The reform also increased the income amount at which the top bracket becomes effective, which increased by approximately 9\% in real terms between 2008 and 2011 (Figure D.2 in the Appendix). This led to a substantial decrease in the marginal tax rate on labor income faced by workers in the middle and top tax brackets. For them, marginal tax rates declined by approximately $16 \%$ and $10 \%$, respectively 
(Figure 6). The decrease was less pronounced in the bottom bracket, where the marginal tax rate decreased by approximately $4 \%$ (for further details, see online Appendix B.5).

Based on this, henceforth, by low-skilled workers, we mean the workers who were either tax exempt or in the bottom tax bracket in 2008 (left of the dashed line in Figure 7). Conversely, we define high-skilled workers as the workers who were in the middle or top tax bracket in 2008. From this group, however, we exclude workers who were in the top bracket in 2008 and who, based on their 2008 real income and the tax schedule in place after the reform, are predicted to be in the bottom tax bracket in 2011. We refer to these workers as the residual group. Workers in this group had incomes just above the lower limit of the top bracket in 2008 (dotted line in Figure 7). When the reform increased this limit (solid line in Figure 7) and abolished the middle bracket, these workers ended up (mechanically) in the bottom bracket after the reform.

Since the supply of hours in the residual group is unchanged by the reform and to keep the empirical framework as close as possible to the stylized model, in the baseline specification, we only study the spillovers from high- to low-skilled workers. ${ }^{18}$ However, we then show in the online Appendix that including the residual group does not affect the conclusions of the baseline analysis. Based on this classification, approximately $34 \%$ of the workers in our sample are low skilled, $54 \%$ are high skilled, the remaining $12 \%$ are in the residual category (Figure 8).

\subsection{The Tax Data}

We base the tax analysis on records from the Danish Tax Register that collects detailed information on all the items that determine individual tax liabilities in Denmark. Marginal tax rates, however, are not directly observable. For this reason, we use the available tax records to simulate marginal tax rates for each worker using a simulator model of the Danish tax system. We do so by extending the tax simulator used in Kleven and Schultz (2014) to the years 20062011. In this simulator, marginal tax rates on labor income are obtained as the increase in tax

\footnotetext{
${ }^{18}$ Relative to the high-skilled, workers in the residual group experienced a net-of-tax rate change that was approximately 3 times as large (Figure 8). As an effect of this, while for high-skilled workers, the income effect prevails and hours decrease as a consequence of the reform (Section 5.6.1), for workers in the residual group, the substitution effect prevails, and the estimated labor supply elasticity is positive but insignificant. In online Appendix C.4, we show that the insignificant effects may be due to the fact that these workers are close, in terms of income, to the top bracket and thus are unwilling to work more hours to avoid substantially higher taxes.
} 
liabilities due to a rise in labor income of 100 DKK. In particular, since the tax liability $\mathrm{T}()$ is a function of labor income $\left(z_{L A B}\right)$ and other income components $\left(z_{1}, \ldots z_{N}\right)$, the marginal tax rate on labor income is derived as follows $\tau=\left[T\left(z_{L A B}+100, z_{1}, \ldots z_{N}\right)-T\left(z_{L}, z_{1}, \ldots z_{N}\right)\right] / 100$.

In the empirical models that we use, we relate changes in labor supply to changes in marginal tax rates over 3-year intervals. Intervals of 3 years are commonly used in the taxation literature (e.g., Feldstein, 1995, Gruber and Saez, 2002, Kleven and Schultz, 2014). In the baseline specification, we focus on the interval 2008-2011 for two main reasons: first to minimize the concerns related to the inter-temporal shift in earnings for tax avoidance purposes that occurred between 2009 and 2010 (Kreiner et al., 2016) and, second, to reduce the possibility that the effects measured could capture lagged effects of a prior tax reform that occurred in 2004. However, as a robustness check, we also consider the years 2006 to 2008, but we exclude the years prior to 2006, as they would be too close to the 2004 reform.

\subsection{The attenuating effects of coordination}

We analyze the effect of the tax reform on the labor supply of high-skilled workers using the following empirical model:

$$
\log \left(\frac{h_{i t+3}^{H}}{h_{i t}^{H}}\right)=\beta_{0}+\beta_{1} \log \left(\frac{1-\tau_{i t+3}^{H}}{1-\tau_{i t}^{H}}\right)+\beta_{3} X_{i j t}+v_{i j t}
$$

In this model, the dependent variable is the log change in hours worked by high-skilled workers between 2008 and 2011. We relate this to the individual variation in the marginal net-of-tax rate on labor income $(1-\tau)$ that occurred over the same period. We control for a number of individual $(i)$ and firm $(j)$ characteristics $X_{i j}$ measured in 2008 (time t). The effect of the reform is captured by $\beta_{1}$, which measures the elasticity of hours worked to changes in the marginal net-of-tax rate.

To test whether the response of high-skilled workers in more coordinated firms is lower than that of similar workers in less coordinated firms, we estimate this model separately on workers employed in high- and low-coordination firms. In the presence of attenuating effects, the elasticity $\beta_{1}$ is expected to be smaller, in absolute terms, for workers in high-coordination 
firms.

In this specification, the labor supply elasticity is inclusive of the income effect. In online Appendix C.5, we attempt to separate the uncompensated elasticity of labor supply from the income elasticity. However, our study is based on a single tax change that primarily affected workers in the upper part of the income distribution. Therefore, unlike other existing studies, we have limited variation in tax rates across the income distribution that is needed to separately estimate the two effects in a precise way. Despite the noisy estimates, the results in online Appendix C.5 support our baseline findings.

\subsection{The spillover effects of a tax change}

In firms that coordinate hours worked, a tax rate change that targets one type of workers can affect hours worked by other workers in the same firm (Prediction 3). We test this prediction by relating the effects of a tax-driven change in hours worked by high-skilled workers to changes in the supply of hours by low-skilled coworkers. The equation to be estimated takes the following form:

$$
\log \left(\frac{h_{i j t+3}^{L}}{h_{i j t}^{L}}\right)=\alpha_{0}+\alpha_{1} \log \left(\frac{\overline{h_{j t+3}^{H}}}{\overline{h_{j t}^{H}}}\right)+\alpha_{2} \log \left(\frac{1-\tau_{i t+3}^{L}}{1-\tau_{i t}^{L}}\right)+\alpha_{3} X_{i j t}+\epsilon_{i j t}
$$

The dependent variable in this model is the log change in the number of hours worked by low-skilled worker $i$ in firm $j$ between 2008 and 2011. The regressor of key interest is

$$
\log \left(\frac{\overline{h_{j t+3}^{H}}}{\overline{h_{j t}^{H}}}\right)=\log \left(\frac{H_{j t+3}^{-1} \sum_{h=1}^{H_{j t+3}} h_{h j t+3}}{H_{j t}^{-1} \sum_{h=1}^{H} h_{h j t}}\right)
$$

This term captures the log change in the average number of hours worked by high-skilled workers in firm $j$. We isolate the tax-related component of this change using the average variation in the marginal net-of-tax rate on labor income among high-skilled workers in firm $j$ as an instrument for the change in hours. Section 5.5 describes this instrument in detail. Based on the theory, we expect $\alpha_{1}$ to be positive and greater in magnitude in more coordinated firms.

The term $\log \left(1-\tau_{i t+3}^{L} / 1-\tau_{i t}^{L}\right)$ in equation (11) captures the changes of the marginal netof-tax rate on labor income faced by low-skilled workers between 2008 and 2011. Since the reform lowered the marginal tax rate paid by low-skilled, this term controls for the direct effect 
of the reform on the supply of hours of low-skilled workers. Finally, $X_{i j t}$ is a vector of firm and individual controls measured in 2008.

The empirical specifications that we have discussed thus far differ from the standard model in the taxable income literature (e.g., Gruber and Saez, 2002) along two important dimensions. First, we estimate the effect of tax changes on hours worked rather than on labor income. In our setting, a tax rate change can shift hours and wage rates in opposite directions, which makes it difficult to interpret the overall effect on labor income. Second, in equation (11), we augment the standard model with an additional term that captures the spillover effects of the tax change among coworkers. This is done to reflect a key feature of our framework whereby the hours worked by one type of worker depend on the hours worked by the other workers in the same firm. Section A.6 in the online Appendix describes how to adapt the standard economic model underlying the empirical specification used in the literature to the specific features of our setting.

\subsection{Identification}

The identification of the effects of the reform from equations (10) and (11) needs to address multiple issues. First, due to the non-linearity of the tax schedule, the marginal tax rate in the post-reform period depends on post-reform income, which is endogenous to the supply of hours. This creates a correlation between $\Delta \log \left(1-\tau_{i t}\right)$ and the error terms in our specifications. Second, changes in the supply of hours by high-skilled workers in equation (11) might be correlated with changes in the supply of hours worked by low-skilled coworkers in endogenous ways. This might be the case, for instance, if both types of workers experience the same unobserved local labor market shocks, local policy reforms or changes specific to a firm (e.g., firm organizational changes, changes to the technologies used in production).

To address the first set of concerns, following the literature (e.g., Gruber and Saez, 2002), we construct a set of instruments based on mechanical tax rate changes that are driven only by variations in the tax laws. In practice, for each individual in the sample, we use a simulator of the Danish tax system to obtain marginal tax rates on labor income $\left(\tau_{M i t+3}\right)$ in the post-reform period (time $t+3$ ) based on income in the pre-reform period (time $t$ ) adjusted for inflation. 
We then construct the mechanical change in the marginal net-of-tax-rate on labor income of high-skilled workers as $\log \left(1-\tau_{M i t+3}^{H}\right)-\log \left(1-\tau_{i t}^{H}\right)$, and we use this as an instrument for the observed change $\Delta \log \left(1-\tau_{i t}^{H}\right)$ in equation (10). Similarly, we use the mechanical change in the marginal net-of-tax rate of low-skilled workers $\log \left(1-\tau_{M i t+3}^{L}\right)-\log \left(1-\tau_{i t}^{L}\right)$ as an instrument for the observed change $\Delta \log \left(1-\tau_{i t}^{L}\right)$ in equation (11).

By holding real income constant between $t$ and $t+3$, these instruments exploit the variation in the marginal tax rates due to changes in the tax schedule only. To give a sense of the identifying variation, Figure 8 plots the average mechanical change in the marginal net-of-tax rates among high- and low-skilled workers between 2008 and 2011. Due to the nature of the reform, the change is more pronounced for high-skilled (18\%) than for low-skilled (2\%) workers.

While these instruments are exogenous to post-reform income, they still depend on prereform income, which is problematic if the latter correlates with the error term due, for instance, to mean reversion or long-term income trends (Slemrod, 1998, Saez et al., 2012). To address this, we follow the existing literature and estimate a set of additional regressions in which we control for pre-reform income in a flexible way. Overall, however, we find that our baseline results are not affected in a noticeable way by these controls. This may be because, unlike most other studies, we estimate separate regressions on rather homogeneous groups of workers (i.e., low-skilled and high-skilled). Furthermore, we study a relatively short time period, thus limiting the concerns related to long-term trends.

Turning to the identification of the spillover effects $\left(\alpha_{1}\right)$ from equation (11), we use simulated marginal tax rates to construct the mechanical change in the average marginal net-of-tax rate on labor income faced by high-skilled workers in each firm $j$ :

$$
\log \left(\overline{\frac{1-\tau_{M j t+3}^{H}}{\overline{1-\tau_{M j t}^{H}}}}\right)=\log \left[\frac{H_{j t+3}^{-1} \sum_{h=1}^{H_{j t+3}}\left(1-\tau_{M h j t+3}\right)}{H_{j t}^{-1} \sum_{h=1}^{H}\left(1-\tau_{M h j t}\right)}\right]
$$

We then use this term as an instrument for $\log \left(\overline{h_{j t+3}^{H}} / \overline{h_{j t}^{H}}\right)$ in equation (11). This instrument isolates the component of the change in hours of the high-skilled due to the tax reform from other confounding factors. Its validity relies on the assumption that the instrument affects hours worked by low-skilled workers only through changes in the average hours of high-skilled 
coworkers. This assumption may be violated if, for instance, the tax reform, while changing the supply of hours by high-skilled workers, also led to the adoption of new technologies that required a different supply of hours by low-skilled workers. However, we fail to find significant effects of the reform on firm size, physical capital or the share of high- relative to low-skilled workers, which suggests that firm technologies were not affected by the reform (Appendix C.6).

Finally, one general concern regarding the instruments that we use is that they might capture other unobserved changes that occurred between $t$ and $t+3$, thus confounding the estimated effect of the tax reform (e.g., other policy reforms or macroeconomic shocks). For this reason, we present additional specifications in which we follow the workers from the baseline regressions back to 2006; then, we estimate our baseline models on all 3-year intervals between 2006 and 2011 while adding base-year fixed effects. These specifications also allow us to control for unobserved characteristics specific to all coworkers using firm fixed effects. While these models have some advantages over the baseline estimation, they result in weaker first stages (Section 5.6.2) and are more likely to capture lagged effects of the 2004 tax reform.

\subsection{Results}

\subsubsection{Coordination and attenuating effects}

Table 5 reports the elasticity of hours worked by high-skilled workers to the net-of-tax rate estimated from equation (10). In columns 1 to 3, we estimate the regression on all high-skilled workers in the sample, while in columns 4 to 7 , we differentiate between workers in high- and low-coordination firms. The base year in all the specifications is 2008. We measure the degree of coordination of each firm in the base year using the standard deviation of hours worked across skill groups, as described in Section 4.3. Highly coordinated firms are in the bottom half of the distribution of the standard deviation across firms, while low-coordination firms are in the top half. To attach each worker to the correct measure of coordination, we restrict the analysis to high-skilled workers who are at the same firm in 2008 and 2011.

The first column in Table 5 shows the OLS estimates, while all other columns are based on the IV model described in the previous section. In the absence of controls for pre-reform income, the elasticity from the IV model in column 2 is approximately -0.07 . Likely due to 
mean reversion, the elasticity increases to -0.05 when we control for income in 2008 (column 3). Based on this estimate, the total hours of high-skilled workers decreased by approximately $0.8 \%$ or about 15 hours on a yearly basis as an effect of the reform. ${ }^{19}$

When we divide the sample between workers at firms with a high (column 4) versus low (column 5) degree of coordination, however, we find substantial differences between the two groups. In line with Prediction 4, we estimate a statistically significant elasticity of approximately -0.1 in low-coordination firms, while in high-coordination firms, the elasticity is insignificant and approximately -0.02. The two elasticities are statistically different at the $5 \%$ level. Therefore, based on these estimates, hours worked by high-skilled workers in firms with a high degree of coordination were not significantly affected by the reform, while high-skilled hours in lowcoordination firms decreased by approximately $1.6 \%$, or about 30 hours per year. ${ }^{20}$

The difference between the two elasticities widens as we move towards the extremes of the distribution of coordination. In fact, workers in the top $25 \%$ most coordinated firms show even lower elasticities than in the baseline. Conversely, workers in the bottom $25 \%$ least coordinated firms are more responsive than the baseline (columns 6 and 7). This indicates that the attenuating effects increase with the degree of hours coordination in a firm.

The differential effects in the two types of firms are not driven by other observable firm characteristics, firm fixed effects or unobserved factors that occurred between 2008 and 2011. In fact, the results hold conditional on firm and base-year fixed effects (columns 1 to 4 in Table 6 ), and they are robust to the interaction between changes in marginal tax rates due to the reform and other base-year firm characteristics such as size, export status, share of unionized workers or productivity (columns 5 to 10 in Table 6 ).

When we separate the sample between salaried and hourly workers (online Appendix Table D.6), we find evidence suggesting that the different responses between high- and lowcoordination firms are driven by changes in the overtime hours of salaried workers (columns 1

\footnotetext{
${ }^{19}$ The result of $-0.5 \%$ is obtained as the product of the the elasticity $(-0.047)$ and the average log change in the net-of-tax rate between 2008 and 2011 (17\%). The figure $-0.8 \%$ is then multiplied by the average number of hours worked in 2008 by the high-skilled workers in the estimation sample (i.e., 1924) to obtain the change in hours due to the reform.

${ }^{20}$ The average change in hours worked is derived as the product of the elasticities in low-coordination firms (i.e., -0.097 for total hours and -0.061 for regular hours), the average net-of-tax rate change (17\%) and the average number of hours worked by high-skilled workers in low-coordination firms (i.e., 1914 total hours).
} 
and 2), while we fail to find sizable differences in the normal hours of salaried workers (columns 3 and 4 ) or in the total hours of hourly workers (columns 5 and 6).

Therefore, in agreement with the existing literature, we find an average elasticity of hours across all firms close to zero (Pencavel, 1986, Triest, 1990, Chetty, 2012). However, we document pronounced attenuating effects associated with coordination that provide a mechanism to explain the low elasticities reported by previous studies. Other studies that focus on labor income (rather than hours) find small and positive elasticities in Denmark (Kleven and Schultz, 2014). However, these studies consider the entire population, while we focus on full-time workers in private firms for whom data on hours are available. Using a comparable sample to analyze the effects on labor income, we find results that are in line with other studies (online Appendix Table D.24).

While coordination attenuates behavioral responses, it also lowers the dead-weight burden of taxation on high-skilled workers. Based on our results, we can conclude that if workers in high-coordination firms were to change their supply of hours as workers in low-coordination firms do, then the marginal excess burden would be twice as large. ${ }^{21}$

\subsubsection{Coordination and spillovers}

Table 7 reports the estimated elasticity of low-skilled hours to the average hours of high-skilled coworkers obtained from equation (11). In these specifications, the base year is 2008, and we focus only on low-skilled workers who are at the same firm in 2008 and 2011. Column 1 reports the OLS estimates, while columns 2 to 7 show the IV estimates. In the first 5 columns, we estimate the effects on regular hours, while in the last two, we examine the effects on total hours.

In line with Prediction 3, we estimate positive and significant spillovers that are robust to controls for pre-reform income (columns 3 and 4). Specifically, in our preferred specification (column 3), we estimate an elasticity of regular hours of low-skilled workers to the average hours of high-skilled coworkers of 0.88 . This implies an increase of 0.85 hours worked by low-skilled workers for each additional hour that high-skilled coworkers provide, on average. Based on

\footnotetext{
${ }^{21}$ The marginal excess burden (MEB) is defined as the ratio between the change in tax revenues due to behavioral responses to the tax reform and the total change in tax revenues (see also online Appendix A.6.1).
} 
this, we estimate that the regular hours of low-skilled coworkers decreased by approximately 8.5 hours (or $0.5 \%$ ) on a yearly basis as an effect of the reform. ${ }^{22}$

When we consider overtime hours, the elasticity of low-skilled to high-skilled hours is higher, which suggests even stronger spillovers from overtime (column 6). However, the point estimate from this specification might be inflated by the low power of the instrument (F-stat of approximately 4). Finally, when we divide the sample in temporary and salaried workers, we only find spillovers among hourly workers (Appendix Table D.8).

The existence of spillovers has two main implications. First, it implies an increase in the marginal excess burden from the tax reform deriving from the change in labor supply (and tax revenues) from low-skilled workers. Specifically, in our setting, we estimate that the the marginal excess burden increases by approximately $15 \%$ due to spillovers (see Appendix A.6.1 for details). Second, with spillovers, the use of untargeted workers as a control group to estimate the labor supply elasticity provides downward-biased estimates. This is yet another reason that may explain the low elasticity estimated in some of the existing studies (e.g., Eissa and Liebman, 1996; Kreiner et al., 2016). In our setting, using low-skilled workers as a control group in a difference-in-difference model would result in an elasticity of high-skilled hours of -0.01 (Figure 9 and Appendix Table D.7). This captures only approximately $20 \%$ of the elasticity obtained from the instrumental variable approach of the previous section .

We would expect the spillovers to be stronger in firms with a high degree of coordination. Consistent with this, Figure 10 shows that the average hours of low-skilled workers in high-coordination firms decreased after the tax reform relative to their counterparts in lowcoordination firms. Ideally, one would obtain a direct measure of the spillovers in the two types of firms by estimating equation (11) separately for workers in high- and low-coordination firms. Based on the results from the previous section, however, hours worked by high-skilled workers in high-coordination firms were not affected by the reform. As a result, we lack the first-stage variation to estimate the spillovers in these firms. Thus, in columns 4 and 7 of Table 7, we restrict the analysis to low-skilled workers in firms with a low degree of coordination

\footnotetext{
${ }^{22} \mathrm{An}$ increase in high-skilled hours by 1 is equivalent to a $0.053 \%$ increase. This causes an increase of $0.043 \%$ of low-skilled hours $(0.053 \% * 0.88)$ that, at the average hours worked by low-skilled workers $(1,812)$, is equivalent to 0.85 hours. The reform caused a decrease of approximately 10 regular hours worked by the high-skilled (elasticity of -0.03, see Table D.22), thus implying a change of 8.5 regular hours worked by low-skilled workers.
} 
where hours of high-skilled coworkers were significantly affected by the reform. Among these workers, we find lower spillovers than across all workers, which suggests weaker spillovers in low-coordination firms.

Our results complement those of other studies that find aggregate evidence of excess mass in the distribution of taxable income at kinks in the tax schedule (bunching) among a minority of workers who do not face these kinks (Chetty et al., 2011, Best, 2014). However, we are the first to provide firm-level evidence that suggests coordination as a mechanism through which changes in preferences over hours spill over to other coworkers. In doing so, we also document a much more pervasive phenomenon than that linked to aggregate bunching. In fact, when excluding taxpayers close to the major kinks in the Danish tax schedule, the spillovers remain significant and of similar magnitude (column 5 of Table D.27 in the Appendix).

In online Appendixes C.4 and C.5, we present a set of additional results and robustness checks that include flexible controls for pre-reform income, the estimation of attenuating and spillover effects based on an alternative database on hours worked, the use of alternative measures of coordination and the estimation of specifications that separate the uncompensated elasticity from the income elasticity.

\subsubsection{Spillovers and peer effects}

Spillovers across coworkers may occur through peer effects rather than hours coordination. The existing studies, however, find significant peer effects only among coworkers with similar skills in Denmark (Fadlon and Nielsen, 2017). On the contrary, we study spillovers across workers with different skills, which would suggest that peer effects may be of secondary importance in our setting.

To better investigate whether this is the case, we estimate equation (11) by distinguishing between spillovers from high-skilled coworkers in the same 3-digit occupation and those from high-skilled coworkers in different occupations. The results reported in column 2 of Appendix Table D.9 are suggestive of stronger spillovers across occupations than within occupations. This would suggest that peers play a secondary role in our results. We further investigate the importance of peer pressure by estimating the spillovers separately for workers in occupations 
characterized by more repetitive tasks and workers in less repetitive occupations. In fact, workers performing more standardized tasks can more easily observe and judge one another's work and therefore may face stronger peer pressure (Cornelissen et al., 2017). We select the most repetitive occupations using the classification proposed by Cornelissen et al. (2017), which also includes occupations such as agricultural helpers or cashiers for which peer effects are known to be strong (Mas and Moretti, 2009; Bandiera et al., 2010). We find significant spillovers only among workers in less-repetitive occupations, which confirms that peer pressure is unlikely to explain the spillovers in our setting (columns 3 to 6 in Table D.9). ${ }^{23}$

\section{Conclusions}

This paper explores how the coordination of hours affects the firm component of wages. Our findings indicate that coordination strongly correlates with wage differentials across firms. Future work might investigate how coordination is associated with other dimensions that are linked to firm wage inequality such as the gender gap (Card et al., 2016).

We also find attenuated responses to tax changes in high-coordination firms and spillovers on the supply of hours by coworkers not targeted by the tax reform. These suggest that the labor supply elasticity of the workers directly targeted by a tax reform captures only a part of the efficiency costs of a tax change. Therefore, future research and policy evaluations should take these effects into account when assessing the excess burden associated with a tax reform.

Finally, the implications of our results go beyond tax reforms and apply to any policy intervention that affects the preferences over hours of one group of workers in a firm. For instance, policies that target the supply of hours of older workers might indirectly affect the supply of hours of younger coworkers. Similarly, policies that directly affect workers with children may have spillovers on other coworkers. It would be interesting to evaluate, in these other settings, the effects of coordination of hours among workers with similar skills and incomes.

\footnotetext{
${ }^{23}$ One alternative explanations of the spillovers is the existence of complementarities in leisure time among coworkers. Unfortunately, the data at hand do not allow us to properly investigate this hypothesis. However, time use data indicate that Danish workers spend, on average, only $2.5 \%$ of their leisure time with non-family members. This suggests that leisure complementarities are likely to be small. In line with this interpretation, Georges-Kot et al. (2017) find small leisure complementarities among coworkers in France.
} 
MONASH UNIVERSITY

COPENHAGEN BUSINESS SCHOOL

\section{Supplementary Material}

An online Appendix for this article can be found at https://drive.google.com/file/d/ OByvVLbcKzrtAbVAwVEJWUVJtQTg/view

\section{References}

Abowd, J., Kramarz, F., and Margolis, D. (1999). High wage workers and high wage firms. Econometrica, 67(2):251-333.

Abowd, J. M. and Ashenfelter, O. C. (1981). Anticipated unemployment, temporary layoffs, and compensating wage differentials. Studies in labor markets, pages 141-170.

Ackerberg, D. A., Caves, K., and Frazer., G. (2015). Identification properties of recent production function estimators. Econometrica., 83 (6):2411 - 2451.

Bandiera, O., Barankay, I., and Rasul, I. (2010). Social incentives in the workplace. The Review of Economic Studies.

Battisti, M., Michaels, R., and Park, C. (2015). Coordinated labor supply within the firm: Evidence and implications. Ideas working paper.

Bender, S., Bloom, N., Van Reenen, J., and Wolter, S. (2018). Management practices, workforce selection, and productivity. Journal of Labor Economics, 36(S1):S371-S409.

Best, M. (2014). The role of firms in workers earnings responses to taxes: Evidence from Pakistan. Working paper.

Bloom, N., Sadun, R., and Van-Reenen, J. (2015). Management as a technology. LSE Memo.

Bluegarden (2014). Hr analyse ferie og forrets helligdage.

Bombardini, M., Gallipoli, G., and Pupato, G. (2012). Skill dispersion and trade flows. American Economic Review, 102(5):2327-48.

Botero, J. C., Simeon, D., Porta, R. L., de Silanes, F. L., and Shleifer, A. (2004). The regulation of labor. The Quarterly Journal of Economics, 119(4):1339-1382.

Burdett, K. and Mortensen, D. T. (1998). Wage differentials, employer size, and unemployment. International Economic Review, 39(2):257-273.

Card, D., Cardoso, A., and Kline, P. (2016). Bargaining, sorting, and the gender wage gap: Quantifying the impact of firms on the relative pay of women. Quarterly Journal of Economics, 131 (2):633-686. 
Card, D., Cardoso, A. R., Heining, J., and Kline, P. (2018). Firms and labor market inequality: evidence and some theory. Journal of Labor Economics, 36(S1):S13-S70.

Card, D., Heining, J., and Kline, P. (2013). Workplace heterogeneity and the rise of west german wage inequality. The Quarterly Journal of Economics, 128 (3):967-1015.

Cardoso, A. R., Hamermesh, D. S., and Varejo, J. (2012). The timing of labor demand. Annals of Economics and Statistics, (105/106):15-34.

Chan, D. C. (2016). Teamwork and moral hazard: Evidence from the emergency department. Journal of Political Economy, forthcoming.

Chaney, T. (2008). Distorted gravity: The intensive and extensive margins of international trade. The American Economic Review, 98 (4):1707-1721.

Chetty, R. (2012). Bounds on elasticities with optimization frictions: A synthesis of micro and macro evidence on labor supply. Econometrica, 80 (3):969-1018.

Chetty, R., Friedman, J. N., Olsen, T., and Pistaferri, L. (2011). Adjustment costs, firm responses, and micro vs. macro labor supply elasticities: Evidence from Danish tax records. The Quarterly Journal of Economics, 126(2):749-804.

Cornelissen, T., Dustmann, C., and Schnberg, U. (2017). Peer effects in the workplace. American Economic Review, 107(2):425-56.

Cross, R. and Gray, P. (2013). Where has the time gone? addressing collaboration overload in a networked economy. California Management Review, 56:50-66.

Dansk-Arbejdsgiverforening (2012). Lønstatistikken.

Delarue, A., Van-Hootegem, G., Procter, S., and Burridg, M. (2008). Teamworking and organizational performance: A review of survey-based research. International Journal of Management Reviews, 10(2):127-148.

Deming, D. J. (2017). The growing importance of social skills in the labor market. Quarterly Journal of Economics, 132(4):1593 - 1640.

Dickens, W. (1986). Wages, employment and the threat of collective action by workers. NBER Working Paper No. 1856.

Dixit, A. K. and Stiglitz, J. E. (1977). Monopolistic competition and optimum product diversity. The American Economic Review, 67(3):297-308.

Eissa, N. O. and Liebman, J. (1996). Labor supply responses to the earned income tax credit. The Quarterly Journal of Economics, 111(2):605-637.

Fadlon, I. and Nielsen, T. H. (2017). Family health behaviors. NBER Working Paper 24042.

Feldstein, M. (1995). The effect of marginal tax rates on taxable income: A panel study of the 1986 tax reform act. Journal of Political Economy, 103(3):551-572.

Feldstein, M. (1999). Tax avoidance and the deadweight loss of the income tax. Review of Economics and Statistics, 81:674-680. 
Garicano, L. and Rossi-Hansberg, E. (2006). Organization and Inequality in a Knowledge Economy. The Quarterly Journal Of Economics, 121(4):1383-1435.

Georges-Kot, S., Goux, D., and ric Maurin (2017). Following the crowd: leisure complementarities beyond the household. Journal of Labor Economics, forthcoming.

Goldin, C. and Katz, L. F. (2016). A most egalitarian profession: Pharmacy and the evolution of a family-friendly occupation. Journal of Labor Economics, 34(3):705-746.

Gruber, J. and Saez, E. (2002). Elasticity of taxable income: Evidence and implications. Journal of Public Economics, 84:1-32.

Hamermesh, D., Myers, C., and Pocock, M. (2008). Cues for Timing and Coordination: Latitude, Letterman, and Longitude. Journal of Labor Economics, 26(2):223-246.

Hamilton, B. H., Nickerson, J. A., and Owan, H. (2003). Team incentives and worker heterogeneity: An empirical analysis of the impact of teams on productivity and participation. Journal of Political Economy, 111(3):465-497.

Helpman, E., Itskhoki, O., Muendler, M.-A., and Redding, S. J. (2016). Trade and inequality: From theory to estimation. Review of Economic Studies, forthcoming.

Hummels, D., Rasmus, Jakob, M., and Chong, X. (2014). The wage effects of offshoring: Evidence from danish matched worker-firm data. American Economic Review, 104(6):15971629.

Ichniowski, C., Kathryn, S., and Prennushi, G. (1997). The american economic review. The American Economic Review, 87, No. 3:291-313.

Iranzo, S., Schivardi, F., and Tosetti, E. (2008). Skill dispersion and firm productivity: An analysis with employer-employee matched data. Journal of Labor Economics, 26(2):247-285.

Irarrazabal, A., Moxnes, A., and Karen-Helene, U.-M. (2014). Heterogeneous firms or heterogeneous workers? Implications for the exporter premium and the impact of labor reallocation on productivity. Review of Economics and Statistics, 95(3):839-849.

Kahn, S. and Lang, K. (1991). The effect of hours constraints on labor supply estimates. The Review of Economics and Statistics, pages 605-611.

Kleven, H. J. and Schultz, E. (2014). Estimating taxable income responses using danish tax reforms. American Economic Journal: Economic Policy, 6(4):271-301.

Kleven, H. J. and Waseem, M. (2013). Using notches to uncover optimization frictions and structural elasticities: Theory and evidence from Pakistan. The Quarterly Journal of Economics.

Kreiner, T. C., Leth-Pedersen, S., and Skov, P. (2016). Tax reforms and intertemporal shifting of wage income: Evidence from danish monthly payroll records. American Economic Journal: Economic Policy, 8:233-257.

Lavetti, K. and Schmutte, I. (2016). Estimating compensating wage differentials with endogenous job mobility. working paper.

Lewis, H. (1969). Employer interests in employee hours of work. University of Chicago, unpublished manuscript. 
Macis, M. and Schivardi, F. (2016). Exports and wages: Rent sharing, workforce composition, or returns to skills? Journal of Labor Economics, 34 (4).

Mas, A. and Moretti, E. (2009). Peers at work. American Economic Review.

Mas, A. and Pallais, A. (2017). Valuing alternative work arrangements. American Economic Review, 107(12):3722-59.

Melitz, M. J. (2003). The impact of trade on intra-industry reallocations and aggregate industry productivity. Econometrica, 71(6):1695-1725.

Mueller, H. M., Ouimet, P. P., and Simintzi, E. (2015). Wage inequality and firm growth. NBER Working Paper No. 20876.

Pencavel, J. (1986). Labor supply of men: A survey. Handbook of Labor Economics, 1:3-102.

Prescott, E. (2004). Why do Americans work so much more than Europeans? Federal Reserve Bank of Minneapolis Quarterly Review, 28:2-13.

Rosen, S. (1986). The theory of equalizing differences. Handbook of labor economics, pages 641-692.

Saez, E., Slemrod, J., and Giertz, S. H. (2012). The elasticity of taxable income with respect to marginal tax rates: A critical review. Journal of Economic Literature, 50(1):3-50.

Siow, A. (1987). The use of wages in coordinating hours of work. Unpublished manuscript. New York: Columbia University.

Slemrod, J. (1998). Methodological issues in measuring and interpreting taxable income elasticities. National Tax Journal, 51(4):773-788.

Song, J., Price, D. J., Guvenen, F., Bloom, N., and von Watcher, T. (2016). Firming up wage inequality. work in progress.

Sorkin, I. (2018). Ranking firms using revealed preference. Quarterly Journal of Economics, forthcoming.

Syverson (2011). What determines productivity? Journal of Economic Literature, 49(2):326365.

Triest, R. (1990). The effect of income taxation on labor supply in the US. Journal of Human Resources, 25:491-516.

Weiss, Y. (1996). Synchronization of work schedules. International Economic Review, 37(1):157-179. 


\section{Tables and Figures}

Table 1: Descriptive statistics

\begin{tabular}{|c|c|c|c|c|c|c|}
\hline & \multicolumn{2}{|c|}{ IDA Sample } & \multicolumn{2}{|c|}{$\begin{array}{c}\text { IDA -Firmstat-LON } \\
\text { sample }\end{array}$} & \multicolumn{2}{|c|}{$\begin{array}{c}\text { Final } \\
\text { sample }\end{array}$} \\
\hline & $(1)$ & $(1)$ & $(2)$ & $(2)$ & $(3)$ & $(3)$ \\
\hline Workers Characteristics & Mean & Std. Dev. & Mean & Std. Dev. & Mean & Std. Dev. \\
\hline Mean Age & 39.82 & 12.87 & 41.11 & 11.09 & 42.05 & 10.91 \\
\hline Fraction $<30$ years old & 0.27 & 0.44 & 0.19 & 0.39 & 0.16 & 0.37 \\
\hline Fraction $>50$ years old & 0.27 & 0.44 & 0.25 & 0.43 & 0.27 & 0.45 \\
\hline Fraction Males & 0.50 & 0.50 & 0.66 & 0.47 & 0.70 & 0.46 \\
\hline Fraction Unionized & 0.70 & 0.46 & 0.73 & 0.44 & 0.77 & 0.15 \\
\hline Fraction Hourly & 0.17 & 0.37 & 0.24 & 0.42 & 0.28 & 0.45 \\
\hline Fraction Primary Educ. & 0.33 & 0.47 & 0.28 & 0.45 & 0.29 & 0.45 \\
\hline Fraction Secondary Educ. & 0.40 & 0.49 & 0.52 & 0.50 & 0.51 & 0.50 \\
\hline Fraction Tertiary Educ. & 0.27 & 0.43 & 0.20 & 0.39 & 0.20 & 0.39 \\
\hline Hourly wage (in DKK) & & & 187.07 & 141.14 & 183.65 & 124.37 \\
\hline Annual Labor Income (in 1000 DKK) & 267.00 & 448.30 & 357.93 & 288.35 & 349.36 & 248.68 \\
\hline Total Annual Hours & & & 1907.99 & 213.01 & 1896.19 & 197.24 \\
\hline Overtime Annual Hours & & & 27.82 & 95.55 & 27.62 & 87.60 \\
\hline \multicolumn{7}{|l|}{ Workers by sector (\% of total) } \\
\hline Agriculture, forestry and fishing, mining and quarrying & 2.52 & & 0.37 & 6.05 & 0.16 & 4.00 \\
\hline Manufacturing & 26.60 & & 32.48 & 46.83 & 35.73 & 47.92 \\
\hline Construction & 10.35 & & 8.67 & 28.15 & 9.43 & 29.23 \\
\hline Electricity, gas, steam and air conditioning supply, & & & & & & \\
\hline Trade and transport & 30.14 & & 43.46 & 49.57 & 40.82 & 49.15 \\
\hline Financial and insurance, Real estate, Other business & 22.95 & & 14.82 & 35.53 & 13.71 & 34.39 \\
\hline Other services & 7.44 & & 0.2 & 4.46 & 0.15 & 3.92 \\
\hline \multicolumn{7}{|l|}{ Firms Characteristics } \\
\hline Mean Firm Size & & & 51.42 & 328.24 & 43.37 & 302.3649 \\
\hline Mean Capital per employee (1000 DKK) & & & 423.49 & 7339.72 & 963.66 & 43505.13 \\
\hline Mean Value Added per employee (1000 DKK) & & & 436.30 & 3040.25 & 504.30 & 1773.43 \\
\hline Mean Revenues per employee (1000 DKK) & & & 1687.35 & 6511.18 & 2132.89 & 8693.84 \\
\hline Exporters (\%) & & & 39.40 & 48.86 & 39.96 & 48.98 \\
\hline Number of observations & $22,379,298$ & & $4,466,676$ & & 787,683 & \\
\hline Number of individuals & $3,518,236$ & & $1,205,301$ & & 400,653 & \\
\hline Number of firms & 266,196 & & 25,249 & & 8,369 & \\
\hline
\end{tabular}

Notes: The table shows the mean and the standard deviations for a set of variables on 3 groups of employees. In all 3 groups, we consider only workers who are between 15 and 65 years of age in the years 2003-2011. The "IDA Sample" refers to the entire Danish population. The "IDA-Firmstat-LON" sample refers to the sample of workers in IDA that can be matched to Firmstat and LON samples. The "Final sample" is composed of all the workers from IDA-Firmstat$L O N$ who are employed in firms in which information on hours is available for at least $95 \%$ of the workforce. Data on employment by industry for the entire population are from Statistikbanken (Statistics Denmark), which does not provide standard errors around mean values. Annual and hourly earnings, value added, capital and sales are expressed in Danish Kroner (DKK) and deflated using the CPI index with 2000 as the base year ( 8 DKK $\simeq 1$ USD in 2000$)$. 


\section{Table 2: Coordination and firm characteristics}

\begin{tabular}{|c|c|c|c|}
\hline & \multicolumn{2}{|c|}{$\begin{array}{l}\text { Stand. Dev. Of Hours } \\
\text { across skill groups } \\
\text { within firms }\end{array}$} & \multirow[t]{2}{*}{ Observations } \\
\hline & $(1)$ & $(2)$ & \\
\hline Value Added per employee & $\begin{array}{c}-0.038^{* * *} \\
(0.008)\end{array}$ & $\begin{array}{c}-0.013^{* *} \\
(0.006)\end{array}$ & 17807 \\
\hline TFP & $\begin{array}{c}-0.133^{* * *} \\
(0.008)\end{array}$ & $\begin{array}{c}-0.080^{* * *} \\
(0.012)\end{array}$ & 16212 \\
\hline Firm size & $\begin{array}{c}-0.032^{* * *} \\
(0.007)\end{array}$ & $\begin{array}{c}-0.095^{* * *} \\
(0.021)\end{array}$ & 17807 \\
\hline Share of tertiary educ. workers & $\begin{array}{c}-0.178^{* * *} \\
(0.007)\end{array}$ & $\begin{array}{c}-0.080^{* * * *} \\
(0.013)\end{array}$ & 17807 \\
\hline Exporter status & $\begin{array}{c}-0.141^{* * *} \\
(0.007)\end{array}$ & $\begin{array}{l}-0.005 \\
(0.009)\end{array}$ & 17807 \\
\hline Fraction of hourly workers & $\begin{array}{c}0.337^{* * *} \\
(0.007)\end{array}$ & $\begin{array}{c}0.257^{* * *} \\
(0.016)\end{array}$ & 17807 \\
\hline Fraction of unionized workers & $\begin{array}{c}0.084^{* * * *} \\
(0.008)\end{array}$ & $\begin{array}{c}0.017 \\
(0.012)\end{array}$ & 17807 \\
\hline Fraction of part-timer workers & $\begin{array}{c}0.225^{* * * *} \\
(0.008)\end{array}$ & $\begin{array}{c}0.120^{* * *} \\
(0.014)\end{array}$ & 17807 \\
\hline Fraction of female workers & $\begin{array}{c}-0.035^{* * *} \\
(0.008)\end{array}$ & $\begin{array}{c}0.035^{* *} \\
(0.015)\end{array}$ & 17807 \\
\hline Mean Managerial Ability & $\begin{array}{c}-0.069^{* * *} \\
(0.008)\end{array}$ & $\begin{array}{l}-0.019^{*} \\
(0.012)\end{array}$ & 16420 \\
\hline Negotiation & $\begin{array}{c}-0.310^{* * *} \\
(0.009)\end{array}$ & $\begin{array}{c}-0.146^{* * * *} \\
(0.016)\end{array}$ & 13441 \\
\hline Persuasion & $\begin{array}{c}-0.313^{* * *} \\
(0.009)\end{array}$ & $\begin{array}{c}-0.153^{* * *} \\
(0.016)\end{array}$ & 13441 \\
\hline Social Perceptiveness & $\begin{array}{c}-0.289^{* * *} \\
(0.009)\end{array}$ & $\begin{array}{c}-0.116^{* * *} \\
(0.015)\end{array}$ & 13441 \\
\hline Adjust Actions to others & $\begin{array}{c}-0.160^{* * *} \\
(0.009)\end{array}$ & $\begin{array}{c}-0.077^{* * * *} \\
(0.013)\end{array}$ & 13441 \\
\hline Sd Vacation Hours & $\begin{array}{c}0.345^{* * *} \\
(0.015)\end{array}$ & $\begin{array}{c}0.211^{* * *} \\
(0.024)\end{array}$ & 3832 \\
\hline Av. Wage Mangers/Av. Wage Production workers & $\begin{array}{c}-0.068^{* * *} \\
(0.008)\end{array}$ & $\begin{array}{c}-0.012 \\
(0.013)\end{array}$ & 13706 \\
\hline Production workerers: 90 th/10th wage ratio & $\begin{array}{c}0.122^{* * *} \\
(0.008)\end{array}$ & $\begin{array}{c}0.081^{* * *} \\
(0.013)\end{array}$ & 15772 \\
\hline Middle managers: 90 th/10th wage ratio & $\begin{array}{c}-0.044^{* * *} \\
(0.008)\end{array}$ & $\begin{array}{l}-0.012 \\
(0.008)\end{array}$ & 13632 \\
\hline Top managers: 90 th/10th wage ratio & $\begin{array}{c}-0.078^{* * *} \\
(0.008)\end{array}$ & $\begin{array}{c}-0.035^{* * *} \\
(0.009)\end{array}$ & 12541 \\
\hline 5 digits industry f.e. & $\mathrm{NO}$ & YES & \\
\hline
\end{tabular}

Notes: The table shows standardized coefficients from a regression of the standard deviation of hours across skill groups within firms from Section 4.3 on a set of firm characteristics and a constant. Each cell in the table corresponds to a different regression. In column 2 , we add 5-digit industry fixed effects to the baseline classification. We use the Danish industry classification DBO7 that for the first 4-digit classification corresponds to NACE rev.2. Regressions are based on firm-year observations from the firms in our final sample (Table 1) over the years 2003-2011. TFP (total factor productivity) is obtained following Ackerberg et al. (2015) (online Appendix B.4). Managerial ability is measured as the average individual fixed effect ( $\hat{\alpha_{i}}$ ) from an AKM model among the workers in the top quartile of the distribution of $\hat{\alpha_{i}}$ in each firm. To avoid confusion, we label the $O * N E T$ descriptor "Coordination" as "Adjust Actions to Others". Standard errors in parentheses are clustered at the firm level. * $p<0.10$, ** $p<0.05$, *** $p<0.01$. 
Table 3: Coordination and wage premiums

\begin{tabular}{|c|c|c|c|c|c|c|}
\hline & (1) & $(2)$ & $\overline{(3)}$ & (4) & $\overline{(5)}$ & $(6)$ \\
\hline Dependent variable & Firm f.e. & Firm f.e. & Firm f.e. & Firm f.e. & Firm f.e. & Firm f.e. \\
\hline Stand. Dev. & $\begin{array}{c}-0.075^{* * *} \\
(0.016)\end{array}$ & $\begin{array}{c}-0.053^{* * *} \\
(0.016)\end{array}$ & $\begin{array}{c}-0.066^{* * *} \\
(0.018)\end{array}$ & $\begin{array}{c}-0.090^{* * *} \\
(0.018)\end{array}$ & & $\begin{array}{c}-0.041^{* *} \\
(0.015)\end{array}$ \\
\hline Stand. Dev. Normal Hours & & & & & $\begin{array}{c}-0.070 * * * \\
(0.016)\end{array}$ & \\
\hline Firm size & & $\begin{array}{l}0.014^{*} \\
(0.007)\end{array}$ & $\begin{array}{c}0.010 \\
(0.007)\end{array}$ & $\begin{array}{c}0.033^{* * *} \\
(0.010)\end{array}$ & $\begin{array}{c}0.010 \\
(0.007)\end{array}$ & $\begin{array}{c}0.011 \\
(0.007)\end{array}$ \\
\hline Exporter status & & $\begin{array}{c}0.061^{* * *} \\
(0.015)\end{array}$ & $\begin{array}{c}0.059^{* * *} \\
(0.016)\end{array}$ & $\begin{array}{c}0.054^{* *} \\
(0.021)\end{array}$ & $\begin{array}{c}0.059 * * * \\
(0.016)\end{array}$ & $\begin{array}{c}0.049 \text { *** } \\
(0.013)\end{array}$ \\
\hline Union. Rate & & $\begin{array}{l}-0.002 \\
(0.027)\end{array}$ & $\begin{array}{c}0.031 \\
(0.024)\end{array}$ & $\begin{array}{c}0.035 \\
(0.031)\end{array}$ & $\begin{array}{c}0.030 \\
(0.024)\end{array}$ & $\begin{array}{c}0.062^{* *} \\
(0.027)\end{array}$ \\
\hline Female Share & & $\begin{array}{l}-0.055 \\
(0.045)\end{array}$ & $\begin{array}{c}-0.109^{* *} \\
(0.043)\end{array}$ & $\begin{array}{c}-0.126 * * * \\
(0.041)\end{array}$ & $\begin{array}{c}-0.106^{* *} \\
(0.043)\end{array}$ & $\begin{array}{c}-0.086^{* * *} \\
(0.022)\end{array}$ \\
\hline Average Hours & & $\begin{array}{c}0.004 \\
(0.025)\end{array}$ & $\begin{array}{c}0.004 \\
(0.026)\end{array}$ & $\begin{array}{c}0.015 \\
(0.024)\end{array}$ & $\begin{array}{c}0.004 \\
(0.025)\end{array}$ & $\begin{array}{l}-0.041 \\
(0.028)\end{array}$ \\
\hline $\log ($ Capital per employee $)$ & & $\begin{array}{c}0.039^{* * * *} \\
(0.012)\end{array}$ & $\begin{array}{l}0.024^{*} \\
(0.013)\end{array}$ & $\begin{array}{c}0.049^{* * *} \\
(0.014)\end{array}$ & $\begin{array}{c}0.024^{*} \\
(0.013)\end{array}$ & $\begin{array}{c}0.032^{* * *} \\
(0.012)\end{array}$ \\
\hline Negotiation & & & & & & $\begin{array}{c}0.348^{* * *} \\
(0.105)\end{array}$ \\
\hline Persuasion & & & & & & $\begin{array}{c}-0.259^{* * *} * \\
(0.093)\end{array}$ \\
\hline Social Perceptiveness & & & & & & $\begin{array}{c}0.008 \\
(0.036)\end{array}$ \\
\hline Adjust Actions to others & & & & & & $\begin{array}{c}0.017 \\
(0.017)\end{array}$ \\
\hline Region f.e. & $\mathrm{NO}$ & YES & YES & YES & YES & YES \\
\hline Compos. cntr & NO & NO & YES & YES & YES & YES \\
\hline Ability Measures & $\mathrm{NO}$ & $\mathrm{NO}$ & YES & YES & YES & YES \\
\hline Av. Hours b/w 36.5 and 37.5 & YES & YES & YES & $\mathrm{NO}$ & YES & YES \\
\hline Part. R-sq SD Hours & 0.008 & 0.003 & 0.006 & 0.008 & 0.007 & 0.002 \\
\hline Part. R-sq VA and TFP & 0.022 & 0.010 & 0.032 & 0.038 & 0.032 & 0.020 \\
\hline Coordination Share & 0.349 & 0.321 & 0.200 & 0.196 & 0.233 & 0.097 \\
\hline R-sq & 0.008 & 0.033 & 0.106 & 0.126 & 0.108 & 0.135 \\
\hline $\mathrm{N}$ & 7312 & 7312 & 7312 & 4415 & 7299 & 6089 \\
\hline
\end{tabular}

Notes: In this table, we report the results of estimating equation (7). The dependent variable is the firm fixed effect from the AKM model (8). "Stand. Dev." in the table refers to our measure of hours coordination that is the standard deviation of the average total (regular and overtime) hours worked across skill groups within a firm (Section 4.3). "Stand. Dev. Normal hours" is the standard deviation of the average regular hours worked across skill groups within a firm. Skill groups are defined as deciles of the distribution of $\hat{\alpha_{i}}+\hat{\beta} X_{i j t}$ from the AKM model (8). All regressions report standardized coefficients. The exporter dummy is defined as the modal exporter status between 2003 and 2011. "Compos. cntr" refers to a vector of controls for the share of workers in each skill group. "Ability Measures" indicates a vector containing the average value of the individual fixed effects $\hat{\alpha}_{i}$ in each quartile of the distribution of $\hat{\alpha}_{i}$ within a firm. The dependent variable (firm f.e.) in column (5) is based on wage rates from regular hours only. To avoid confusion, we label the O*NET descriptor "Coordination" as "Adjust Actions to Others". Coordination Share is derived as the ratio of "Part. R-sq SD Hours" and "Part. R-sq VA and TFP" (Section 4.1). "Part. R-sq VA and TFP" is from Table D.18. Standard errors are clustered at the 2-digit industry level. *, ** and *** indicate significance at the 10 , 5 and 1 percent levels. 
Table 4: Coordination and wage differentials within sectors

\begin{tabular}{|c|c|c|c|c|c|c|c|c|}
\hline & (1) & $(2)$ & (3) & (4) & (5) & (6) & (7) & (8) \\
\hline Dependent variable & Firm f.e. & Firm f.e. & Firm f.e. & Firm f.e. & Firm f.e. & Firm f.e. & Firm f.e. & Firm f.e. \\
\hline Stand. Dev. & $\begin{array}{c}-0.060 * * * \\
(0.018)\end{array}$ & $\begin{array}{c}-0.031^{*} \\
(0.016)\end{array}$ & $\begin{array}{c}-0.028^{*} \\
(0.016)\end{array}$ & & & & $\begin{array}{c}-0.064^{* * *} \\
(0.019)\end{array}$ & $\begin{array}{l}-0.018 \\
(0.017)\end{array}$ \\
\hline Median Abs. Dev. & & & & $\begin{array}{c}-0.075^{* * *} \\
(0.014)\end{array}$ & $\begin{array}{c}-0.045^{* * *} \\
(0.014)\end{array}$ & $\begin{array}{c}-0.040^{* *} \\
(0.015)\end{array}$ & & \\
\hline Firm size & $\begin{array}{c}0.009 \\
(0.006)\end{array}$ & $\begin{array}{c}0.006 \\
(0.005)\end{array}$ & $\begin{array}{l}0.017^{*} \\
(0.009)\end{array}$ & $\begin{array}{c}0.010 \\
(0.007)\end{array}$ & $\begin{array}{c}0.006 \\
(0.005)\end{array}$ & $\begin{array}{l}0.018^{*} \\
(0.009)\end{array}$ & $\begin{array}{c}0.011 \\
(0.008)\end{array}$ & $\begin{array}{l}0.010^{*} \\
(0.005)\end{array}$ \\
\hline Exporter status & $\begin{array}{c}0.065^{* * *} \\
(0.018)\end{array}$ & $\begin{array}{c}0.030^{* *} \\
(0.013)\end{array}$ & $\begin{array}{c}0.021 \\
(0.013)\end{array}$ & $\begin{array}{c}0.062^{* * *} \\
(0.018)\end{array}$ & $\begin{array}{c}0.029 * * \\
(0.013)\end{array}$ & $\begin{array}{c}0.020 \\
(0.013)\end{array}$ & $\begin{array}{c}0.063^{* * *} \\
(0.015)\end{array}$ & $\begin{array}{c}0.032^{* *} \\
(0.014)\end{array}$ \\
\hline Union. Rate & $\begin{array}{c}0.040 \\
(0.025)\end{array}$ & $\begin{array}{c}0.039 \\
(0.029)\end{array}$ & $\begin{array}{c}0.039 \\
(0.030)\end{array}$ & $\begin{array}{c}0.042 \\
(0.025)\end{array}$ & $\begin{array}{c}0.040 \\
(0.029)\end{array}$ & $\begin{array}{c}0.040 \\
(0.030)\end{array}$ & $\begin{array}{c}0.032 \\
(0.024)\end{array}$ & $\begin{array}{c}0.051^{* *} \\
(0.022)\end{array}$ \\
\hline Female Share & $\begin{array}{c}-0.140^{* * *} \\
(0.040)\end{array}$ & $\begin{array}{c}-0.069^{* *} \\
(0.027)\end{array}$ & $\begin{array}{c}-0.057^{*} \\
(0.029)\end{array}$ & $\begin{array}{c}-0.140^{* * *} \\
(0.038)\end{array}$ & $\begin{array}{c}-0.069^{* *} \\
(0.026)\end{array}$ & $\begin{array}{c}-0.057^{*} \\
(0.028)\end{array}$ & $\begin{array}{c}-0.113^{* * *} \\
(0.042)\end{array}$ & $\begin{array}{c}-0.120^{* * *} \\
(0.034)\end{array}$ \\
\hline Average Hours & $\begin{array}{c}-0.006 \\
(0.022)\end{array}$ & $\begin{array}{l}-0.033 \\
(0.023)\end{array}$ & $\begin{array}{c}-0.039^{*} \\
(0.023)\end{array}$ & $\begin{array}{l}-0.018 \\
(0.021)\end{array}$ & $\begin{array}{c}-0.038^{*} \\
(0.021)\end{array}$ & $\begin{array}{c}-0.043^{* *} \\
(0.021)\end{array}$ & $\begin{array}{c}0.001 \\
(0.026)\end{array}$ & $\begin{array}{l}-0.034 \\
(0.022)\end{array}$ \\
\hline $\log ($ Capital per employee $)$ & $\begin{array}{c}0.028^{* *} \\
(0.013)\end{array}$ & $\begin{array}{c}0.031^{* * *} \\
(0.010)\end{array}$ & $\begin{array}{c}0.035^{* * *} \\
(0.010)\end{array}$ & $\begin{array}{c}0.028^{* *} \\
(0.013)\end{array}$ & $\begin{array}{c}0.030^{* * *} \\
(0.010)\end{array}$ & $\begin{array}{c}0.035^{* * *} \\
(0.010)\end{array}$ & $\begin{array}{l}0.022^{*} \\
(0.013)\end{array}$ & $\begin{array}{c}-0.089^{* * *} \\
(0.023)\end{array}$ \\
\hline $\log$ (Value added per employee) & & & & & & & & $\begin{array}{c}0.381^{* * *} \\
(0.070)\end{array}$ \\
\hline 1 digit Sector f.e. & YES & $\mathrm{NO}$ & NO & YES & $\mathrm{NO}$ & $\mathrm{NO}$ & NO & $\mathrm{NO}$ \\
\hline 2 digits Sector f.e. & $\mathrm{NO}$ & YES & $\mathrm{NO}$ & $\mathrm{NO}$ & YES & $\mathrm{NO}$ & YES & YES \\
\hline 3 digits Sector f.e. & $\mathrm{NO}$ & $\mathrm{NO}$ & YES & $\mathrm{NO}$ & $\mathrm{NO}$ & YES & YES & YES \\
\hline Part. R-sq SD Hours & 0.004 & 0.001 & 0.001 & 0.006 & 0.002 & 0.001 & 0.009 & \\
\hline Part. R-sq VA and TFP & 0.033 & 0.016 & 0.014 & 0.033 & 0.016 & 0.014 & & \\
\hline Coordination Share & 0.113 & 0.049 & 0.042 & 0.181 & 0.113 & 0.095 & & \\
\hline R-sq & 0.113 & 0.155 & 0.162 & 0.115 & 0.156 & 0.162 & 0.112 & 0.104 \\
\hline $\mathrm{N}$ & 7306 & 7306 & 7306 & 7306 & 7306 & 7306 & 7060 & 7060 \\
\hline
\end{tabular}

Notes: In this table, we report the results of estimating equation (7). The dependent variable is the firm fixed effect from the AKM model (8). "Stand. Dev." in the table refers to our measure of hours coordination that is the standard deviation of the average total (regular and overtime) hours worked across skill groups within a firm (Section 4.3). The "Median Abs. Dev." is the the median absolute deviation of median hours across skill groups within a firm. Skill groups are defined as deciles of the distribution of $\hat{\alpha_{i}}+\hat{\beta} X_{i j t}$ from the AKM model (8). All regressions report standardized coefficients. The exporter dummy is defined as the modal exporter status between 2003 and 2011. (Cap/empl) stands for physical capital over the number of full-time equivalent employees. "Compos. cntr" refers to a vector of controls for the share of workers in each skill group. "Ability Measures" indicates a vector containing the average value of the individual fixed effects $\hat{\alpha}_{i}$ in each quartile of the distribution of $\hat{\alpha_{i}}$ within a firm. In column ( 8 ), TFP is used as an instrument for valued added per employee (log(V.A./empl)). TFP is obtained as in Ackerberg et al. (2015) (online Appendix B.4). Coordination Share is derived as the ratio of "Part. R-sq SD Hours" and "Part. R-sq VA and TFP" (Section 4.1). "Part. R-sq VA and TFP" is from Table D.19. Standard errors are clustered at the 2-digit industry level. *, ** and *** indicate significance at the 10 , 5 and 1 percent levels. 
Table 5: The elasticity of hours of high-skilled workers

\begin{tabular}{|c|c|c|c|c|c|c|c|}
\hline & (1) & $\begin{array}{l}(2) \\
\end{array}$ & (3) & $\begin{array}{c}(4) \\
\text { High } \\
\text { Coordination } \\
\text { Top } 50 \%\end{array}$ & $\begin{array}{c}(5) \\
\text { Low } \\
\text { Coordination } \\
\text { Bottom } 50 \%\end{array}$ & $\begin{array}{c}(6) \\
\text { High } \\
\text { Coordination } \\
\text { Top } 25 \%\end{array}$ & $\begin{array}{c}(7) \\
\text { Low } \\
\text { Coordination } \\
\text { Bottom } 25 \%\end{array}$ \\
\hline Dependent variable & $\Delta \log h^{H}$ & $\Delta \log h^{H}$ & $\Delta \log h^{H}$ & $\Delta \log h^{H}$ & $\Delta \log h^{H}$ & $\Delta \log h^{H}$ & $\Delta \log h^{H}$ \\
\hline$\Delta \log \left(1-\tau^{H}\right)$ & $\begin{array}{c}-0.067^{* * *} \\
(0.008)\end{array}$ & $\begin{array}{c}-0.069^{* * *} \\
(0.018)\end{array}$ & $\begin{array}{c}-0.047^{* * *} \\
(0.014)\end{array}$ & $\begin{array}{l}-0.017 \\
(0.016)\end{array}$ & $\begin{array}{c}-0.097^{* * * *} \\
(0.025)\end{array}$ & $\begin{array}{c}0.003 \\
(0.018)\end{array}$ & $\begin{array}{c}-0.147^{* * *} \\
(0.055)\end{array}$ \\
\hline Log base-year income & & & $\begin{array}{c}-0.008^{* * *} * \\
(0.003)\end{array}$ & $\begin{array}{l}-0.002 \\
(0.003)\end{array}$ & $\begin{array}{c}-0.023^{* * *} \\
(0.006)\end{array}$ & $\begin{array}{l}-0.001 \\
(0.003)\end{array}$ & $\begin{array}{c}-0.038^{*} \\
(0.022)\end{array}$ \\
\hline IV & $\mathrm{NO}$ & YES & YES & YES & YES & YES & YES \\
\hline Region f.e. & YES & YES & YES & YES & YES & YES & YES \\
\hline Overtime Hours & YES & YES & YES & YES & YES & YES & YES \\
\hline Mean Hours & 1924.47 & 1924.47 & 1924.47 & 1928.33 & 1914.91 & 1917.40 & 1870.33 \\
\hline Pvalue $H i g h=L o w$ & & & & 0.01 & & 0.01 & \\
\hline F-stat Excl. Inst. & & 1355.19 & 754.51 & 1293.74 & 192.94 & 566.19 & 133.53 \\
\hline P-value Excl. Inst. & & 0.00 & 0.00 & 0.00 & 0.00 & 0.00 & 0.00 \\
\hline N Firms & 1167 & 1167 & 1167 & 584 & 583 & 293 & 291 \\
\hline $\mathrm{N}$ & 26488 & 26488 & 26488 & 18875 & 7613 & 8307 & 2371 \\
\hline
\end{tabular}

Notes: This table reports the results from estimating equation (10). It shows the elasticity of high-skilled hours to the net-of-tax rate (1- $\tau^{H}$ ). In columns 4 and 5, we distinguish between high-and low-coordination firms based on whether the firm is in the bottom or top half of the distribution of the standard deviation of hours across skill groups in 2008, respectively (Section 4.3). In columns 6 and 7 , we define high-coordination firms as being in the bottom $25 \%$ of the distribution of the standard deviation of hours across skill groups in 2008 and low-coordination firms as firms in the top $25 \%$ of the standard deviation of hours across skill groups in 2008. Specifications in columns 2 to 7 use mechanical changes in the net-of-tax rate on labor income as an instrument for observed changes in 1- $\tau^{H}$ (Section 5.5). First-stage regressions are in Table D.31. Each regression contains the following controls measured in the base year: work experience, work experience squared, sex, age, number of children, marital status, education, local unemployment (municipality), region fixed effects, firm size, exporter status, and share of high-and low-skilled workers in the firm (the residual group is omitted). "P-value High=Low" refers to the p-value of the null hypothesis that the coefficient attached to $\Delta \log \left(1-\tau^{H}\right)$ in low-and high-coordination firms is equal. We only consider high-skilled workers who are at the same firm between 2008 and 2011 and in firms that employ at least 1 low-skilled worker. We estimate this regression on 3-year changes between 2008 and 2011. Observations are weighted by labor income. Standard errors in parentheses are clustered at the firm level. ${ }^{*} p<0.10, * * p<0.05, * * * p<0.01$.

Table 6: Elasticity of high-skilled hours: additional specifications

\begin{tabular}{|c|c|c|c|c|c|c|c|c|c|c|}
\hline Dependent variable & $\begin{array}{c}(1) \\
\text { High } \\
\text { Coordination } \\
\Delta \log h^{H} \\
\end{array}$ & $\begin{array}{c}(2) \\
\text { Low } \\
\text { Coordination } \\
\Delta \log h^{H} \\
\end{array}$ & $\begin{array}{c}(3) \\
\text { High } \\
\text { Coordination } \\
\Delta \log h^{H} \\
\end{array}$ & $\begin{array}{c}(4) \\
\text { Low } \\
\text { Coordination } \\
\Delta \log h^{H} \\
\end{array}$ & $\begin{array}{c}(5) \\
\text { High } \\
\text { Coordination } \\
\Delta \log h^{H} \\
\end{array}$ & $\begin{array}{c}(6) \\
\text { Low } \\
\text { Coordination } \\
\Delta \log h^{H} \\
\end{array}$ & $\begin{array}{c}(7) \\
\text { High } \\
\text { Coordination } \\
\Delta \log h^{H} \\
\end{array}$ & $\begin{array}{c}(8) \\
\text { Low } \\
\text { Coordination } \\
\Delta \log h^{H} \\
\end{array}$ & $\begin{array}{c}(9) \\
\text { High } \\
\text { Coordination } \\
\Delta \log h^{H} \\
\end{array}$ & $\begin{array}{c}(10) \\
\text { Low } \\
\text { Coordination } \\
\Delta \log h^{H} \\
\end{array}$ \\
\hline$\Delta \log \left(1-\tau^{H}\right)$ & $\begin{array}{l}-0.027 \\
(0.017)\end{array}$ & $\begin{array}{c}-0.075 * * * \\
(0.026)\end{array}$ & $\begin{array}{l}-0.010 \\
(0.016)\end{array}$ & $\begin{array}{c}-0.099 * * \\
(0.039)\end{array}$ & $\begin{array}{l}0.045 \\
(0.043)\end{array}$ & $\begin{array}{c}-0.121^{* *} \\
(0.059)\end{array}$ & $\begin{array}{l}-0.041 \\
(0.032)\end{array}$ & $\begin{array}{c}-0.125^{* *} \\
(0.052)\end{array}$ & $\begin{array}{l}0.006 \\
(0.027)\end{array}$ & $\begin{array}{c}-0.073^{* *} \\
(0.036)\end{array}$ \\
\hline$\Delta \log \left(1-\tau^{H}\right) \times$ Size & & & $\begin{array}{c}-0.000 \\
(0.000)\end{array}$ & $\begin{array}{c}0.000 \\
(0.000)\end{array}$ & & & & & & \\
\hline$\Delta \log \left(1-\tau^{H}\right) \times$ Export & & & & & $\begin{array}{l}-0.073 \\
(0.048)\end{array}$ & $\begin{array}{l}0.041 \\
(0.083)\end{array}$ & & & & \\
\hline$\Delta \log \left(1-\tau^{H}\right) \times$ High Union Share & & & & & & & $\begin{array}{c}0.038 \\
(0.040)\end{array}$ & $\begin{array}{l}0.044 \\
(0.072)\end{array}$ & & \\
\hline$\Delta \log \left(1-\tau^{H}\right) \times$ High TFP & & & & & & & & & $\begin{array}{l}-0.040 \\
(0.038)\end{array}$ & $\begin{array}{l}-0.052 \\
(0.072)\end{array}$ \\
\hline Firm f.e. & YES & YES & NO & NO & NO & NO & $\mathrm{NO}$ & NO & NO & NO \\
\hline Base-year f.e. & YES & YES & NO & NO & NO & NO & NO & NO & NO & NO \\
\hline N Firms & 785 & 675 & 584 & 583 & 584 & 583 & 584 & 583 & 584 & 583 \\
\hline $\mathrm{N}$ & 26497 & 10267 & 18875 & 7613 & 18875 & 7613 & 18875 & 7613 & 18875 & 7613 \\
\hline
\end{tabular}

Notes: This table reports the results from estimating equation (10) while controlling for additional variables and fixed effects. The main variable of interest is the elasticity of high-skilled total hours (regular and overtime) to the net-of-tax rate (1- $\tau^{H}$ ) reported in the first row. We distinguish between highand low-coordination firms based on whether the firm is in the bottom or top half of the distribution of the standard deviation of hours across skill groups in 2008, respectively. The dummy variables "High Union Share" (columns 9 and 10) and "High TFP" (columns 7 and 8) take value 1 if the firm had a share of unionized workers and TFP above the median in 2008, respectively. "Size" (columns 3 and 4) and "Export Status" (columns 5 and 6) are measured in 2008. All specifications use mechanical changes in the net-of-tax rate on labor income as an instrument for observed changes in $1-\tau^{H}$ (Section 5.5). First-stage regressions are in Tables D.32 and D.33. Each regression contains the following controls measured in the base year: log base-year labor income, work experience, work experience squared, sex, age, number of children, marital status, education, local unemployment (municipality), region fixed effects, firm size, exporter status, high unionization rate dummy, high TFP dummy, and share of high- and low-skilled workers in the firm (the residual group is omitted). We only consider high-skilled workers who are at the same firm between 2008 and 2011 and in firms that employ at least 1 low-skilled worker. In columns 1 and 2, we consider 3-year changes over the period 2006-2011. In columns 3 to 10, we consider 3-year changes between 2008 and 2011. Observations are weighted by labor income. Standard errors in parentheses are clustered at the firm level. * $p<0.10$, ** $p<0.05, * * * p<0.01$. 
Table 7: The spillover effects on hours worked by the low-skilled

\begin{tabular}{|c|c|c|c|c|c|c|c|}
\hline & $(1)$ & $\overline{(2)}$ & (3) & $(4)$ & $\begin{array}{c}\text { (5) } \\
\text { Low } \\
\text { Coordination } \\
\text { Bottom 50\% }\end{array}$ & 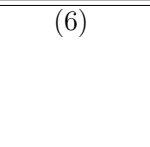 & $\begin{array}{c}\text { Low } \\
\text { Loordination } \\
\text { Bottom } 50 \%\end{array}$ \\
\hline Dependent variable & $\Delta \log h^{L}$ & $\Delta \log h^{L}$ & $\Delta \log h^{L}$ & $\Delta \log h^{L}$ & $\Delta \log h^{L}$ & $\Delta \log h^{L}$ & $\Delta \log h^{L}$ \\
\hline$\Delta \log \overline{h_{\text {normal }}^{H}}$ & $\begin{array}{c}0.540^{* * *} \\
(0.112)\end{array}$ & $\begin{array}{c}0.899 * * * \\
(0.304)\end{array}$ & $\begin{array}{c}0.878^{* * *} \\
(0.301)\end{array}$ & $\begin{array}{c}0.894^{* *} \\
(0.373)\end{array}$ & $\begin{array}{c}0.624^{* *} \\
(0.297)\end{array}$ & & \\
\hline$\Delta \log \overline{h_{\text {total }}^{H}}$ & & & & & & $\begin{array}{l}1.375^{* *} \\
(0.612)\end{array}$ & $\begin{array}{c}0.706^{* *} \\
(0.345)\end{array}$ \\
\hline$\Delta \log \left(1-\tau^{L}\right)$ & $\begin{array}{l}-0.005 \\
(0.009)\end{array}$ & $\begin{array}{c}0.023 \\
(0.088)\end{array}$ & $\begin{array}{c}0.051 \\
(0.114)\end{array}$ & $\begin{array}{c}0.053 \\
(0.126)\end{array}$ & $\begin{array}{l}-0.060 \\
(0.115)\end{array}$ & $\begin{array}{c}0.056 \\
(0.138)\end{array}$ & $\begin{array}{l}-0.053 \\
(0.115)\end{array}$ \\
\hline IV & $\mathrm{NO}$ & YES & YES & YES & YES & YES & YES \\
\hline $\begin{array}{l}\text { Region f.e. } \\
\text { Splines of } \log \text { t- } 1 \text { Inc. and }\end{array}$ & YES & YES & YES & YES & YES & YES & YES \\
\hline$\Delta \log$ inc. $\mathrm{t}-1-\mathrm{t}$ & $\mathrm{NO}$ & NO & YES & YES & YES & YES & YES \\
\hline Log Mean Inc. High Sk. & NO & $\mathrm{NO}$ & NO & YES & $\mathrm{NO}$ & NO & NO \\
\hline Overtime Hours & NO & $\mathrm{NO}$ & NO & NO & $\mathrm{NO}$ & YES & YES \\
\hline F-stat Excl. Inst. & & $13.09,160.40$ & $15.45,76.76$ & $4.66,55.84$ & $11.90,48.55$ & $4.43,76.72$ & $8.39,50.92$ \\
\hline P-value Excl. Inst. & & $0.00,0.00$ & $0.00,0.00$ & $0.03,0.00$ & $0.00,0.00$ & $0.04,0.00$ & $0.00,0.00$ \\
\hline Mean Hours Low Sk. & 1812.51 & 1812.51 & 1812.51 & 1812.51 & 1742.05 & 1828.87 & 1760.74 \\
\hline Mean Hours High Sk. & 1875.00 & 1875.00 & 1875.00 & 1875.00 & 1846.56 & 1905.60 & 1879.90 \\
\hline N Firms & 968 & 968 & 968 & 968 & 484 & 968 & 484 \\
\hline $\mathrm{N}$ & 10091 & 10091 & 10091 & 10091 & 4100 & 10091 & 4100 \\
\hline
\end{tabular}

Notes: This table reports the results from estimating equation (11). It shows the elasticity of low-skilled hours to the average hours worked by highskilled coworkers. We consider both regular (normal) hours (columns 1 to 5) and total (regular and overtime) hours (columns 6 and 7). Specifications in columns 2 to 7 use mechanical changes in the average net-of-tax rate among high-skilled workers in a firm as an instrument for the average change in hours and the mechanical change in the net-of-tax rate of low-skilled as an instrument for observed changes in 1- ${ }^{L}$ (Section 5.5). First-stage results are in Table D.34. Low-coordination firms (columns 5 and 7) are defined as being in the top half of the distribution of the standard deviation of hours across skill groups in 2008. Each regression contains the following controls measured in the base year (2008): work experience, work experience squared, sex, age, number of children, marital status, education, local unemployment (municipality), region fixed effects, firm size, exporter status, and share of high- and low-skilled workers in the firm (the residual group is omitted). "Splines" refer to a flexible piecewise linear functional form with 5 components. We only consider low-skilled workers who are at the same firm between 2008 and 2011. We estimate this regression on $3-y e a r$ changes between 2008 and 2011. Observations are weighted by labor income. Standard errors in parentheses are clustered at the firm level.* ${ }^{*}<0.10$, ** $p<0.05$, *** $p<0.01$. 
Figure 1: The distribution of hours across sectors in Denmark
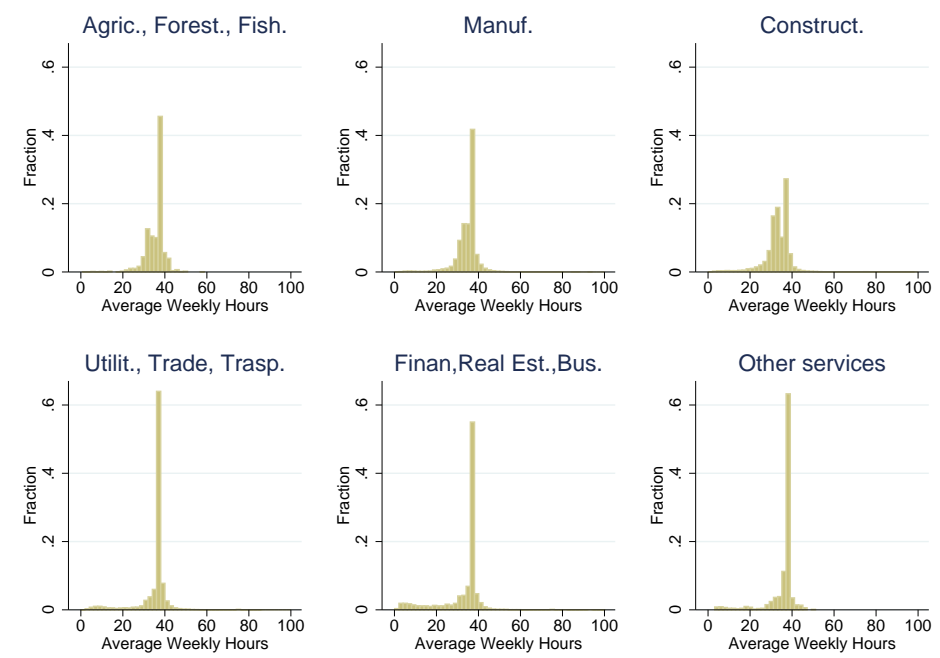

Notes: The figure presents histograms of weekly total (regular and overtime) hours worked in the six major sectors in Denmark over the years $2003-2011$. Weekly hours are obtained dividing annualized hours by 52 . Observations are grouped into bins of 2 hours. Figures are based on a total of 875,078 individual-year observations that include full-time and part-time workers in firms where hours are available for least $95 \%$ of the workforce. From the top left to the bottom right, we have the following sectors: Agriculture, forestry, fishing, mining and quarrying; Manufacturing; Construction; Utilities, trade and transport; Financial, insurance, real estate and other businesses; and Other services.

Figure 2: Variance of hours decomposition: between and within component

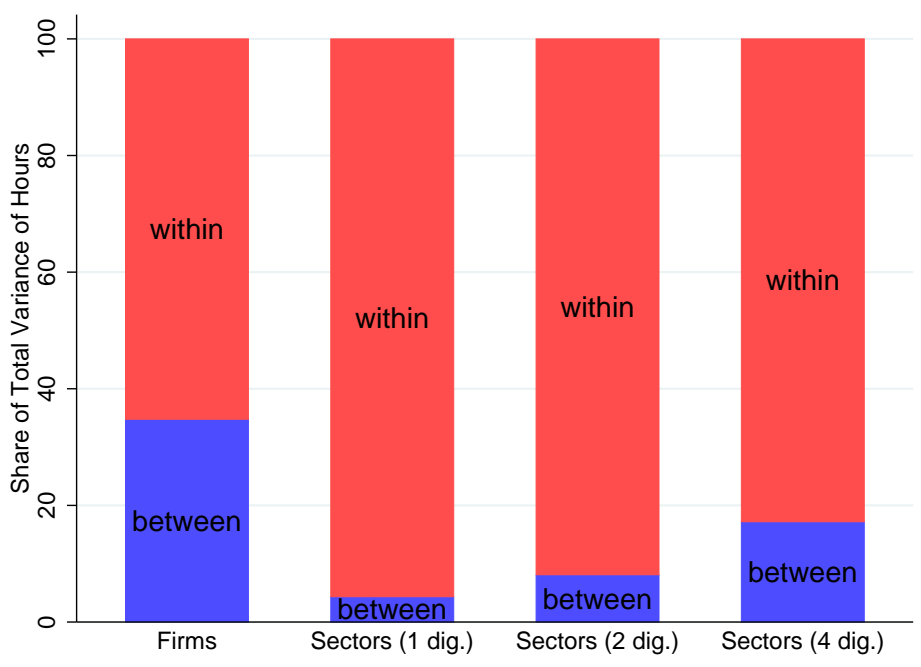

Notes: The figure depicts the decomposition of the variance of hours worked into between and within components (footnote 5 ). We consider the total annualized hours (including overtime) of full-time workers. The figure is based on the 787,683 individual-year observations in our final sample (Table 1). The first bar shows the decomposition into between and within firm components. The second, third and fourth bars show the within-between decomposition for 1-, 2- and 4-digit sectors, respectively. Industries are defined using the classification NACE rev. 2. 
Figure 3: Wage rates and hours worked

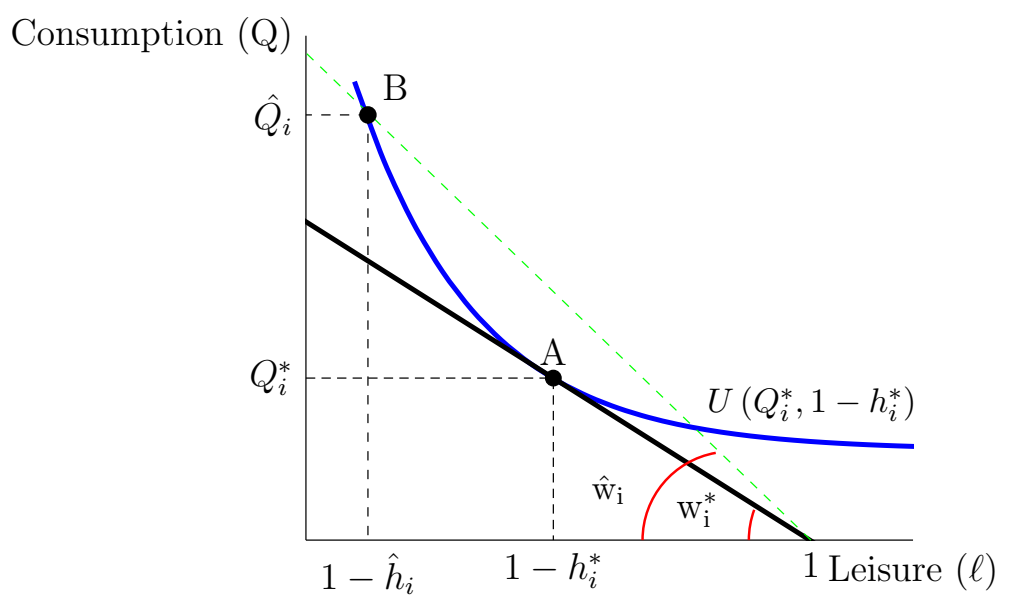

Figure 4: The effects of a tax rate change on wages

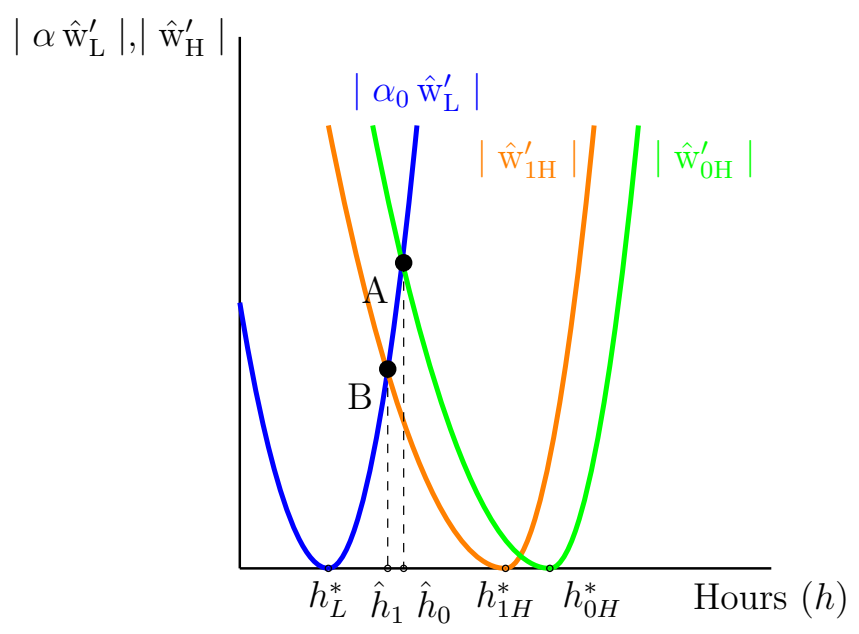

Notes: The figure shows on the $\mathrm{y}$-axis the absolute value of the first derivative of the wage hours function in coordinated firms for high-skilled ( $\hat{\mathrm{w}}_{\mathrm{H}}^{\prime}$ ) and low-skilled workers $\left(\hat{\mathrm{w}}_{\mathrm{L}}^{\prime}\right) . \alpha=\hat{n}_{L} \div \hat{n}_{H}$ is the ratio between the number of low- and high-skilled workers in coordinated firms. At the optimum, $\hat{\mathrm{w}}_{\mathrm{H}}^{\prime}+\alpha \hat{\mathrm{w}}_{\mathrm{L}}^{\prime}=0$. Therefore, we plot the absolute value of $\hat{\mathrm{w}}_{\mathrm{H}}^{\prime}$ and $\hat{\mathrm{w}}_{\mathrm{L}}^{\prime}$ to have them on the same quadrant. The shift from point A to $\mathrm{B}$ represents the change in optimal hours and wage rates in coordinated firms when the tax rate decreases and the income effect prevails, such that the desired hours of the high-skilled shift down from $h_{0 H}^{*}$ to $h_{1 H}^{*}$. 
Figure 5: Validation: standard deviation of hours vs. coordination in $\mathrm{O}^{*} \mathrm{NET}$
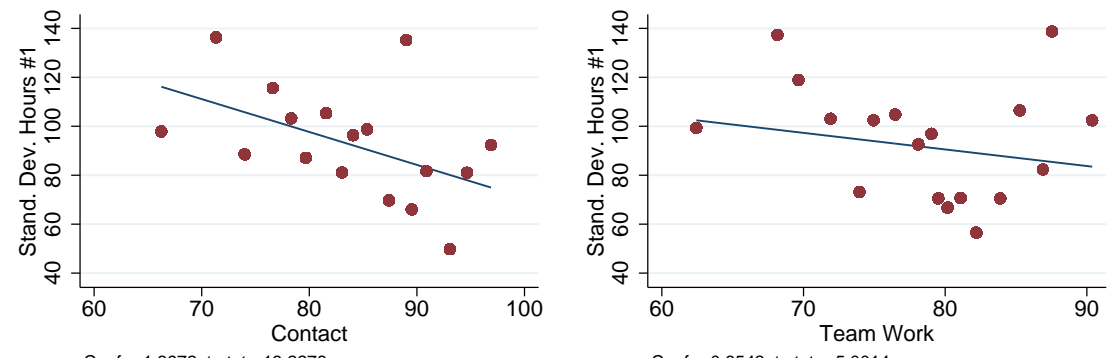

Coef $=-1.3972, \mathrm{t}-\mathrm{stat}=-13.2278$

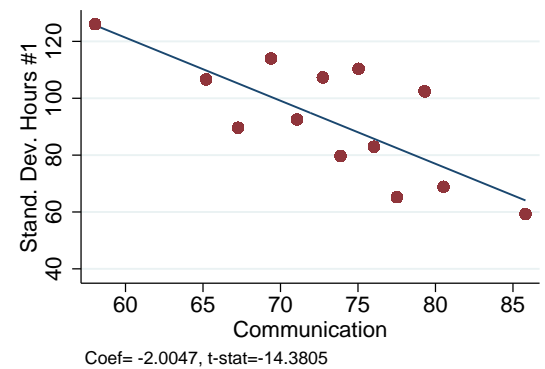

Coef $=-0.6542$, t-stat $=-5.0014$

Notes: The figure shows on the $\mathrm{y}$-axis the standard deviation of hours across skill groups within firms (Section 4.3) and on the $\mathrm{x}$-axis 3 measures of firm-level coordination based on $\mathrm{O}^{*}$ Net: Contact, Team Work and Communication. These variables are measured on a scale of importance from 0 to 100. For each firm, we take the median importance of Contact, Team Work and Communication across workers. We break ties in median scores using the average. Firms are grouped into 20 bins, with each one containing the same number of firms. We plot mean values within each bin. At the bottom of each graph, we report the coefficient and the associated t-stat from a regression of the $\mathrm{y}$ on the $\mathrm{x}$ variable. We map the ISCO-88 classification of the Danish registers to the SOC classification in $\mathrm{O}^{*} \mathrm{Net}$ using the cross-walk provided by the National Crosswalk Center.

Figure 6: The evolution of the marginal tax rate on labor income

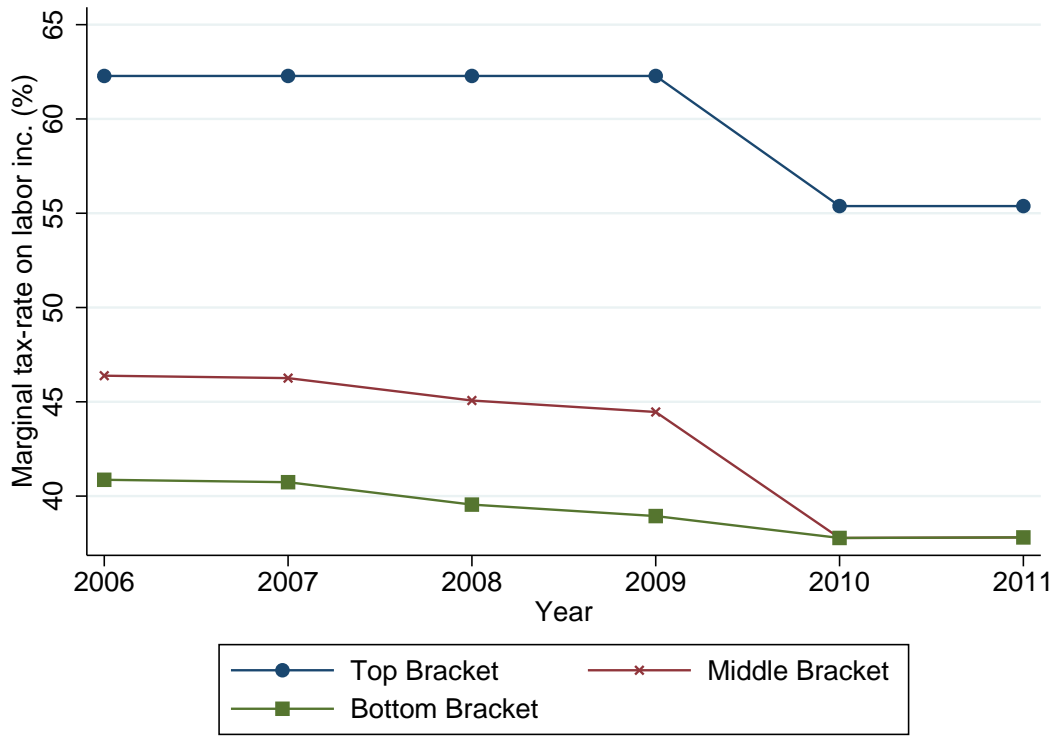

Notes: The figure shows the evolution of the marginal tax rate on labor income between 2006 and 2011. The figure is based on Table D.21. Marginal tax rates on labor income in the bottom and middle brackets are obtained as follows: Statutory Marginal Tax rate * (1-Labor Market contribution) +Labor Market contribution - EITC; in the top bracket, they are obtained as Marginal Tax Ceiling*(1-Labor Market contribution) +Labor Market contribution. 
Figure 7: Mechanical marginal net-of-tax rate change across taxable income

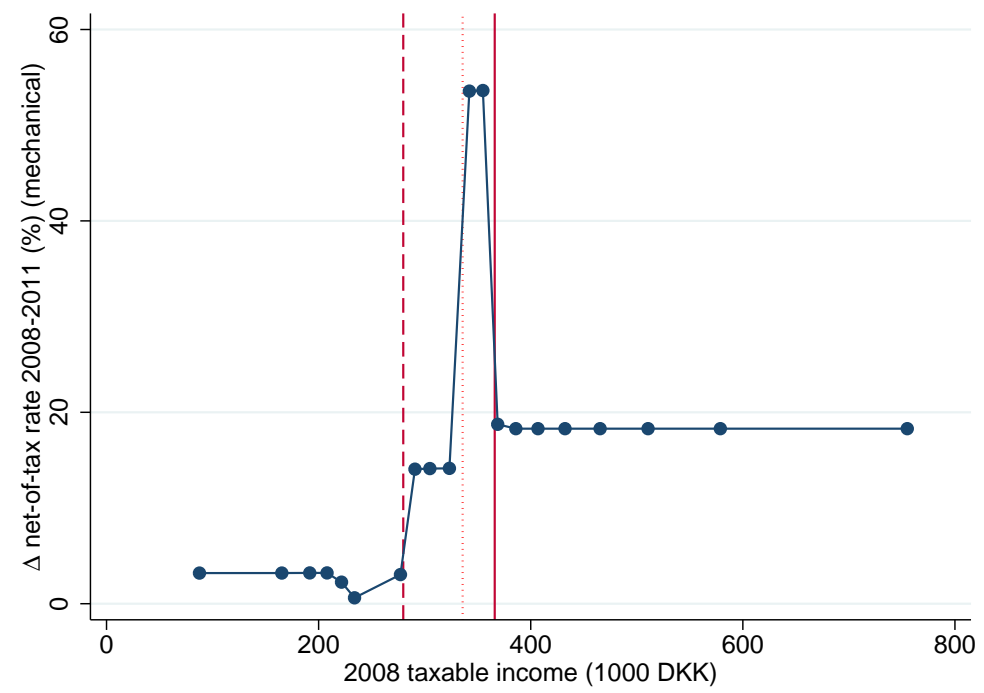

Notes: This figure plots the mechanical change in marginal net-of-tax rates on labor income between 2008 and 2011 over 2008 taxable income for each individual who is in our sample in 2008 and 2011. Taxable income is expressed in 1000 DKK (5 DKK $\simeq 1$ USD). Mechanical marginal tax rates in 2011 are based on 2008 income adjusted by inflation. Each bin contains the same number of workers. The graph plots the median value in each bin. The dashed line delimits the bottom tax bracket in $2008(279,800$ DKK). The dotted line is the lower boundary of the top tax bracket in 2008 ( 335,800 DKK, see Table D.21). The solid line is the lower boundary of the top tax bracket in 2011 expressed in 2008 DKK (nominal 389,900 DKK discounted by 1.06 CPI; see Table D.21).

Figure 8: Average (mechanical) marginal net-of-tax rate change across groups

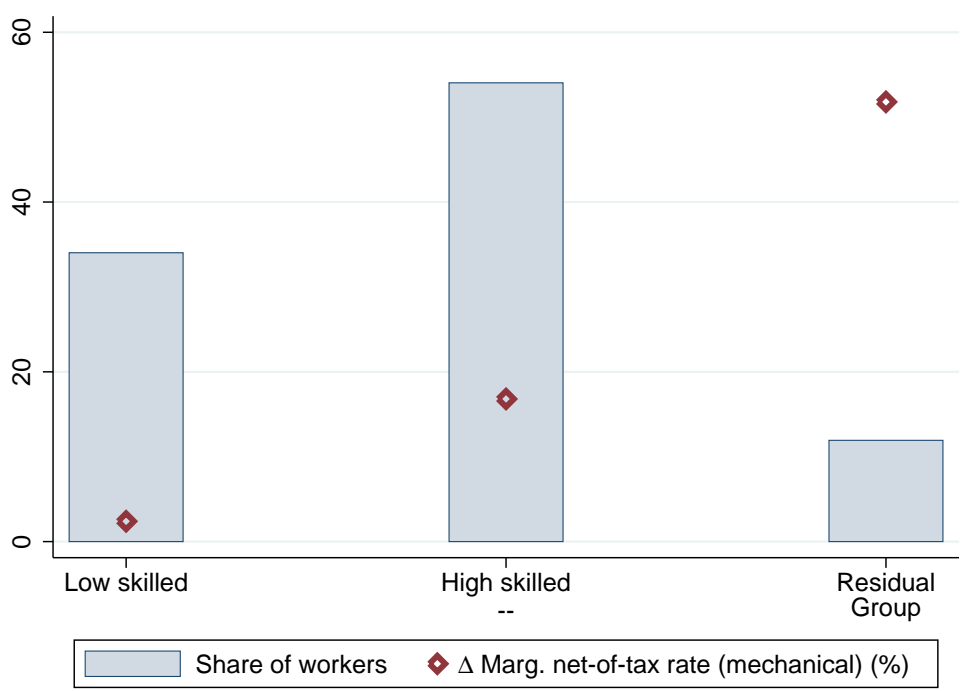

Notes: This figure plots the share of workers in each skill group and the average mechanical change in marginal net-of-tax rates on labor income between 2008 and 2011 in each group. Mechanical marginal tax rates in 2011 are based on 2008 income adjusted by inflation. Low-skilled workers are defined as tax exempt or in the bottom tax bracket in 2008. Workers in the residual group were in the top tax bracket in 2008 and, based on their 2008 income adjusted by inflation, are predicted to be in the bottom tax bracket in 2011. The high-skilled are all workers who are neither in the residual group nor adjusted by inflation, 
Figure 9: Trends in working hours of high-skilled relative to low-skilled workers

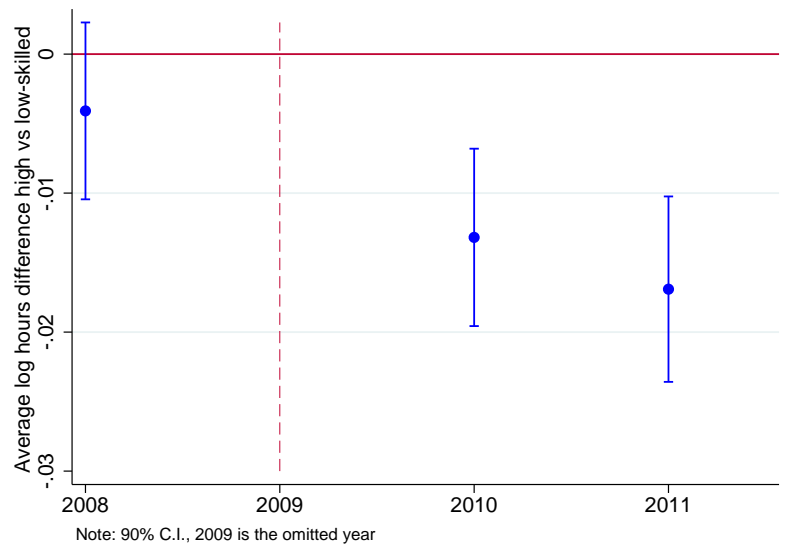

Notes: This figure plots the set of coefficients $\hat{\beta_{t}}$ from the following regression: $h_{i t}=\alpha_{i}+\gamma_{t}+\sum_{t=2008}^{2011} \beta_{t} H i g h S k i l l e d_{i} \times \gamma_{t}+\epsilon_{i t}$, where $h_{i t}$ is the log number of total (regular and overtime) hours worked by worker $i$ in year $t . \alpha_{i}$ and $\gamma_{t}$ are individual and year fixed effects, respectively. The variable HighSkilled $_{i}$ takes value 1 if the worker is high skilled and 0 if the worker is low skilled. High-skilled and low-skilled workers are defined as in Section 5.1. 2009 is the reference year. Standard errors are clustered at the firm level.

Figure 10: Trends in working hours of low-skilled workers in high vs. low coordination firms
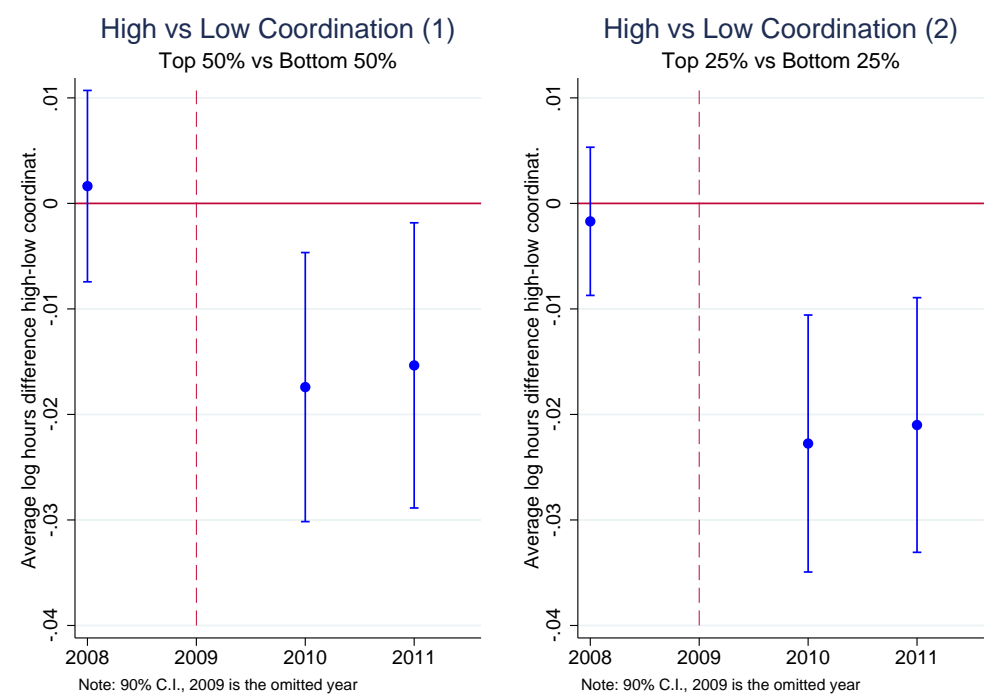

Notes: This figure plots the set of coefficients $\hat{\beta_{t}}$ from the following regression: $h_{i t}=\alpha_{i}+\gamma_{t}+\sum_{t=2008}^{2011} \beta_{t}$ HighCoordination $_{i} \times \gamma_{t}+\epsilon_{i t}$, where $h_{i t}$ is the log number of regular hours worked by low-skilled worker $i$ in year t. $\alpha_{i}$ and $\gamma_{t}$ are individual and year fixed effects, respectively. The variable HighCoordination i takes value 1 if worker $i$ is in a high-coordination firm and 0 if the worker is in a low-coordination firm. High- and low-coordination firms are those in the top and bottom $50 \%$ of the distribution of coordination in panel (1) and in the top and bottom $25 \%$ of the distribution of coordination in panel (2), respectively. 2009 is the reference year. Standard errors are clustered at the firm level. 


\title{
Online Appendix to:
}

\section{Coordination of Hours within the Firm}

\author{
Claudio Labanca \\ Dario Pozzoli \\ Monash University \\ Copenhagen Business School
}

July 26, 2018

\begin{abstract}
Although coworkers are spending an increasing share of their working time interacting with one another, little is known about how the coordination of hours among heterogenous coworkers affects pay, productivity and labor supply. In this paper, we use new linked employer-employee data on hours worked in Denmark to first document evidence of positive correlations between wages, productivity and the degree of hours coordination - measured as the dispersion of hours - within firms. We then estimate labor supply elasticities by exploiting changes made to the personal income tax schedule in 2010. We find that hours coordination is associated with attenuated labor supply elasticity and spillovers on coworkers not directly affected by the tax change. These spillovers led to a $15 \%$ increase in the marginal excess burden from the 2010 tax reform, and if ignored, they induce substantial downward bias in estimates of the labor supply elasticity. We explain these findings in a framework in which differently productive firms choose whether to coordinate hours in exchange for productivity gains, leading more productive firms to select into coordinating hours and to pay compensating wage differentials.
\end{abstract}

JEL Codes: J31, H20, J20 


\section{A Supplementary derivations of the theoretical model}

\section{A.1 The optimal demand of consumption and leisure}

Workers with skill $i$ maximize utility (1) given an hourly wage rate $\mathrm{w}_{i}$ and an income tax rate $t_{i}$ and facing the budget constraint

$$
E_{i} \equiv \int_{\omega \in \boldsymbol{\Omega}} p(\omega) q_{i}(\omega) \mathrm{d} \omega \leq h_{i} \mathrm{w}_{i}\left(1-t_{i}\right)+T+\bar{\pi} \equiv Y_{i},
$$

where $E_{i}$ is expenditures, $Y_{i}$ is after-tax income under a lump-sum transfer $T$ that balances the

government's budget (there are no other government expenditures), and $\bar{\pi} \equiv \int_{\omega \in \boldsymbol{\Omega}} \pi(\omega) \mathrm{d} \omega /\left(n_{H}+\right.$ $n_{L}$ ) represents the equal distribution of firm profits as dividends. A worker $i$ 's optimal product demand then is

$$
q_{i}^{*}(\omega)=\left[\frac{p(\omega)}{P}\right]^{-\sigma} Q_{i}
$$

and labor supply is implicitly given by

$$
\eta v^{\prime}\left(\ell^{*}\right)=\frac{\mathrm{w}_{\mathrm{i}}^{*}\left(1-t_{i}\right)}{P Q}
$$

for the (exponentiated) price index $P^{\sigma-1} \equiv \int_{\omega \in \boldsymbol{\Omega}} p(\omega)^{-(\sigma-1)} \mathrm{d} \omega$. Finally, note that in optimum, $E_{i}=P Q_{i}$.

\section{A.2 Wage-hours function and optimal hours: the case of an ad- ditive separable utility function}

Since the indifference condition (2) implicitly defines the wage rate as a function of the hours worked, it can be used to express $\hat{\mathrm{w}}^{\prime}(\hat{h})$ in terms of marginal utilities. Thus, starting from

$\Phi\left(\hat{\mathrm{w}}_{\mathrm{i}}, \hat{h}\right)=U\left(\mathrm{P}^{-1} \hat{\mathrm{w}}_{\mathrm{i}}\left(1-t_{i}\right) \hat{h}+P^{-1}(T \bar{\pi}), 1-\hat{h}\right)-U\left(\mathrm{w}_{\mathrm{i}}^{*}\left(1-t_{i}\right) h_{i}^{*}++P^{-1}(T \bar{\pi}), 1-h_{i}^{*}\right)=0$,

we have

$$
\hat{\mathrm{w}}_{i}^{\prime}(\hat{h})=-\left(\frac{\partial \Phi\left(\hat{\mathrm{w}}_{\mathrm{i}}, \hat{h}\right)}{\partial \hat{h}}\right)\left(\frac{\partial \Phi\left(\hat{\mathrm{w}}_{\mathrm{i}}, \hat{h}\right)}{\partial \hat{\mathrm{w}}_{\mathrm{i}}}\right)^{-1}=-\frac{\left[P^{-1} U_{C} \hat{\mathrm{w}}_{\mathrm{i}}\left(1-t_{i}\right)-U_{\ell}\right]}{P^{-1} U_{C} \hat{h}\left(1-t_{i}\right)} .
$$


Under decreasing marginal rates of substitution

$$
\hat{\mathrm{w}}_{i}^{\prime}(\hat{h})=-\frac{\left[P^{-1} U_{C} \hat{\mathrm{w}}_{\mathrm{i}}\left(1-t_{i}\right)-U_{\ell}\right]}{P^{-1} U_{C} \hat{h}\left(1-t_{i}\right)}\left\{\begin{array}{ll}
<0 & \text { if } \hat{h}<h_{i}^{*} \\
=0 & \text { if } \hat{h}=h_{i}^{*} \\
>0 & \text { if } \hat{h}>h_{i}^{*}
\end{array} .\right.
$$

Assuming that the utility function is additive separable as in (1), the second derivative of the wage rate with respect to hours is

$\hat{\mathrm{w}}_{i}^{\prime \prime}(\hat{h})=-\left[\frac{\hat{\mathrm{w}}_{i}^{\prime} \hat{h}-\hat{\mathrm{w}}_{i}}{\hat{h}^{2}}\right]-\left[\frac{P}{\hat{h}^{2}\left(1-t_{i}\right)}\right] \frac{U_{\ell}}{U_{C}}-\frac{U_{C} U_{l l}+U_{C C} U_{\ell}\left[P^{-1} \hat{\mathrm{w}}_{i}^{\prime} \hat{h}\left(1-t_{i}\right)+P^{-1} \hat{\mathrm{w}}_{\mathrm{i}}\left(1-t_{i}\right)\right]}{P^{-1} U_{C}^{2}\left(1-t_{i}\right) \hat{h}}$.

Thus, rearranging the terms in (7), we have ${ }^{1}$ :

$$
\hat{\mathrm{w}}_{i}^{\prime \prime}(\hat{h})=-\frac{2}{\hat{h}} \hat{\mathrm{w}}_{i}^{\prime}-\frac{U_{C} U_{l l}+U_{C C} U_{\ell}\left[P^{-1} \hat{\mathrm{w}}_{i}^{\prime} \hat{h}\left(1-t_{i}\right)+P^{-1} \hat{\mathrm{w}}_{i}\left(1-t_{i}\right)\right]}{P^{-1} U_{C}^{2}\left(1-t_{i}\right) \hat{h}} .
$$

In (8), we notice that

$$
\left[P^{-1} \hat{\mathrm{w}}_{i}^{\prime} \hat{h}\left(1-t_{i}\right)+P^{-1} \hat{\mathrm{w}}_{i}\left(1-t_{i}\right)\right]=\frac{-P^{-1} U_{C} \hat{\mathrm{w}}_{\mathrm{i}}\left(1-t_{i}\right)+U_{\ell}+P^{-1} U_{C} \hat{\mathrm{w}}_{\mathrm{i}}\left(1-t_{i}\right)}{U_{C}}=\frac{U_{\ell}}{U_{C}}>0 .
$$

Assuming $U_{C}>0, U_{\ell}>0, U_{C C}<0$ and $U_{l l}<0$, it follows that the second term in (8):

$$
-\frac{U_{C} U_{l l}+\frac{U_{C C} U_{\ell}^{2}}{U_{C}}}{P^{-1} U_{C}^{2}\left(1-t_{i}\right) \hat{h}}>0 .
$$

(10) captures the loss in terms of marginal utilities from working one extra hour. This loss requires wage rates to increase at an increasing rate when hours increase. Combining (10) and (8), we have

$$
\hat{\mathrm{w}}_{i}^{\prime \prime}(\hat{h})=-\frac{2}{\hat{h}} \hat{\mathrm{w}}_{i}^{\prime}-\frac{U_{C} U_{l l}+\frac{U_{C C} U_{k}^{2}}{U_{C}}}{P^{-1} U_{C}^{2}\left(1-t_{i}\right) \hat{h}} .
$$

If $\hat{h}=h^{*}$ since $\hat{\mathrm{w}}_{i}^{\prime}(\hat{h})=0$, then $\hat{\mathrm{w}}_{i}^{\prime \prime}(\hat{h})>0$. If $\hat{h}<h_{i}^{*}$ then $\hat{\mathrm{w}}_{i}^{\prime}(\hat{h})<0$ and $\hat{\mathrm{w}}_{i}^{\prime \prime}(\hat{h})>0$. Finally, if $\hat{h}>h_{i}^{*}$, then $\hat{\mathrm{w}}_{i}^{\prime}(\hat{h})>0$ and the sign of $\hat{\mathrm{w}}_{i}^{\prime \prime}(\hat{h})$ is ambiguous. Using (5) to rearrange (11) $\hat{\mathrm{w}}_{i}^{\prime \prime}>0$ implies

$$
2 \frac{\hat{\mathrm{w}}_{i}\left(1-t_{i}\right)}{P}>\frac{U_{\ell}}{U_{C}}+\frac{U_{\ell \ell}}{U_{C}}-\frac{U_{C C} U^{2}}{U_{C}^{2}} .
$$

\footnotetext{
${ }^{1}$ The rearrangement here involves substituting (5) into the first term on the right-hand side of (7). Then we take the sum of the first two terms. To gain a more transparent intuition of the results, we then express the sum of the first two terms in (7) in terms of w'(h).
} 
This is the case when $P$ is particularly small and/or $U_{\ell \ell}$ is particularly high.

\section{A.3 Optimal hours worked in coordinated firms: derivations}

The first-order conditions relative to the minimization problem of section 2.3 .2 are

$$
\begin{gathered}
\hat{\mathrm{w}}_{\mathrm{L}}^{\prime} \hat{h} \hat{n}_{L}+\mathrm{w}_{\mathrm{L}} \hat{n}_{L}+\hat{\mathrm{w}}_{\mathrm{H}}^{\prime} \hat{h} \hat{n}_{H}+\hat{\mathrm{w}}_{\mathrm{H}} \hat{n}_{H}=G_{H} \hat{n}_{H}+G_{L} \hat{n}_{L}, \\
G_{H}=\hat{\mathrm{w}}_{\mathrm{H}}(\hat{h}), \\
G_{L}=\hat{\mathrm{w}}_{\mathrm{L}}(\hat{h}), \\
\hat{\gamma} \phi G\left(\hat{n}_{L} \hat{h}, \hat{n}_{H} \hat{h}\right)=\hat{q}(\omega) .
\end{gathered}
$$

Replacing $G_{H}$ from (14) and $G_{L}$ from (15) into (13) we obtain

$$
\hat{\mathrm{w}}_{\mathrm{H}}^{\prime}(\hat{h}) \hat{n}_{H} \hat{h}+\hat{\mathrm{w}}_{\mathrm{L}}^{\prime} \hat{n}_{L} \hat{h}=0,
$$

dividing by $\hat{h}$ we obtain condition (4).

The optimality condition (4) implicitly defines optimal hours in coordinated firms as a function of the marginal tax rate faced by high-skilled workers. Thus it can be used to obtain the derivative of $\hat{h}$ with respect to the tax rate $t_{H}$. Defining the implicit function

$$
\Phi_{t_{H}}\left(h, t_{H}\right)=\hat{\mathrm{w}}_{\mathrm{H}}^{\prime}(\hat{h})+\alpha \hat{\mathrm{w}}_{\mathrm{L}}^{\prime}=0,
$$

we have

$$
\frac{d \hat{h}}{d t_{H}}=-\left(\frac{\partial \Phi_{t_{H}}}{\partial t_{H}}\right)\left(\frac{\partial \Phi_{t_{H}}}{\partial \hat{h}}\right)^{-1} .
$$

Using (5) to solve for the numerator in (19) gives equation (6).

\section{A.4 The product market: prices, revenues and profits}

A firm producing variety $\omega$ maximizes its profits by setting the variety-specific price $p(\omega)$ given total demand. By summing the demand indexes $Q_{i}^{*}$ and $\hat{Q}_{i}$ over all consumers of different skills and with employment in different labor markets, we arrive at aggregate consumption $Q$, which firms take as given under monopolistic competition. However, in the product market for their individual variety $\omega$, firms are monopoly price setters, taking demand for their variety into 
account:

$$
q(\omega)=[p(\omega) / P]^{-\sigma} Q
$$

after summing (2) over all consumer groups. ${ }^{2}$ The generic profit maximization problem is

$$
\pi(\omega) \equiv \max _{p(\omega)} p(\omega) q(\omega)-\frac{\mu}{\gamma \phi} q(\omega)-F \quad \text { s.t. } \quad q(\omega)=\left[\frac{p(\omega)}{P}\right]^{-\sigma} Q
$$

where the constant $\mu$ is the marginal production cost (given constant returns to scale). Note that $F=0, \gamma=1$ and $\mu=\mu^{*}$ in the non-coordinated market, whereas $F=\hat{F}, \gamma=\hat{\gamma}>1$ and $\mu=\hat{\mu}$ for firms that enter the coordinated market. Applying Euler's rule to constant-returnsto-scale production (with homogeneity of degree one in production factors), the minimized cost function in uncoordinated firms takes the form

$$
C^{*}(\omega)=\frac{\mu^{*}}{\phi} q^{*}(\omega) \quad \text { with } \quad \mu^{*} \equiv \mu\left(\mathrm{w}_{H}^{*}, \mathrm{w}_{L}^{*}, h_{H}^{*}, h_{L}^{*}\right)
$$

where $\mu^{*}$ is the Lagrange multiplier of the constrained minimization problem $(3)$, and $q^{*}(\omega)=$ $\phi G\left(n_{H}^{*} h_{H}^{*}, n_{L}^{*} h_{L}^{*}\right)$, whereas the function $\mu(\cdot)$ also depends on the parameters of the production function. In coordinated firms the minimized costs function takes the form:

$$
\hat{C}(\omega)=\frac{\hat{\mu}}{\hat{\gamma} \phi} \hat{q}(\omega) \quad \text { with } \quad \hat{\mu} \equiv \mu\left(\hat{\mathrm{w}}_{H}, \hat{\mathrm{w}}_{L} ; \hat{h}\left(\eta, P, t_{H}, t_{L} ; \phi\right)\right),
$$

where $\hat{\mu}$ is the Lagrange multiplier of the constrained minimization problem in Section 2.3.2 and $\hat{q}(\omega)=\hat{\gamma} \phi \hat{h} G\left(\hat{n}_{H}, \hat{n}_{L}\right)$. The optimal prices resulting from (20) are

$$
p^{*}(\omega)=\frac{\sigma}{\sigma-1} \frac{\mu^{*}}{\phi} \quad \text { and } \quad \hat{p}(\omega)=\frac{\sigma}{\sigma-1} \frac{\hat{\mu}}{\hat{\gamma} \phi} .
$$

By profit maximization (20), firms with the same $\phi$ choose the same optimal price--over-cost markups, production and revenue, regardless of their specific product variety $\omega$. We therefore adopt the simplifying notation that optimal prices are $p(\phi)$, optimal production is $q(\phi)$, and optimal revenues are $p(\phi) q(\phi)$. Summing (2) over all consumer groups, total demand for a firm's output can be written as $q(\phi)=[p(\phi) / P]^{-\sigma} Q$ and the firm's equilibrium revenues are

$$
p(\phi) q(\phi)=[p(\phi) / P]^{-(\sigma-1)} P Q=[p(\phi) / P]^{-(\sigma-1)} E,
$$

where $E=P Q$ is economy-wide expenditure, aggregated over all consumer groups. By (20),

\footnotetext{
${ }^{2}$ Concretely, aggregate demand is $Q \equiv \sum_{i=H, L} N_{i}^{*} Q_{i}^{*}+\hat{N}_{i} \hat{Q}_{i}$, where $Q_{i}^{*}=E_{i}^{*} / P$ and $\hat{Q}_{i}=\hat{E}_{i} / P$ with $E_{i}^{*}=h_{i}^{*} w_{i}^{*}\left(1-t_{i}\right)+T$ and $\hat{E}_{i}=\hat{h} \hat{w}_{i}\left(1-t_{i}\right)+T$.
} 
the profits of a firm with productivity $\phi$ are

$$
\pi(\phi)=\frac{p(\phi) q(\phi)}{\sigma}-F=\left[\frac{p(\phi)}{P}\right]^{-(\sigma-1)} \frac{E}{\sigma}-F
$$

Using optimal prices (21) for non-coordinated and coordinated firms in this profit relationship, we can state a firm $\phi$ 's prospective profits in the two labor market segments as in Section 2.3.3.

\section{A.5 Tax changes and wage rates with coordination}

In the setting described in Section 2, a tax change that affects coordinated hours also affects wage rates through the wage-hours function. The sign of the effect on wages depends on whether the income or the substitution effect prevails and on whether high-skilled workers desire to work more or less hours than low-skilled workers. Figure 4 shows the case in which the tax rate decreases, the income effect prevails and high-skilled workers desire to work more hours (i.e., $h_{H}^{*}>h_{L}^{*}$ ). In this case, a decrease in the tax rate moves the equilibrium from $\mathrm{A}$ to B. At the new equilibrium, both $\left|\mathrm{w}_{\mathrm{H}}^{\prime}\right|$ and $\left|\mathrm{w}_{\mathrm{L}}^{\prime}\right|$ are lower, implying lower wage rates for both high-skilled and low-skilled workers. Intuitively, the lower supply of hours induced by the tax drop moves low-skilled workers (who work more than desired at the original equilibrium) closer to the optimum. This shift results in lower wage premiums for low-skilled workers. For high-skilled workers, the reform drives down both their coordinated and desired hours worked. Coordinated hours, however, decrease less than the desired hours, thus shrinking the gap between the optimum and the coordinated hours. This shift results in lower wage rates. The other possible cases can be derived following a similar reasoning, and they lead to the conclusion that wage rates and hours move together if, in equilibrium, low-skilled workers prefer to work less than high-skilled workers, while hours and wages move in opposite directions if low-skilled workers prefer to work more.

Unfortunately, the specific setting of our empirical analysis does not allow us to distinguish between the two cases. In fact, using the instrumental variable approach described in Section 5 , we fail to find significant effects of the 2010 tax reform on wage rates (Table D.10), which may be due to the fact that the spillover effects on hours were too small to generate a significant wage effect. 


\section{A.6 A framework for the empirical model of taxation with spillovers}

Similar to Gruber and Saez (2002), we assume that type $i$ workers maximize a utility function that depends on consumption $(c)$ and labor income $(z)$. For simplicity, we assume that labor income is given as the product of wage rates and hours worked such that the utility function takes the following form: $U_{i}\left(c_{i}, h_{i} \mathrm{w}_{\mathrm{i}}\right)$. Following Kleven and Schultz (2014), we define $c_{i}=$ $z_{i}-T_{i}(z)=z_{i}\left(1-\tau_{i}\right)+y_{i}$, where $T_{i}(z)$ is tax liability, $\tau_{i}=T_{i}^{\prime}()$ and virtual income is defined as $y_{i}=z_{i} \tau_{i}-T_{i}(z)$. In uncoordinated firms, the wage rate is exogenously set by the market at $\mathrm{w}_{\mathrm{i}}=\mathrm{w}_{\mathrm{i}}^{*}$. The optimal choice of hours is then a function of the marginal net-of-tax rate, virtual income and the exogenous wage rate: $h_{i}=h\left(1-\tau_{i}, y_{i}, \mathrm{w}_{\mathrm{i}}^{*}\right)$. In this framework, changes in $\tau_{i}$ and $y_{i}$ affect the supply of hours as follows:

$$
d h_{i}=-\frac{\partial h}{\partial\left(1-\tau_{i}\right)} d \tau_{i}+\frac{\partial h}{\partial y_{i}} d y_{i}
$$

Defining the uncompensated elasticity of hours with respect to the net-of-tax rate as $\alpha_{2}=$ $\left[\left(1-\tau_{i}\right) / h_{i}\right]\left[\partial h / \partial\left(1-\tau_{i}\right)\right]$ and the income elasticity as $\alpha_{3}=\left(1-\tau_{i}\right)\left[\partial h / \partial y_{i}\right]$, then the terms in equation (22) can be rearranged as

$$
\frac{d h_{i}}{h_{i}}=-\alpha_{2} \frac{d \tau_{i}}{\left(1-\tau_{i}\right)}+\alpha_{3} \frac{d y_{i}}{h_{i}\left(1-\tau_{i}\right)}
$$

Using a log-log specification, equation (23) can be estimated as

$$
\Delta \log \left(h_{i}\right)=\alpha_{0}+\alpha_{2} \Delta \log \left(1-\tau_{i}\right)+\alpha_{3} \Delta \log \left(y_{i}\right)+\varepsilon_{i}
$$

The compensated elasticity of hours to a net-of-tax rate change $\left(\zeta^{c}\right)$ can be obtained from $\alpha_{2}$ and $\alpha_{3}$ using the Slutsky equation: $\zeta^{c}=\alpha_{2}-\alpha_{3}$.

If firms coordinate hours among workers, then the supply of hours by type $i$ workers in a firm will also depend on the hours worked by other types of workers in the same firm. Hours worked by other types will, in turn, depend on the net-of-tax rate, the virtual income and the market wage rate that the other types face. We assume there is one type of other workers, indexed as $-i$. Hours worked by type $i$ workers can then be expressed as $h_{i}=h\left(1-\tau_{i}, y_{i}, h_{-i}, \mathrm{w}_{\mathrm{i}}^{*}\right)$, where $h_{-i}=h\left(1-\tau_{-i}, y_{-i}, \mathrm{w}_{-\mathrm{i}}^{*}\right)$. In defining $h_{-i}$, we assume that hours worked by type $-i$ workers are independent of the tax rate and virtual income faced by type $i$ workers. This assumption, while restrictive, fits well our empirical setting in which tax changes experienced by low-skilled 
workers (type $i$ ) are of small magnitude and do not affect hours worked by high-skilled (type $-i$ ) workers in a significant way. We assume that the assignment of workers to a type does not change when the tax rate changes. This finding is consistent with our framework, in which workers are defined as high- or low-skilled based on the marginal tax rate that they face prior to the reform and the mechanical marginal tax rates that they face after the reform.

Changes in $\tau_{i}, y_{i}, \tau_{-i}$ and $y_{-i}$ affect the supply of hours of type $i$ workers as follows:

$$
\frac{d h_{i}}{h_{i}}=-\alpha_{2} \frac{d \tau_{i}}{\left(1-\tau_{i}\right)}+\alpha_{3} \frac{d y_{i}}{h_{i}\left(1-\tau_{i}\right)}+\frac{\partial h}{\partial h_{-i}} \frac{1}{h_{i}}\left[-\beta_{2} \frac{h_{-i} d \tau_{-i}}{\left(1-\tau_{-i}\right)}+\beta_{3} \frac{d y_{-i}}{\left(1-\tau_{-i}\right)}\right]
$$

In a log-log specification, equation (25) can be estimated using the following empirical model:

$$
\left.\Delta \log \left(h_{i}\right)=\alpha_{0}+\alpha_{1} \Delta \widehat{\log \left(h_{-i}\right.}\right)+\alpha_{2} \Delta \log \left(1-\tau_{i}\right)+\alpha_{3} \Delta \log \left(y_{i}\right)+\varepsilon_{i}
$$

Where $\widehat{\Delta \log \left(h_{-i}\right)}$ is predicted using $\Delta \log \left(1-\tau_{-i}\right)$ and $\Delta \log \left(y_{-i}\right)$ as instruments.

\section{A.6.1 Marginal excess burden with hours coordination}

We measure the marginal excess burden (MEB) as the ratio of the change in tax revenues due to behavioral responses $(\mathrm{dB})$ to total changes in tax revenues $(\mathrm{dR})$. Abstracting from spillovers, we have

$$
M E B=\frac{d B}{d R}=\frac{d B_{H}+d B_{L}}{d M_{H}+d M_{L}+d B_{H}+d B_{L}}
$$

where the change in tax revenues due to behavioral responses for a type $i$ worker is defined as $d B_{i}=\left(e_{i} \cdot h_{i} \cdot w_{i} \cdot \frac{\tau_{i}}{1-\tau_{i}} d \tau_{i}\right) \times N_{i}$, and $e_{i}, h_{i}, w_{i}, \tau_{i}, N_{i}$ are, respectively, the elasticity of type $i$ hours, average hours, average wage rates, average marginal tax rates and the number of type $i$ workers in our sample. $d \tau_{i}$ measures the average change in marginal tax rates on labor income due to the reform among type $i$ workers. The mechanical change in tax revenues is defined as $d M_{i}=d \tau_{i} \cdot h_{i} \cdot w_{i}$ and captures losses (gains) in revenues due to changes in the tax schedule absent behavioral changes.

In our setting, $e_{L}$ is insignificant, so $d B_{L}$ can be ignored. In comparing the MEB with coordination relative to the MEB that would be implied by low coordination, we first estimate MEB assuming $e_{H}=-0.05$, which is the elasticity across all firms. Then we compute MEB under $e_{H}=-0.1$, which is the elasticity in low-coordination firms (column 5 in Table 4). 
Including spillovers, we have

$$
M E B^{\text {Spillover }}=\frac{d B^{\text {Spillover }}}{d R}=\frac{d B_{L}^{\text {Spillover }}+d B_{H}+d B_{L}}{d B_{L}^{\text {Spillover }}+d M_{H}+d M_{L}+d B_{H}+d B_{L}}
$$

where $d B_{L}^{\text {Spillover }}=e_{L}^{\text {Spillover }} \cdot\left(d h_{H} / h_{H}\right) \cdot w_{L} \cdot h_{L} \cdot \tau_{L}$. Here, $e_{L}^{\text {Spillover }}$ is the elasticity of low-skilled hours to the hours of high-skilled coworkers, and $d h_{H}$ is the change in hours of high-skilled workers due to the reform. In practice, we consider spillovers from normal hours only because they have better power in first-stage regressions (column 3 in Table 6).

\section{B Further institutional details and data descriptions}

\section{B.1 The overtime and vacation time regulation in Denmark}

Overtime work is defined in the large majority of collective agreements as the number of weekly hours worked beyond the normal hours set in the employment contract. In order to remunerate overtime work, there are two options: i) an hour of paid leave for each hour of overtime work or ii) an increase in the hourly wage according to the rates set in the collective agreements. ${ }^{3}$ Many agreements, for example, set the overtime premium to $50 \%$ for the first three hours of overtime and to $100 \%$ for overtime over three hours. Work on Sundays and during public holidays is also considered overtime work, which is usually rewarded with a $100 \%$ increase in the hourly rate. Collective agreements generally establish a cap on overtime hours per week unless explicitly agreed upon differently by the employer and the union representatives at the company level. ${ }^{4}$

Moreover, overtime work is also indirectly affected by two laws regarding working time. The first law states that every worker is entitled to rest at least 11 hours per day on average and at least one day per week (Health and Safety Act, passed in 1996). ${ }^{5}$ The daily rest period of 11 hours can be reduced by a local agreement, even though it cannot be below 8 hours per day on average.

\footnotetext{
${ }^{3}$ This is not the case for salaried workers, who are not entitled to overtime pay.

${ }^{4}$ In the manufacturing sector, the cap on overtime work is currently 8 hours, and it can be increased to 12 hours for the reparation of machines (Industriens Overenskomst 2014-2017). In the transport sector, the same cap is set to 3 hours per week (Industriens Overenskomst 2014-2017). In the financial sector, there is not an explicit limit on overtime work (Standardoverenskomst 2014- Finansforbundet), but there is a reference to the rule on maximum weekly working hours.

${ }^{5}$ Arbejdsmiljloven (2010)
} 
The second law sets the maximum weekly working hours, including overtime work, to an average of 48 hours per week over a reference period (Directive on working time, passed in 2002). ${ }^{6}$ The reference period, however, can vary substantially from sector to sector. For instance, both in the manufacturing sector and in the public sector, the 48-hour maximum is always determined over a reference period of 4 months, unless a shorter or longer period of maximum 12 months is negotiated at the company level. In the service sector, the picture is more blurred. The reference period is 4 months for employees working in shops, but those employees working in offices and warehouses have a reference period of 6 months. ${ }^{7}$ However, deviations from the 4or 6-month period can be specified at the sectoral level. Finally, employees in the transportation sector have stricter limitations on maximum weekly hours, which should not exceed 42 hours.

As far as vacation time is concerned, the "holiday year" runs from the 1st of May until the 30th of April. Under the Danish Holiday Act, every employee in Denmark receives five weeks of leave per year as long as they have worked for one calendar year before the beginning of the holiday year. If the employee has not completed a full calendar year, they are entitled to 2.08 days of holiday for every month in which they have been employed. Any employee who has not earned their full five-week holiday allowance is still entitled to take up to five weeks per year as unpaid holiday. Generally, if the employee does not take vacation during the holiday year, they can transfer some of this vacation time to the next vacation year or convert the fifth week of holiday into wages. Employees are also entitled to additional vacation days, which are often referred to as the sixth week of vacation. These days are not covered by the Danish Holiday Act and are usually part of bilateral negotiation between employers and employees. Therefore, the rules can differ from place to place with regard to eligibility, use and possible payout.

\section{B.2 Construction of the data on hours and earnings}

In equation (8) of the main paper, we use hourly wages derived as the ratio of labor earnings gross of taxes and total working hours. We use hours and earnings relative to the highest-paying job in the November spell. This is the only spell that can be matched to employers' data through

\footnotetext{
${ }^{6}$ Bekendtgrelse af lov om gennemfrelse af dele af arbejdstidsdirektivet (2004)

${ }^{7}$ In the financial sector, the reference period is set to 13 weeks (Standardoverenskomst 2014- Finansforbundet).
} 
FIDA. For workers whose November spell lasts less than 1 entire year, we annualize hours and earnings multiplied by the inverse of the share of the year in which they stayed in the spell. We exclude from the analysis the workers with annualized earnings lower than $2000 \$(13000 \mathrm{DKK})$ or those with annual hours greater than 5,616 $(18 \times 6 \times 52)$. This results in the exclusion of approximately 10,000 observations over the years 2003-2011 (Table D.2).

We use the gross labor earnings variable called joblon from IDA based on yearly labor earning records, which include all forms of labor compensation, excluding pension contributions. ${ }^{8}$. Following Kleven and Schultz (2014), we use information on labor and total earnings stemming from the income register $(I N D K)$ in the tax simulator. ${ }^{9}$ As a deflator for the income variables, we use the Consumer Price Index from Statistics Denmark with 2000 as the base year. ${ }^{10}$

Normal working hours are from Lønstatistikken (LON thereafter) and are inclusive of vacation, weekends, legal holidays and lunch breaks, whereas unpaid leave and overtime hours are excluded. Lønstatistikken also reports information on overtime hours (i.e., overtid), which takes a value of zero for approximately $70 \%$ of our final sample. Among salaried workers, this share increases to $81 \%$, while among hourly workers, this share is approximately $42 \%$. All the information contained in LON originates from employers.

For most private companies (with the equivalent of at least 10 full-time employees), the data are collected by the Danish employers confederation (Dansk Arbejdsgiverforening and Finanssektorens Arbejdsgiverforening). Employers in Denmark report hours worked because they make contributions for each employee to a pension fund (Additional Pension from the Labor Market, known as ATP), and the size of the contribution depends on hours and the contract type (i.e., monthly paid, weekly paid and casual work, see also Table D.1).

Over the 2003-2011 period, only approximately 55\% of the observations in IDA can be matched to LON. Attrition can be partially explained by the fact that data on approximately $15 \%$ of the firms surveyed are judged to be of low quality by Statistics Denmark, and they are

\footnotetext{
${ }^{8} I D A$ also contains two alternative measures of earnings. The first is lonind, which measures the gross annual labor earnings, not just those for the November spell. The second is timelon, which measures hourly wages. However, this measure is missing for approximately 20,000 observations. Additional details about how the gross annual earnings are measured can be found at http://www.dst.dk/da/TilSalg/Forskningsservice/ Dokumentation/hoejkvalitetsvariable/loenforhold-der-vedroerer-ida-ansaettelser-/joblon

${ }^{9}$ In this register, the variable capturing labor earnings is qlontmp2.

${ }^{10}$ This index can be accessed at http://www.statistikbanken.dk/PRIS6
} 
not released in LON. Data on hours are also available in 2002 when, however, only $30 \%$ of the observations in IDA can be matched to LON. For this reason, we exclude the year 2002 from the analysis. We do not consider part-timers, who are defined as those working less than 26 weekly hours, where weekly hours are calculated by dividing annual hours by 52 .

With the introduction of the e-income registry (E-indkomst), the Danish tax authorities obtained information on hours worked by all employees over the age of 14, including employees in smaller enterprises, on a monthly basis. ${ }^{11}$ This database is available only for the years 2008-2011. For this reason, we use E-indkomst as a secondary source of data to check the robustness of our baseline results. We make hours in E-indkomst comparable to those in LON by aggregating monthly hours into annual hours. We also exclude observations for which hours are imputed.

\section{B.3 Accounting data}

As far as firms' variables are concerned, capital stock (MAAT) is measured as the value of land, buildings, machines, equipment and inventory, according to the Accounting Statistics register (Regnskabsstatistik). ${ }^{12}$ We obtain total sales (OMS) from the same register. The definition of value added is that suggested by Statistics Denmark. This definition changes over the sample period to account for adjustments in accounting standards. Specifically, from 2002 to 2003, the value added is calculated as

$$
\begin{aligned}
& (O M S+A U E R+A D R+D L G)- \\
& (K R H+K E N E+K L O E+U D H L+U A S I+U D V B+U L O L+E K U D+S E U D)
\end{aligned}
$$

where AUER is the value of work performed for one's own purposes and capitalized as a part of fixed assets, ADR represents other non-operating income (such as interest payments), DLG measures inventories, KRH consists of purchases of raw materials, finished goods and packaging (excluding electricity), KENE denotes energy purchases, KLOE represents labor costs, UDHL measures rents, UASI represents losses on small inventories, UDVB denotes the costs of hiring workers from other companies (such as temporary agency employment), ULOL measures leasing

\footnotetext{
${ }^{11}$ The hours variable that we use is called ajoloentimer.

12 http://www.dst.dk/da/Statistik/dokumentation/Times/regnskabsstatistik-for-firmaer/
} 
costs, EKUD represents other external costs (a part from secondary costs), and SEUD measures secondary costs.

From 2004 to 2012, the valued added is calculated as

$$
\begin{aligned}
& (O M S+A U E R+A D R+D L G)- \\
& (K V V+K R H E+K E N E+K L O E+U A S I+U D H L+U D V B+U L O L+E K U D+S E U D)
\end{aligned}
$$

where KVV is the purchase of goods for resale, while KRHE consists of purchases of raw materials, finished goods and packaging (excluding electricity).

\section{B.4 Total factor productivity}

Total factor productivity (TFP) is obtained from a Cobb-Douglas production function:

$$
y_{i t}=\beta_{0}+\beta_{l} \ell_{i t}+\beta_{k} k_{i t}+v_{i t}+\varepsilon_{i t}
$$

where $y$ is $\log$ value added, $\ell$ is the $\log$ number of full-time employees and $k$ is the $\log$ of

physical capital in firm $i$ at time $t$. We assume that the error component $\varepsilon_{i t}$ cannot be observed or predicted by firms, while the productivity shock $v_{i t}$ is assumed to follow a Markov process so that $p\left(v_{i t+1} \mid I_{i t}\right)=p\left(v_{i t+1} \mid v_{i t}\right)$, where $I_{i t}$ - the information held by a firm at time $t$-includes the realization of $v_{i}$ up to $t$ (Olley and Pakes, 1996). This assumption implies that

$$
v_{i t}=g\left(v_{i t-1}\right)+\xi_{i t}
$$

where $E\left[\xi_{i t} \mid I_{i t}\right]=0$ by construction. We assume that capital at $t$ is a function of capital and investments at $t-1: k_{i t}=\kappa\left(k_{i t-1}, i_{i t-1}\right)$, while labor is chosen after $t-1$. Furthermore, following Ackerberg et al. (2015) (henceforth ACF), we assume that labor is part of the demand of intermediate inputs $\left(m_{i t}\right)$ :

$$
m_{i t}=f\left(k_{i t}, v_{i t}, \ell_{i t}\right)
$$

As in other studies, we assume that $f()$ is strictly increasing in $v_{i t}$ so that

$$
v_{i t}=f^{-1}\left(k_{i t}, m_{i t}, \ell_{i t}\right)
$$

and replacing this equation in (27), we have

$$
y_{i j t}=\beta_{0}+\beta_{l} \ell_{i t}+\beta_{k} k_{i t}+f^{-1}\left(k_{i t}, m_{i t}, \ell_{i t}\right)+\varepsilon_{i t}=\Phi_{i t}\left(k_{i t}, \ell_{i t}, m_{i t}\right)+\varepsilon_{i t}
$$


As in ACF we use the following moment condition to obtain an estimate of $\Phi_{i t}\left(\hat{\Phi}_{i t}\right)$ through GMM:

$$
E\left[\varepsilon_{i t} \mid I_{i t}\right]=E\left[y_{i t}-\Phi_{i t}\left(k_{i t}, \ell_{i t}, m_{i t}\right) \mid I_{i t}\right]=0
$$

Then, we estimate $\beta_{0}, \beta_{l}$ and $\beta_{k}$ through GMM from the following moment condition:

$$
\begin{aligned}
& E\left[\varepsilon_{i t}+\xi_{i t} \mid I_{i t-1}\right]= \\
& \quad E\left[y_{i t}-\beta_{0}-\beta_{l} \ell_{i t}-\beta_{k} k_{i t}-g\left(\Phi_{i t}\left(k_{i t-1}, \ell_{i t-1}, m_{i t-1}\right)-\beta_{0}-\beta_{l} \ell_{i t-1}-\beta_{k} k_{i t-1}\right) \mid I_{i t-1}\right]=0
\end{aligned}
$$

Finally, TFP is derived as

$$
T F P_{i t}=\hat{\Phi}_{i t}-\hat{\beta}_{l} \ell_{i t}-\hat{\beta}_{k} k_{i t}
$$

In practice, we proxy for $f^{-1}()$ using a 4th order polynomial function of $\mathrm{k}, \ell, m$ and a full set of interactions among these terms, while $g()$ is assumed to be a quadratic function of $v_{i t-1}$.

\section{B.5 The Danish Tax System}

Table D.20 reports all types of income relevant to the Danish tax system. ${ }^{13}$ The taxable income (TI) is defined as the sum of personal income (PI) and capital income (CI) minus deductions (D). Personal income is given by the sum of labor income (LI) and other sources of income, such as transfers or grants. Table D.21 shows tax rates and tax bases in the years 2008-2011. The tax system consists of a flat regional tax ${ }^{14}$, progressive national taxes, labor market and EITC contributions. Income deriving from stocks (SI) is taxed following a separate progressive schedule. The tax rates shown in the table are cumulative. This means, for instance, that the tax rate for a taxpayer in the top tax bracket is the sum of the tax rates in the bottom, middle and top tax brackets, along with the regional tax rate, the labor market contribution and the EITC contribution rates. The sum of the tax rates, however, cannot exceed a marginal tax rate ceiling. If it does, then the ceiling is binding.

As shown in Table D.21, several changes to the tax system occurred over the years consid-

\footnotetext{
${ }^{13}$ We base Table D.20 on Table 1 in Kleven and Schultz (2014). We update the table to reflect the tax code relevant in the period that we analyze.

${ }^{14}$ The regional tax consists of a church, a municipality and a county tax. In the exposition that follows, we show regional tax rates in the average municipality.
} 
ered. In 2009, the income cutoff of the middle and top tax brackets were equalized, while the bottom tax rate slightly decreased. The changes were particularly beneficial to taxpayers in the middle bracket, for whom the marginal tax rate ceiling was not binding and who had a tax base wide enough to fully exploit the change in bottom tax rates. In the following year, the 2010 Tax Reform abolished the middle tax bracket and lowered the bottom tax rate from 5.04\% to $3.67 \%$. As an effect of those changes, the marginal tax rate ceiling was also lowered from $59 \%$ to 51.5\%. As a result, between 2008 and 2011, the marginal tax rate on labor income in the top tax bracket decreased from $62.28 \%$ to $55.83 \%$, while in the middle tax bracket, it decreased from $45.06 \%$ to $37.78 \%$ (Figure 6 ). Finally, in the bottom tax bracket, the marginal tax rate on labor income decreased from $39.54 \%$ to $37.78 \%$. The same reform also introduced a 40,000 DKK deduction on capital income in the top bracket while increasing the income cutoff of the top tax bracket. In fact, the lowest income amount to be considered in the top tax bracket increased in nominal terms from 335,800 DKK to 389,900 DKK. This shift corresponds to an increase of $9 \%$ in real terms, which further reduced the actual marginal tax rate faced by high incomes.

\section{Appendix: additional results}

\section{C.1 AKM estimation: exogenous mobility and separability}

We estimate equation (8) in the main paper using the methodology developed by Abowd et al. (2002) to identify sets of connected firms. These sets consist of firms that have movers in common. In the analysis that follows, we focus on the largest set of connected firms. Due to the high mobility that characterizes the Danish labor market, the largest connected set contains more than $99 \%$ of the workers and firms in the sample (Table D.11). The simultaneous identification of the firm and the individual wage component requires setting to zero either one firm fixed effect or one individual fixed effect. Thus, the firm effect $\psi_{j(i, t)}$ has to be interpreted as the proportional wage premium or discount paid by firm $j$ to all employees.

The estimation of unbiased coefficients from equation (8) requires that the unobserved component of the hourly wage rate $r_{i j t}$ is mean independent of individual and firm fixed effects 
and time-varying characteristics:

$$
\mathbb{E}\left(r_{i j t} \mid X_{i j t}, \alpha_{i}, \psi_{j(i, t)}\right)=0
$$

To gain a better understanding of condition (35), following Card et al. (2013) (henceforth CHK), we assume that the error component $r_{i j t}$ consists of 3 parts:

$$
r_{i j t}=\eta_{i j(i, t)}+\zeta_{i t}+\varepsilon_{i t}
$$

$\eta_{i j(i, t)}$ is a match-specific component that captures an idiosyncratic wage premium (or discount) earned by individual $\mathrm{i}$ at firm $\mathrm{j}$. This component is assumed to have a mean zero for all $i$ and j. $\zeta_{i t}$ is a unit root component meant to capture drifts in the portable component of the individual's earning power (e.g., health shocks, unobserved human capital accumulation, etc.). This component is also assumed to have a zero mean. Finally, $\varepsilon_{i t}$ is a residual mean-reverting component.

Under these assumptions, $\mathbb{E}\left(r_{i j t} \alpha_{i}\right)=0$ for all $i$ and $t$. Furthermore, assuming that the components of $X_{i j t}$ are exogenous (i.e., $\left.\mathbb{E}\left(r_{i j t} X_{i j t}\right)=0 \forall i, t\right)$, then condition (35) holds if the vector of firm fixed effects is exogenous to the error component (i.e., $\left.\mathbb{E}\left(r_{i j t} \psi_{j(i, t)}\right)=0 \forall i, t\right)$. As shown in CHK, for this condition to hold, the assignment of workers to firms must obey a strict exogeneity condition (i.e., the "conditional exogenous mobility").

Following CHK, we investigate the plausibility of the "conditional exogenous mobility" assumption by considering 3 cases in which the assumption is violated. First, we consider the case of sorting based on the idiosyncratic employer-employee match component of wages $\eta_{i j(i, t)}$. This type of sorting is problematic because workers are paid differently in each firm, depending on the match component. Absent any match effect, the average wage gains and losses from moving from high- to low-wage firms are expected to be symmetric. This is the case for both males and females. The existence of match effects, however, will tend to offset the losses associated with moving to a low-wage firm. In the extreme case, in which all transitions were voluntary and selection was based only on the match component, movers will experience no wage losses.

To check this possibility, we follow CHK and construct the mean of log coworkers' wages for each person in each year to obtain a distribution of coworkers' wages in each year. Thus, 
we assign each worker to a quartile of the coworkers' wages distribution in a year based on the average log wage of his/her coworkers in that year. We then identify movers as workers who move from one firm to another and who can be observed for two consecutive years in both the sending firm and the receiving firm. Thus, we derive average wage rates of movers in the two years before and after the move in each quartile of the coworkers' wages distribution. ${ }^{15}$ Figure D.3 shows the wage trends of movers from the 1st (i.e., low paying) or 4th (i.e., high paying) quartile of the coworkers' wage distribution. Similar to other studies, we find rather symmetric wage losses and wage gains for workers moving from high- to low-paying firms, and vice versa. This evidence is confirmed in Tables D.12 and D.13, which show the average log wage changes associated with transitions from and to each quartile of the coworker wage distribution. We also fail to find large changes in the wages of workers moving across firms in the same quartile of the coworkers' wage distribution. Overall, this evidence suggests that the sorting based on a match component is likely to play a minor role in our setting.

A second case in which the exogenous conditional mobility is violated is when mobility is related to the drifts in the expected wage a person can earn at all jobs (i.e., the shocks at the unit root component of $\left.\zeta_{i t}\right)$. For instance, if a worker's ability is revealed slowly over time and if it is valued differently at different firms, workers who are more productive than expected will experience rising wages at their initial employer and may be more likely to move to higherpaying firms. The absence of any systematic trend in wages prior to a move for workers who move to high- versus low-paying firms (Figure D.3) suggests that this type of mobility likely plays a minor role in our setting.

Finally, a third problematic case might arise if mobility is related to the transitory fluctuations in the unobserved component $\varepsilon_{i t}$ of wages. This is the case, for example, if workers leave firms that experience negative shocks and join firms that experience positive shocks. This type of correlation would imply systematic dips in the wage of leavers and unusual growth in the wage of joiners, which we fail to find in our data (Figure D.3).

Related to the particular framework discussed in this paper, mobility might be attributable to unobserved shocks to preferences over hours worked. An unexpected disease, for instance,

\footnotetext{
${ }^{15}$ Since our sample period ranges from 2003 to 2011, we focus on movers who moved in the years 2005-2009.
} 
might induce a worker to move to a lower-paying firm in exchange for a working schedule that better fits the new desired hours. If this is the case, however, we would observe substantial changes in hours worked by movers, particularly for workers moving from top- to bottom-paying firms, and vice versa. Table D.14 shows the average percentage change in annual hours worked by movers in the two years prior versus the two years after the job change. Hours worked by movers are relatively stable across employers paying different wages. This is the case for males and females, independent of whether they move between the top- and bottom-paying firms or not. ${ }^{16}$ This finding suggests that unobserved shocks to preferences over hours play a minor role in determining mobility in our sample. The sample that we consider, however, is composed of full-time workers who move between firms in the private sector only. Therefore, we do not consider movers from full-time to part-time work and from the private sector to the public sector, for whom we might expect greater variation in hours (Arizo et al., 2016).

Overall, the evidence from this paragraph suggests that the matching between firms and workers in our sample is based predominately on a combination of permanent firm and individual characteristics. Other recent studies reach similar conclusions (e.g., Card et al., 2013; Card et al., 2016; Song et al., 2016).

Equation (8) assumes additive separable firm and individual fixed effects. Systematic departures from this assumption would imply great residuals from (8). Following CHK, Figure D.4 plots mean residuals within cells defined by deciles of the estimated worker and firm effects. Reassuringly, the mean residuals are uniformly low and never exceed 3.7\%, with the largest deviations appearing among the lowest deciles of the individual and firm effects. Therefore, while for some workers and firms, we observe small deviations from the additivity assumption, these appear unlikely to play a major role.

\footnotetext{
${ }^{16}$ The average wage changes by quartiles of the coworkers' wage distribution in the sending firm never exceed $0.5 \%$, which is equivalent to approximately 9 hours on a yearly basis.
} 


\section{C.2 Validation of coordination measures using survey data}

\section{C.2.1 Survey of Adult Skills (PIAAC)}

The Survey of Adult Skills (PIAAC) collects, among other variables, information on a range of generic skills required of individuals in their work. The survey covers approximately 166,000 adults aged 16-65 who were surveyed in the following countries: Australia, Austria, Belgium (Flanders), Canada, the Czech Republic, Denmark, Estonia, Finland, France, Germany, Ireland, Italy, Japan, Korea, the Netherlands, Norway, Poland, the Slovak Republic, Spain, Sweden, the United Kingdom (England and Northern Ireland), the United States, Cyprus and the Russian Federation. The data collection took place from August 1, 2011, to March 31, 2012, in most participating countries.

In the analysis that follows, we exclude from PIAAC workers in the public sector, selfemployed workers and students. We focus on the following two characteristics of a job: Sharing work-related information and Time cooperating with coworkers, both of which imply the coordination of hours. These characteristics are measured on a discrete scale ranging from 1 to 5 , where 1 means that the characteristic is not important and 5 means that it is extremely important. In order to merge this information with the Danish Registers, we first take the modal value of each characteristic within each 4-digit (ISCO-08) occupation and then merge them to the registers using the same occupation code. We finally take the average value of each characteristic within a firm as a measure of the importance of each characteristic. Figure D.5 plots the standard deviation of hours across skill groups against the importance of these characteristics in each firm-year of our sample. We find a strong and negative correlation of the standard deviation with both job characteristics that is consistent with the evidence presented in section 4.3.1. That is, in firms in which these characteristics are more important, hours coordination is also high.

\section{C.2.2 Measures of coordination in time use survey data}

The time use survey was conducted in 2001 and 2008 by the Danish National Institute of Social Research. Industry information, however, is available only in the 2001 survey, and for this 
reason, in the following analysis, we use only 2001 data. The data collection consists of a questionnaire interview that collects information on demographic and labor market characteristics and two diaries; one diary is for a weekday, while the other is for a weekend day. Each diary is divided into 10-minute intervals and stretches from $4 \mathrm{am}$ to $4 \mathrm{am}$ the following day. In each interval, the respondent must note i) what he/she did (the primary activity) and ii) where he/she was. The survey includes a representative sample of approximately 3,000 individuals. We restrict our analysis to full-time employees (>26 weekly hours) in the private sector or approximately 750 observations. ${ }^{17}$

Based on this specification, we construct a coordination index as follows: we group workers into two educational groups, the tertiary educated and all others. For each educational group and in each sector and hour of the day, we compute the share of workers who are at work relative to the total number of workers in that educational group:

$$
\text { Share }_{\text {ehs }}=\frac{N_{\text {ehs }}}{N_{e s}}
$$

where $e$ indicates either tertiary educated $(t)$ or other workers $(o) ; h$ is hour of the day, which ranges from $4 \mathrm{am}$ to $4 \mathrm{am}$ the following day; while $s$ indicates sector. Due to the limited number of observations in the survey, we use a 1-digit sector classification analogous to the one used in Table D.4. The coordination index in a sector is defined as the correlation between the share of tertiary educated and other workers across the 24 hours of the day:

$$
\text { Coordination inde } x_{s}=\text { correlation }\left(\text { Share }_{t h s}, \text { Share }_{\text {ohs }}\right)
$$

High correlation between the share of differently educated workers throughout the day can be interpreted as signaling high coordination.

Table D.15 shows the coordination index in each sector. In line with Table D.4, the index is extremely high in some of the service industries, such as utilities, trade and the financial sector, while it takes relatively low values in agriculture and construction. In line with Table D.15, the index is higher in manufacturing than in construction and agriculture but lower than in most of the service sectors. Differently from Table D.4, the residual sector (i.e., "Public

\footnotetext{
${ }^{17}$ The variable that identifies workers in the private sector is missing for 1,073 observations out of 3,000. We also exclude from the analysis self-employed workers, students and workers whose industry of employment is missing.
} 
administration, education, health and arts") shows a lower index relative to the other services. In our final sample, however, only 29 firms out of more than 8,000 are part of this sector.

\section{C.2.3 Coordination and regular work schedule}

Following the same procedure as in Section 4.3.1, we use O*NET to derive a measure of the importance of a regular work schedule at the firm level. In Figure D.6, we plot this measure against our measure of coordination. The figure shows that greater coordination is associated with a lower importance of having a regular work schedule, thus suggesting that our measure is not driven merely by the use of traditional work arrangements (i.e., 9am to 5pm jobs).

\section{C.3 Coordination and wage differentials: additional robustness checks}

Hours worked might be measured with errors, which might bias the estimated correlation between coordination and wage premiums. To obtain a sense of the size and the direction of this bias, in column 1 of Table D.16, we use the average importance of the Contact, Teamwork and Communication in a firm (see Section 4.3) as an instrument for the standard deviation of hours in equation (7). To the extent that the importance of these factors is correlated with the coordination of hours, this IV approach allows us to better separate the coordination component from the measurement error in $\sigma_{j}$. The coefficient from this specification is negative and greater in magnitude than that in the baseline model, which suggests that measurement errors generate attenuation bias and that the division bias (Borjas, 1980) is unlikely to play a major role in our setting. ${ }^{18}$

Column 2 of Table D.16 shows the results obtained while using the median absolute deviation from the median hours (MAD) as an alternative measure of coordination. This measure is less sensitive to outliers. The magnitude of the standardized coefficients in this specification increases, suggesting that, if anything, outliers might drive down the correlation between wages and coordination.

\footnotetext{
${ }^{18}$ If the first and second moments of the distributions of the errors and the actual hours are uncorrelated, then measurement error can be shown to generate downward-biased estimates.
} 
Van Reenen (1996) finds that innovation in a firm causes higher wages. While we cannot directly measure innovation, if we control for the stock of immaterial assets in a firm, we find that the coefficient on coordination is barely affected (column 3). Moreover, coordination may be expected to be more important among workers of the same plant. In fact, when we restrict the analysis to single-plant firms ( $80 \%$ of the sample), we find the coefficient to be greater in magnitude than in the baseline (column 4). In the last column (5) of Table D.16, we control for the number of skill groups in a firm as a way to remove any spurious correlation between high dispersion in hours and the skill diversity of the workforce in a firm. The results are robust to this control.

In the baseline specification, we focus only on the firms in which attrition in hours worked is low (i.e., less than $5 \%$ of the workforce in a year). Columns 1 and 2 in Table D.17 report the coefficients estimated when we consider all firms in the largest set of connected firms. The coefficient is negative and significant, and the coordination share within 3-digit industries (column 2) is similar to that estimated in the baseline model.

In the baseline version of equation (8) of the main paper, we control for firm time-varying characteristics to isolate the firm fixed effects from capturing temporary fluctuations in wages due to firm-specific shocks. ${ }^{19}$ As a robustness check in columns 3 and 4 of Table D.17, we show the results obtained from estimating equation (8) with a parsimonious specification in which we include only workers' time-varying controls. ${ }^{20}$ The coefficients of these regressions are still negative and significant, even if less precisely estimated possibly because the temporary variations in wages add some noise to the firm fixed effects in this specification.

Finally, in order to check whether the correlation we find is driven by other period-specific factors, we divide the overall sample period into 3 sub-periods (2003-2005, 2006-2018 and 20092011). Then, we estimate equation (8) separately for each of these shorter panels to obtain the firm component of the wages specific to a sub-period $\left(\psi_{j(i, t)}^{s}\right)$. In the second step, we then relate

\footnotetext{
${ }^{19}$ The time-varying characteristics that we use are value added, sales per employee, exporter status and the share of salaried workers

${ }^{20}$ These controls are a set of interactions between year dummies and educational attainments and interaction terms between quadratic and cubic terms in age and educational attainments.
} 
$\psi_{j(i, t)}^{s}$ to coordination in that sub-period $\sigma_{j}^{s}$, a set of controls and sub-period fixed effects $\gamma^{s}$.

$$
\widehat{\psi_{j(i, t)}^{s}}=\delta_{0}+\delta_{1} \sigma_{j}^{s}+\delta_{2} \bar{Z}_{j}^{s}+\gamma^{s}+v_{j}^{s}
$$

While the fixed effects allow us to control for factors specific to a sub-period, this panel regression is based on firm fixed effects $\left(\psi_{j(i, t)}^{s}\right)$ estimated for shorter panels and thus for a lower number of movers, which might be reflected in less accurate estimates. With these caveats in mind, column 5 in Table D.17 shows $\delta_{1}$ estimated from equation (39). The coefficient remains negative and significant but less precisely estimated, as expected..$^{21} 0$

\section{C.4 Additional robustness checks on the coordination of the labor supply and tax changes}

Table D.23 shows the labor supply elasticity of normal hours in the residual group, obtained through the same empirical model used for high-skilled workers (equation (10)). Independently of the specific controls for base-year income, the elasticity remains positive, close to zero and insignificant (columns 2 to 5). At the point estimate, however, the elasticity is twice as large among workers who are in the bottom half of the income distribution within the residual group. These workers are also more distant from the top tax bracket, which is suggestive of weaker responses among workers who are more likely to end up in the top bracket by increasing their hours.

In columns 1 and 2 of Table D.24, we examine the labor supply response of high-skilled women with children and of high-skilled workers in the top $10 \%$ of the income distribution in 2008. In line with other recent studies, we find stronger responses among women and top incomes. Differently from high-skilled males, women show a positive elasticity. The type of specification that we use assumes away bunching at the kink points. With significant bunching, however, bias may be created. Thus, in column 3, we exclude workers at the major kink points of the tax schedule. The estimated elasticity is extremely robust to this specification. Finally, in column 4, we estimate the effect of the reform on labor income rather than hours. In order to compare our results with those of other studies, we estimate this specification for

\footnotetext{
${ }^{21}$ The lower precision, however, is likely due to outliers because when we use the median absolute deviation of hours as a measure of coordination, the coefficient is much more precisely estimated (column 6)
} 
all wage earners. In line with Kleven and Schultz (2014), we estimate a positive and small (0.03) elasticity of labor income, which suggests that the negative elasticity of hours that we find might be linked to the specific sample for which data on hours are available.

For the reasons discussed in Section 5.5, the instrumental variables that we use depend on income at time $t$. This can be problematic due to mean reversion or to the existence of other trends that unevenly affect the labor supply of workers across the distribution of income at the same time as the tax reform. In columns 3 to 7 of Table 4, we control for pre-reform income using piece-wise splines of income at $t-1$ and the log change of income between time $t-1$ and $t$ (similar to Kopczuk, 2005). We select this specification based on the strength of the first stage. However, to check whether the baseline results are sensitive to controls of base-year income, in Table D.25, we estimate equation (10) in the main paper by controlling for pre-reform income in a number of flexible ways. In columns 1 and 2, we control for 5-piece splines of income at time $t$ (similar to Gruber and Saez, 2002), while in columns 3 and 4, we control for a 5th-order polynomial function of income at time $t$ and an indicator function for positive base-year income (as in Dahl and Lochner, 2012). Finally, in columns 5 and 6, we include 5-piece splines of income at $t-1$ and the change of income between $t-1$ and $t$ (similar to Kopczuk, 2005). ${ }^{22}$ The results from these alternative specifications are very much in line with the baseline ones. In particular, the labor supply in low-coordination firms is significantly more elastic than that in firms with a high degree of coordination in all the specifications. The magnitude of the elasticity in low-coordination firms is close to that estimated in the baseline regressions, and it ranges from -0.07 to -0.1 , depending on the specification.

In Table D.26, we perform a similar set of robustness checks on the spillover effects estimated through equation (11) of the main paper. In these specifications, we control for base-year income (column 1), 5-piece splines of income at $t$ (column 2), and a 5th-order polynomial function of income at time $t$ (column 3). The coefficient on $\Delta \log \overline{h^{H}}$ remains significant, positive and of comparable magnitude to the baseline results.

The significance and magnitude of the spillovers that we find is robust to the inclusion of

\footnotetext{
${ }^{22}$ Gruber and Saez (2002) use 10-piece splines, while we use 5-piece splines of the base year income. Since we focus on a limited sample of the Danish population and since we exploit only one tax reform, we do not have enough power to estimate more than 5 -piece splines of income.
} 
firm and base-year fixed effects that capture the unobserved characteristics of a firm or of the time period over which the reform occurred (columns 1 and 2 in Table D.27). The coefficient capturing the spillovers is of greater magnitude, but less precisely estimated, when we condition it on the effects of being in a firm with a share of unionized workers above the median (column 3 in Table D.27). This result suggests that spillovers are not driven by differences in unionization. The spillovers remain of similar magnitude and significance when we control for the average change in hours among coworkers in the residual group. In addition, consistent with the fact that hours in the residual group are unaffected by the reform, we do not find significant spillovers from this group on low-skilled coworkers (column 4 of Table D.27).

In columns 1 to 4 in Table D.28, we present the results obtained from using the alternative measure of coordination described in Section 4.3, where skill groups are defined from the intersection of education (primary, secondary and tertiary) and occupation (blue collar, middle and top manager) groups. In columns 1 and 2, we estimate equation (10) from Section 5.3 on workers in high- and low-coordination firms. As in the baseline model, the labor supply in low-coordination firms remains significantly more elastic, and the magnitude of the coefficients is close to the baseline. Columns 3 and 4 show the results obtained from estimating equation (11) in Section 5.4 for workers in low-coordination firms. In column 3, we focus on normal hours of work, while in column 4, we consider total hours inclusive of overtime. The spillovers remain significant and of similar magnitude to those estimated in the baseline model.

In columns 5 and 6 in Table D.28, we estimate equation (10) of the main paper using data on hours worked from E-indkomst (called "BFL hours" in the tables). This database is an alternative source of administrative data on hours worked for the years 2008-2011 only (see Appendix B.2). We restrict the analysis to the workers included in the baseline specification, which can be matched to E-indkomst. As in the baseline regressions, we do not find significant effects on the elasticity of hours of high-skilled workers in high-coordination firms. The elasticity in low-coordination firms remains significant and of similar magnitude as in the baseline regressions. In column 7, we estimate the spillovers from equation (11) of the main paper using data on hours from E-indkomst. The spillovers remain significant and of a magnitude comparable with that of the baseline specification. However, these results must be interpreted with 
caution because some of the first-stage regressions lack power (i.e., F-stat lower than 2).

\section{C.5 Income and uncompensated elasticity to tax changes}

In the specifications that we discuss in the paper, the labor supply elasticity is inclusive of the income effect. In the robustness section, we also present separate estimates of the income effects for both high- and low-skilled workers. To estimate the income effects, we follow the standard model used in the taxable income literature, and we modify equation (10) and equation (11) of the main paper in the following way:

$$
\begin{gathered}
\log \left(\frac{h_{i j t+3}^{H}}{h_{i j t}^{H}}\right)=\theta_{0}+\theta_{1} \log \left(\frac{1-\tau_{i t+3}^{H}}{1-\tau_{i t}^{H}}\right)+\theta_{2} \log \left(\frac{v y_{i t+3}^{H}}{v y_{i t}^{H}}\right)+\theta_{3} X_{i j t}+v_{i j t} \\
\log \left(\frac{h_{i j t+3}^{L}}{h_{i j t}^{L}}\right)=\mu_{0}+\mu_{1} \log \left(\frac{\overline{h_{j t+3}^{H}}}{\overline{h_{j t}^{H}}}\right)+\mu_{2} \log \left(\frac{1-\tau_{i t+3}^{L}}{1-\tau_{i t}^{L}}\right)+\mu_{3} \log \left(\frac{v y_{i t+3}^{L}}{v y_{i t}^{L}}\right)+\mu_{4} X_{i j t}+\epsilon_{i j t}
\end{gathered}
$$

In these models, the terms $\log \left(v y_{i t+3}^{L} / v y_{i t}^{L}\right)$ and $\log \left(v y_{i t+3}^{H} / v y_{i t}^{H}\right)$ indicate the changes in virtual income of low- and high-skilled workers, respectively, between time $\mathrm{t}$ and $t+3$. Due to the same endogeneity problems that we discussed in Section 5.5, we estimate these specifications using mechanical changes of the virtual incomes and net-of-tax rates as instruments for the observed changes in these variables. Mechanical changes of the virtual income are obtained from simulating the post-reform virtual income while assuming that the real income remained constant between $t$ and $t+3$ as described (Section 5.5).

Following Kleven and Schultz (2014), we define virtual income as $\tau z_{L A B}+\sum_{n=1}^{N} t^{n} z_{n}-$ $T\left(z_{L A B}, z_{1}, . . z_{N}\right)$, where $\mathrm{T}()$ indicates total tax liabilities, $\tau$ is the marginal tax rate on labor income $\left(z_{L A B}\right)$, and $t^{n}$ is the marginal tax rate on the $n^{\text {th }}$ component of income $z_{n}$. This characterization is a generalization of the standard definition of virtual income to a situation with multiple income components. It differs from the definition used in some of the existing studies (e.g., Gruber and Saez, 2002) where virtual income is defined as after-tax income. Based on this, the coefficients $\theta_{1}$ and $\mu_{2}$ measure the uncompensated elasticity of hours worked to the marginal net-of-tax rates. $\theta_{2}$ and $\mu_{3}$ measure the elasticity of hours with respect to virtual 
income (see Section A.6). ${ }^{23}$

In columns 1 and 2 of Table D.29, we estimate equation (40) in high- and low-coordination firms, respectively. Unfortunately, due to the fact that our identifying variation is based on one tax reform only, we miss the power to estimate the income effect and the uncompensated elasticity separately. Even if they are imprecisely estimated, the point estimates show a substantial difference in both the income and the uncompensated elasticity between firms at high versus low degrees of coordination. In fact, in line with the baseline results, the uncompensated elasticity and the income effects are greater in magnitude in low-coordination firms. In the last column of Table D.26, we show the spillover effects obtained from estimating equation (41). In this specification, we use the mechanical change in the virtual income of low-skilled workers as an instrument for the observed change in virtual income. In the first-stage regressions, we also use the average virtual income of high-skilled coworkers as an additional instrument. Adding these additional controls does not have sizable effects on the estimated spillovers, which remain significant and of similar magnitude as in the baseline model.

\section{C.6 The effect of the 2010 tax reform on firm characteristics}

We investigate the effects of the tax reform on firm characteristics using the following regression model:

$$
\log \left(\frac{y_{j t+3}}{y_{j t}}\right)=\gamma_{0}+\gamma_{1} \log \left(\overline{\frac{1-\tau_{j t+3}^{H}}{\overline{1-\tau_{j t}^{H}}}}\right)+\gamma_{2} Z_{j t}+\varepsilon_{j t}
$$

We estimate this model considering 4 different $y$ variables: firm size, the share of high-skilled workers, the share of low-skilled workers in a firm and the amount of physical capital. The regressor of interest in this model is

$$
\log \left(\overline{\frac{1-\tau_{j t+3}^{H}}{\overline{1-\tau_{j t+3}^{H}}}}\right)=\log \left[\frac{H_{j t+3}^{-1} \sum_{i \in H_{j t+3}}\left(1-\tau_{i j t+3}\right)}{H_{j t}^{-1} \sum_{i \in H_{j t}}\left(1-\tau_{i j t+3}\right)}\right]
$$

\footnotetext{
${ }^{23}$ Other studies in this literature use the after-tax income rather than virtual income in estimating similar types of regressions (e.g., Gruber and Saez, 2002). In these studies, the analogue of $\theta_{1}$ or $\mu_{2}$ in our specification measure the compensated elasticity of hours. In our specification, $\theta_{1}$ and $\mu_{2}$ can be combined to $\theta_{2}$ and $\mu_{3}$, respectively, using the Slutsky equation to obtain the compensated elasticity (Section A.6).
} 
This equation measures the log change of the average net-of-tax-rate on labor income faced by high-skilled workers in a firm. We see this as a proxy of the intensity of the effect of the tax reform on firm $j$. For reasons similar to those discussed in Section 5.5, we use the mechanical change $\log \left(\overline{1-\tau_{M j t+3}^{H}}\right)-\log \left(\overline{1-\tau_{j t}^{H}}\right)$ defined in equation (13) as an instrument for the actual change defined in equation (43). $Z_{j t}$ is a vector of firm characteristics measured in the base year.

Table D.30 shows the results from this model. The coefficient of interest in these specifications is the one attached to the variable $\Delta \log \left(\overline{1-\tau^{H}}\right)$ that corresponds to $\gamma_{1}$ in equation $(42)$. Each column of the table reports the effects on a different outcome variable $y$. In column 1 , the outcome variable is the log change in firm size, in columns 2 and 3, we analyze the effects on the log change of the share of high-skilled workers and the share of low-skilled workers in a firm, respectively. Finally, in column 4, we look at the effects on the amount of physical capital in a firm. The coefficient $\gamma_{1}$ estimated in all these specifications remains small and insignificant, consistent with the fact that firms did not change their production technologies as an effect of the reform. 


\section{Appendix: Additional Tables and Figures}

\section{D.1 Additional graphs and tables}

Figure D.1: Variance of vacation hours: between and within firm component

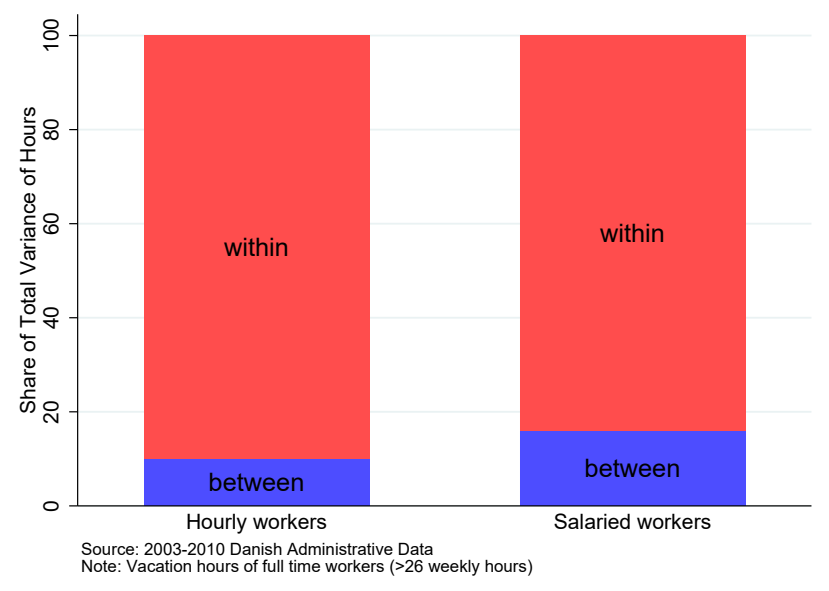

Notes: The figure shows the decomposition of the variance in vacation hours in between and within firm components (footnote 5 ) in the main paper. We consider total vacation hours of full-time workers ( $>26$ weekly hours). The first bar refers to vacation hours of hourly workers, the second one to salaried workers. Data on hours of vacation are available between 2003 and 2010.

Figure D.2: The Danish tax schedule

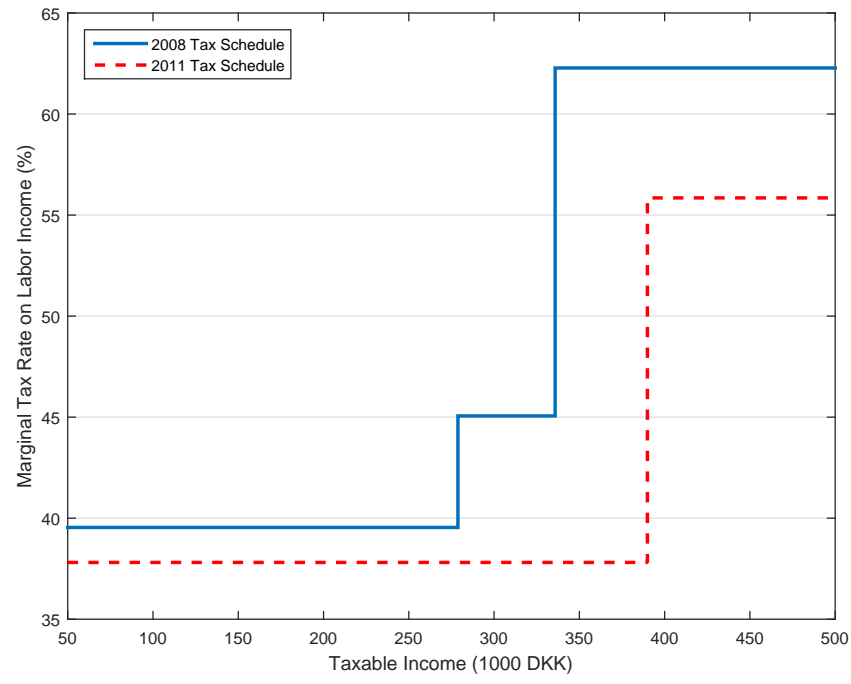

Notes: The figure plots the marginal tax rate on labor income over taxable income in 1000 DKK (5 DKK $\simeq 1$ USD). Taxable income is in nominal terms. The solid line plots the tax schedule prior to the tax reform (2008). The dashed line plots the tax schedule after the tax reform (2011). The figure is based on Table D.21. Marginal tax rates on labor income in the bottom and middle brackets are obtained as follows: Statutory Marginal Tax rate* (1 - Labor Market contribution) + Labor Market contribution - EITC; in the top bracket, they are obtained as Marginal Tax Ceiling*(1 - Labor Market contribution) + Labor Market contribution. 
Figure D.3: Wage dynamics of movers

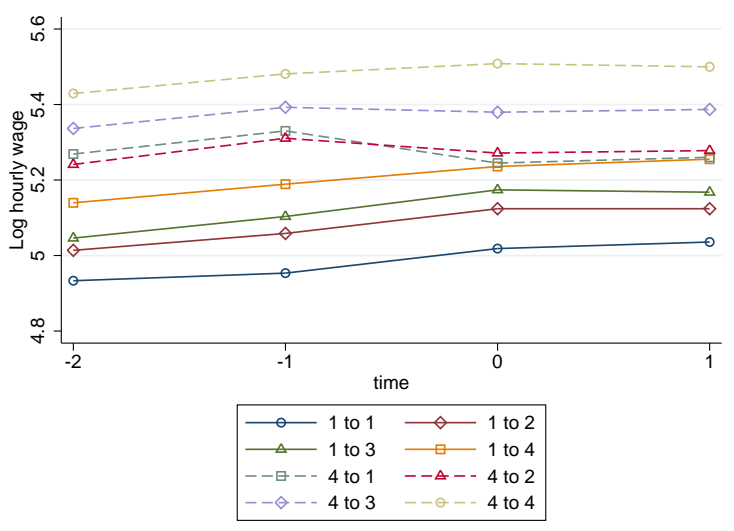

(a) Females

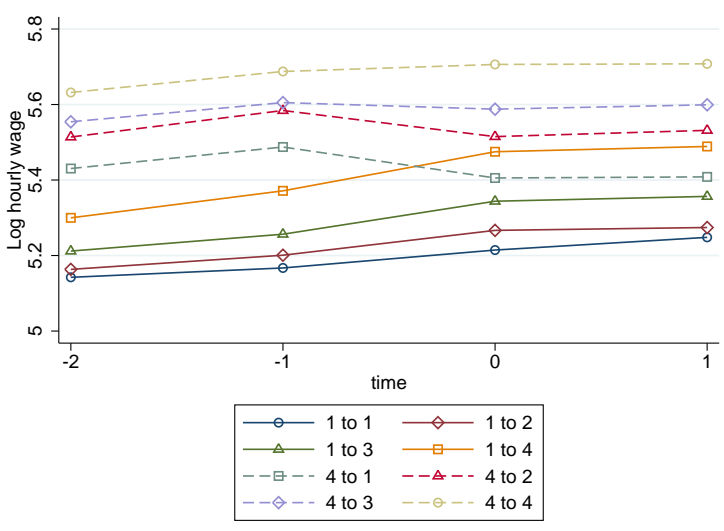

(b) Males

Figure D.4: Mean residuals by person-establishment deciles

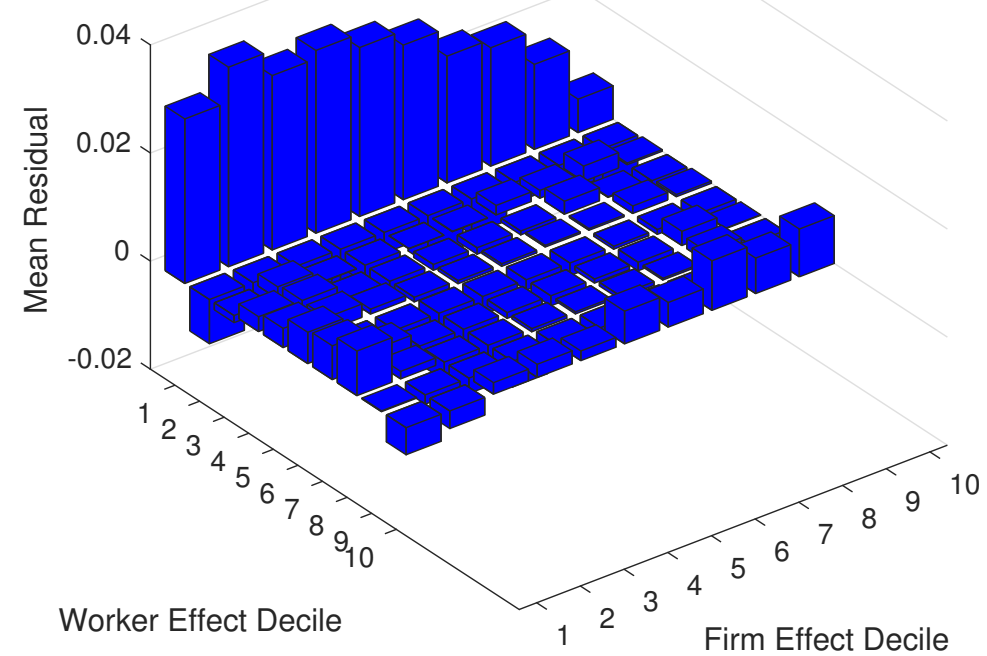

Notes: The figure shows the mean residuals from estimated AKM with cells defined by decile of estimated firm effect, interacted with decile of the estimated person effect. 
Figure D.5: PIAAC validation exercise coordination
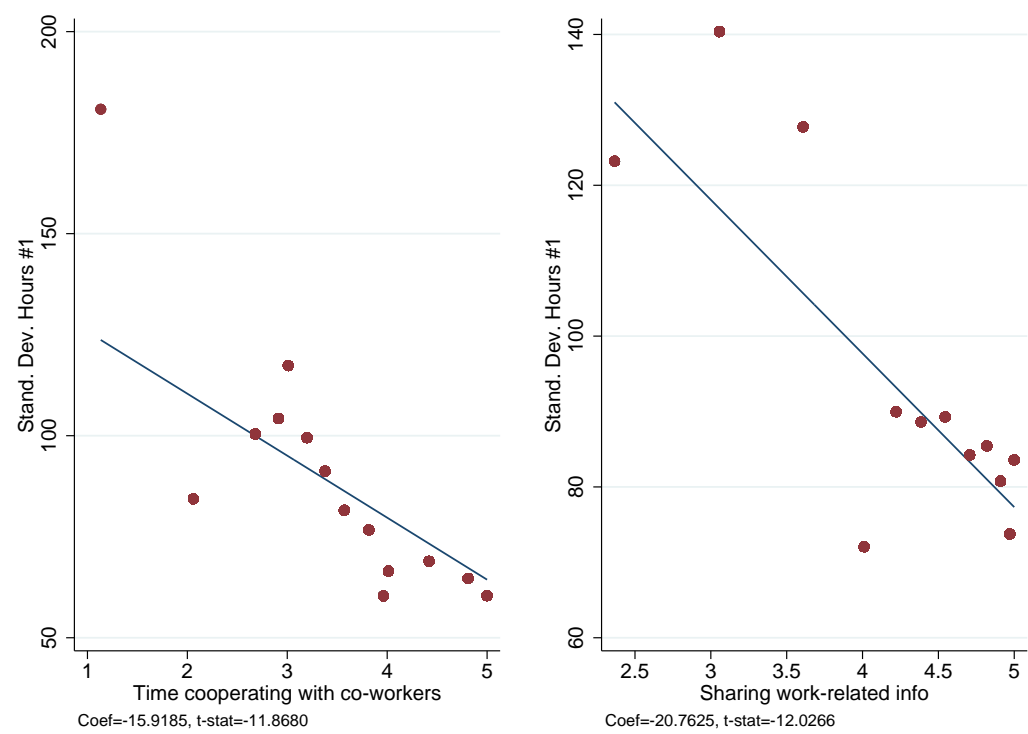

Note: Classification of the variable "sharing work related information": 1-Never, 2-Less than once a month, 3-Less than once a week but at least once a month, 4-At least once a week but not every day, 5-Every day. Classification of the variable "time cooperating with coworkers": 1-None of the time,

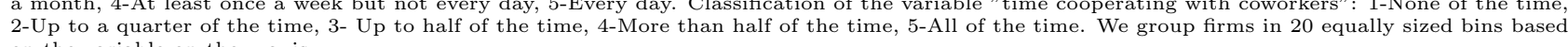

Figure D.6: Coordination and regular work schedule job from O*NET

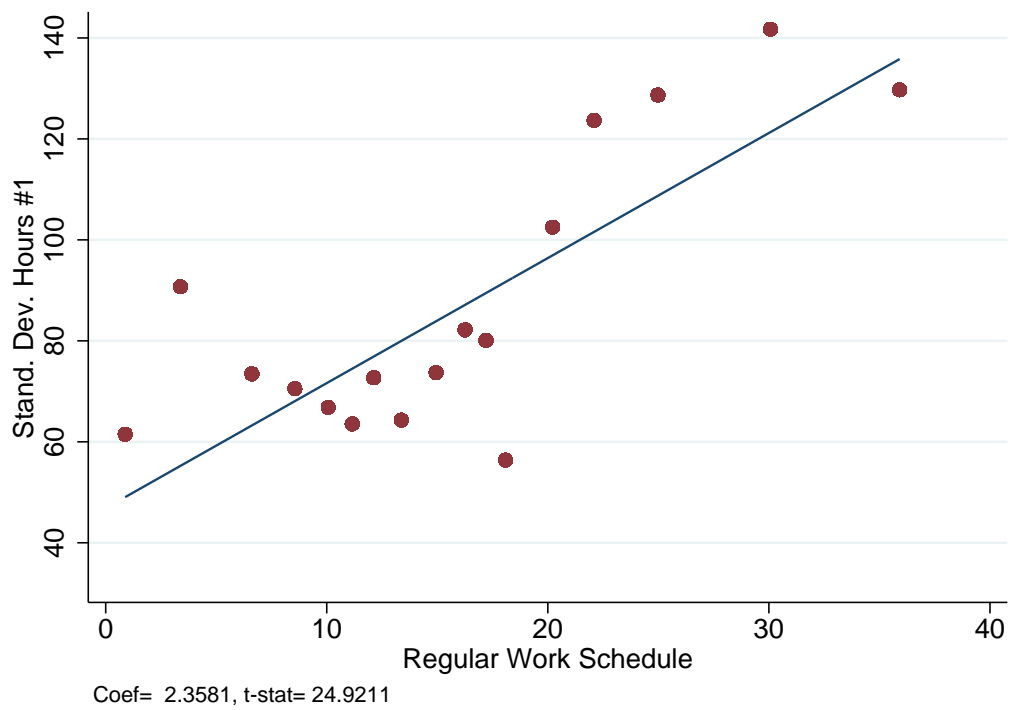

Notes: The figure shows the standard deviation of hours across skill groups within firms on the y-axis (Section 4.3 of the main paper) and the importance of a regular work schedule in that firm, based on $\mathrm{O}^{*} \mathrm{Net}$, on the x-axis. This variable measures the importance of a regular work schedule on a scale that ranges between 0 and 100 for each SOC occupation. We map the SOC classification in O*Net with the ISCO-88 classification of the Danish registers ranges between 0 and 100 for each SOC occupation. We map the SOC classification in O*Net with the ISCO- 88 classification of the Danish registers
using the crosswalk provided by the National Crosswalk Center. For each firm, we then compute the median importance of a regular work schedule among workers. We break ties in median scores using the average. In the graph, firms are grouped into 20 bins, which each one containing the same number of firms. We plot mean values within each bin. At the bottom of each graph, we show the coefficient and the associated t-stat from a regression of the $y$ variable in the graph on the $x$ variable. 
Table D.1: ATP contributions and hours worked (2008-2015)

\begin{tabular}{|c|c|c|c|}
\hline & Contributions paid by workers (in DKK) & Contributions paid by employers (in DKK) & Total contributions \\
\hline $\begin{array}{l}\text { Montly paid workers } \\
\text { (Working hours per month) } \\
\text { At least } 117 \\
\text { Between } 78 \text { and less than } 117 \\
\text { Between } 39 \text { and less than } 78 \\
\text { Less than } 39\end{array}$ & $\begin{array}{c}\text { Monthly Contribution } \\
90 \\
60 \\
30 \\
0\end{array}$ & $\begin{array}{c}\text { Monthly Contribution } \\
180 \\
120 \\
60 \\
0\end{array}$ & $\begin{array}{c}\text { Monthly Contribution } \\
270 \\
180 \\
90 \\
0\end{array}$ \\
\hline $\begin{array}{l}\text { Forthrightly paid workers } \\
\text { (Working hours per fortnight) } \\
\text { At least } 54 \\
\text { Between } 36 \text { and less than } 54 \\
\text { Between } 18 \text { and less than } 36 \\
\text { Less than } 18\end{array}$ & $\begin{array}{l}\text { Forthrightly contributions } \\
\qquad \begin{array}{c}47.4 \\
31.6 \\
31.6 \\
0\end{array}\end{array}$ & $\begin{array}{l}\text { Forthrightly contributions } \\
\qquad \begin{array}{c}94.8 \\
63.2 \\
15.8 \\
0\end{array}\end{array}$ & $\begin{array}{c}\text { Forthrightly contributions } \\
142.2 \\
94.8 \\
47.4 \\
0\end{array}$ \\
\hline $\begin{array}{l}\text { Weekly paid workers } \\
\text { (Working hours per week) } \\
\text { At least } 27 \\
\text { Between } 18 \text { and less than } 27 \\
\text { Between } 9 \text { and less than } 18 \\
\text { Less than } 9\end{array}$ & $\begin{array}{c}\text { Weekly contributions } \\
23.7 \\
15.8 \\
7.9 \\
0\end{array}$ & $\begin{array}{c}\text { Weekly contributions } \\
47.4 \\
31.6 \\
15.8 \\
0\end{array}$ & $\begin{array}{c}\text { Weekly contributions } \\
71.1 \\
47.4 \\
23.7 \\
0\end{array}$ \\
\hline Casual workers & $\begin{array}{c}\text { Hourly contributions } \\
0.64\end{array}$ & $\begin{array}{c}\text { Hourly contributions } \\
1.28\end{array}$ & $\begin{array}{c}\text { Hourly contributions } \\
1.92\end{array}$ \\
\hline
\end{tabular}

Table D.2: Steps of the data preparation

\begin{tabular}{|c|c|c|c|c|c|c|}
\hline & Obs. & Workers & Firms & $\begin{array}{c}\text { Obs. } \\
\text { share tot. }\end{array}$ & $\begin{array}{l}\text { Workers } \\
\text { share tot. }\end{array}$ & $\begin{array}{c}\text { Firms } \\
\text { share tot. }\end{array}$ \\
\hline 1. Entire Population & $22,379,298$ & $3,518,236$ & 266,196 & 100 & 100 & 100 \\
\hline 2. Lønstatistikken sample & $12,130,358$ & $2,649,618$ & 39,778 & 54.20 & 75.31 & 14.94 \\
\hline 3. Firms administrative data sample & $5,211,149$ & $1,485,789$ & 29,957 & 23.29 & 42.23 & 11.25 \\
\hline 4. Keep firms with more than 2 workers & $5,209,536$ & $1,485,478$ & 29,576 & 23.28 & 42.22 & 11.11 \\
\hline 5. Keep full time workers only & $4,476,222$ & $1,207,580$ & 29,116 & 20.00 & 34.32 & 10.94 \\
\hline 6. Drop Outliers in hours and income & $4,466,676$ & $1,205,301$ & 29,111 & 19.96 & 34.26 & 10.94 \\
\hline 7. Keep firms with less than $5 \%$ of obs. missing & 787,683 & 400,653 & 8,293 & 3.52 & 11.39 & 3.12 \\
\hline
\end{tabular}


Table D.3: Desired hours by skill groups

\begin{tabular}{lcc}
\hline \multicolumn{1}{c}{ Skills Definion 1 } & Average desired weekly hours & Obs. \\
\hline & & \\
skill $\leq$ 10th percentile & 37.34 & 465 \\
10th percentile $<$ skill $<$ 20th percentile & 36.78 & 462 \\
20th percentile $<$ skill $<$ 30th percentile & 37.69 & 463 \\
30th percentile $<$ skill $\leq$ 40th percentile & 37.72 & 461 \\
40th percentile $<$ skill $\leq$ 50th percentile & 38.55 & 461 \\
50th percentile $<$ skill $\leq$ 60th percentile & 38.33 & 463 \\
60th percentile $<$ skill $\leq$ 70th percentile & 38.48 & 463 \\
70th percentile $<$ skill $\leq$ 80th percentile & 39.33 & 461 \\
80th percentile $<$ skill $\leq$ 90th percentile & 38.79 & 462 \\
skill $>$ 90th percentile & 40.42 & 461 \\
& & \\
\hline \multicolumn{1}{c}{ Skills Definition 2 } & & \\
\hline & Average desired weekly hours & \\
\hline & & 963 \\
Primary education, blue collar & 37.67 & 1,512 \\
Secondary education, blue collar & 37.73 & 106 \\
Tertiary education, blue collar & 38.31 & 245 \\
Primary education, middle manager & 38.39 & 852 \\
Secondary education, middle manager & 38.25 & 693 \\
Tertiary education, middle manager & 39.17 & 43 \\
Primary education, manager & 41.55 & 96 \\
Secondary education, manager & 41.72 & \\
Tertiary education, manager & 43.97 & \\
\hline
\end{tabular}

Notes: Information on desired hours is obtained from the 2008-2010 Danish labor force survey data. We focus on workers whose refskill groups defined as deciles of the distribution of $\hat{\alpha_{i}}+\hat{\beta} X_{i j t}$ from equation (8) (AKM regression). AKM regressions are estimated
A A on the years 2008-2010. Skills definition 2 refers to skill groups defined at the intersection of occupational and educational category. 


\section{Table D.4: Coordination by sector}

\begin{tabular}{lccc}
\hline & \multicolumn{2}{l}{ Stand. Dev. Of Total Hours } & $\begin{array}{c}\text { Unionization } \\
\text { rate }\end{array}$ \\
\hline Coordination by Industry (2003-2011) & Mean & Std. Dev. & \\
Agriculture, forestry and fishing, mining and quarrying & 118.69 & 90.47 & 0.71 \\
Manufacturing & 104.08 & 86.92 & 0.77 \\
Constructions & 140.70 & 104.12 & 0.72 \\
Utilities,Trade and Transport & & & 0.64 \\
Financial and insurance, Real estate, Other business services & 84.72 & 84.09 & 0.63 \\
Other services & 65.04 & 57.37 & 0.71 \\
Overall sectors & 95.59 & 94.00 & 0.68 \\
Observations & 8182 & & \\
\hline
\end{tabular}

Notes: The first 2 columns of the table show the mean and standard deviation of our measure of coordination (i.e., the standard deviation of hours across skill groups from Section 4.3) in each of the 6 major sectors of the Danish economy. The last column shows the average share of workers unionized in each sector. For each firm in the sample (8182 total) and in each year (2003-2011), we compute the share of workers unionized and the standard deviation of hours across skill groups within that firm-year. Then, we take the average (and standard deviations) within each sector.

Table D.5: Wage differentials from hours coordination: Lavetti and Schmutte (2016) approach

\begin{tabular}{lcc}
\hline \hline & $(1)$ & $(2)$ \\
& OME & TWFE \\
Dependent Variable & Log Wage $-\hat{\beta} X$ & Log Wage \\
\hline Stand. Dev. Def. 2 & $-0.052^{* * *}$ & $-0.050^{* * *}$ \\
& $(0.009)$ & $(0.010)$ \\
& & \\
\hline R-squared & 0.911 & 0.684 \\
Obs. & 664632 & 664632 \\
\hline \hline
\end{tabular}

Notes: Following Lavetti and Schmutte (2016), column 1 reports the effects from an orthogonal match effect model (OME) obtained from a two-step procedure. In the first step, we estimate the following regression: $\ln \mathrm{w}_{\mathrm{it}}=\beta_{1} X_{i t}+\beta_{2} \sigma_{j t}+\Phi_{i j(i, t)}+\epsilon_{i t}$, where $\sigma_{j t}$ (labeled as "Stand. Dev. Def. 2") is the measure of coordination described in Section 4.3, and skills are defined as the intersection of education and occupation groups (definition 2) so that they do not depend on the estimates from the AKM model. $\Phi_{i j(i, t)}$ is the match effect between individual $i$ and firm $j$, and $X_{i t}$ includes the following set of controls: year dummies interacted with education dummies, quadratic and cubic terms in age interacted with education dummies, VA per employee, capital per employee, sales per employee, exporter status, and the fraction of salaried workers. The second step consists of estimating the following regression: $P_{i t}=\alpha_{i}+\lambda_{t}+\gamma_{o m e} \sigma_{j t}+\psi_{j(i, t)}+r_{i t}$ where $P_{i t}=\ln \mathrm{w}_{\mathrm{ijt}}-\hat{\beta_{1}} X_{i t}, \alpha_{i}$ is an individual fixed effect, $\lambda_{t}$ is a year fixed effect, and $\Psi_{j(i, t)}$ is a firm fixed effect. Column 1 in the table reports the coefficient $\hat{\gamma}_{\text {ome }}$ estimated from the second step regression that captures the wage differentials from hours coordination. In column 2, we estimate a two-way fixed effects model (TWFE) of the following type: ln $\mathrm{w}_{\mathrm{it}}=\alpha_{i}+\gamma_{t w f e} \sigma_{j t}+\psi_{j(i, t)}+\beta_{1} X_{i t}+\xi_{i t}$ where the notation is the same as in the OME model above. Column 2 in the table reports $\hat{\gamma}_{t w f e}$. The table shows standardized coefficients that are therefore comparable to those of Table 2. Standard errors are clustered at the 2-digit industry level. 
Table D.6: Elasticity of high-skilled hours: salaried and hourly workers

\begin{tabular}{|c|c|c|c|c|c|c|}
\hline Dependent variable & $\begin{array}{c}(1) \\
\text { High Coord. } \\
\Delta \log h^{H}\end{array}$ & $\begin{array}{c}(2) \\
\text { Low Coord. } \\
\Delta \log h^{H}\end{array}$ & $\begin{array}{c}(3) \\
\text { High Coord. } \\
\Delta \log h^{H}\end{array}$ & $\begin{array}{c}(4) \\
\text { Low Coord. } \\
\Delta \log h^{H}\end{array}$ & $\begin{array}{c}(5) \\
\text { High Coord. } \\
\Delta \log h^{H}\end{array}$ & $\begin{array}{c}(6) \\
\text { Low Coord. } \\
\Delta \log h^{H}\end{array}$ \\
\hline$\Delta \log \left(1-\tau^{H}\right)$ & $\begin{array}{l}-0.012 \\
(0.017)\end{array}$ & $\begin{array}{l}-0.026 \\
(0.031)\end{array}$ & $\begin{array}{l}-0.004 \\
(0.013)\end{array}$ & $\begin{array}{c}0.002 \\
(0.032)\end{array}$ & $\begin{array}{l}-0.058 \\
(0.051)\end{array}$ & $\begin{array}{l}-0.045 \\
(0.051)\end{array}$ \\
\hline Log base-year income & $\begin{array}{l}-0.001 \\
(0.003)\end{array}$ & $\begin{array}{l}-0.010 \\
(0.007)\end{array}$ & $\begin{array}{l}-0.001 \\
(0.001)\end{array}$ & $\begin{array}{l}-0.007 \\
(0.007)\end{array}$ & $\begin{array}{l}-0.016 \\
(0.019)\end{array}$ & $\begin{array}{c}-0.116^{* * *} \\
(0.030)\end{array}$ \\
\hline Salaried work. only & YES & YES & YES & YES & $\mathrm{NO}$ & $\mathrm{NO}$ \\
\hline Hourly workers only & NO & $\mathrm{NO}$ & $\mathrm{NO}$ & $\mathrm{NO}$ & YES & YES \\
\hline IV & YES & YES & YES & YES & YES & YES \\
\hline Overtime Hours & YES & YES & $\mathrm{NO}$ & $\mathrm{NO}$ & YES & YES \\
\hline Mean Hours & 1937.70 & 1965.55 & 1913.64 & 1928.79 & 1833.02 & 1813.96 \\
\hline Pvalue $H i g h=$ Low & 0.69 & & 0.87 & & 0.87 & \\
\hline F-stat Excl. Inst. & 1132.07 & 98.27 & 1132.07 & 98.27 & 141.89 & 139.60 \\
\hline P-value Excl. Inst. & 0.00 & 0.00 & 0.00 & 0.00 & 0.00 & 0.00 \\
\hline N Firms & 576 & 522 & 576 & 522 & 93 & 349 \\
\hline $\mathrm{N}$ & 17183 & 5059 & 17183 & 5059 & 1685 & 2548 \\
\hline
\end{tabular}

Notes: Each regression contains the following controls measured in the base year: work experience, work experience squared, sex, age, number of children, marital status, education, local unemployment (municipality), region fixed effects, firm size, exporter status, share of high- and low-skilled workers in the firm (the residual group is omitted). Observations are weighted by labor income. The table report Angrist-Pischke F-stats and P-values relative to the variable $\Delta$ log $\left(1-\tau^{H}\right)$. First-stage regressions are available from the authors upon request. Standard errors in parentheses are clustered at the firm level. $* \quad p<0.10, * * \quad p<0.05, * * * \quad p<0.01$.

Table D.7: Elasticity of high-skilled hours: difference in difference

\begin{tabular}{lcc}
\hline \hline & $(1)$ & $(2)$ \\
& Log Hours & Log Hours \\
\hline High Sk. $\times$ Post & $-0.011^{* * *}$ & $-0.011^{* * *}$ \\
& $(0.003)$ & $(0.003)$ \\
& & \\
High Skilled & $0.052^{* * *}$ & $0.048^{* * *}$ \\
& $(0.003)$ & $(0.003)$ \\
& & \\
Post & $0.018^{* * *}$ & $0.018^{* * *}$ \\
& $(0.003)$ & $(0.003)$ \\
\hline Individual Controls & NO & YES \\
N Firms & 1518 & 1518 \\
N & 156591 & 156591 \\
\hline \hline
\end{tabular}

Notes: The regressions are based on data for the 2008-2011 period. The variable Post is a dummy that takes a value of 1 in the post taxreform years of 2010 and 2011. The treatment group consists of high-skilled workers, while the control group is composed of low-skilled workers, both of which are defined in section 5.1. The specification in column 2 includes the following controls averaged over the pre-reform year (20082009): work experience, work experience squared, age, and the number of children. Column 2 also includes as controls the modal value over the pre-tax reform period of the following dummy variables: gender; marital status; and primary, secondary and tertiary education. We consider total hours worked (regular and overtime). Standard errors in parentheses are clustered at the firm level. $* \quad p<0.10$, ** $p<0.05, * * * \quad p<0.01$. 
Table D.8: The spillover effects on low-skilled hours: salaried and hourly workers

\begin{tabular}{lcccc}
\hline \hline & $(1)$ & $\begin{array}{c}(2) \\
\text { Low Coord. }\end{array}$ & $(3)$ & $(4)$ \\
& \multicolumn{4}{c}{ Low Coord. } \\
& $\Delta \log h^{L}$ & $\Delta \log h^{L}$ & $\Delta \log h^{L}$ & $\Delta \log h^{L}$ \\
\hline & & & & \\
$\Delta \log \overline{h^{H}}$ & $0.779 *$ & 0.655 & 0.047 & -0.055 \\
& $(0.464)$ & $(0.568)$ & $(0.685)$ & $(0.584)$ \\
$\Delta \log \left(1-\tau^{L}\right)$ & -0.194 & -0.101 & $0.240 *$ & 0.150 \\
& $(0.172)$ & $(0.174)$ & $(0.134)$ & $(0.154)$ \\
& & & & \\
\hline Hourly workers only & YES & YES & NO & NO \\
Salaried work. only & NO & NO & YES & YES \\
IV & YES & YES & YES & YES \\
Overtime Hours & NO & NO & NO & NO \\
Mean Hours Low Sk. & 1700.72 & 1668.11 & 1889.59 & 1882.18 \\
Mean Hours High Sk. & 1840.16 & 1832.65 & 1899.04 & 1872.92 \\
N Firms & 380 & 315 & 826 & 355 \\
N & 4117 & 2684 & 5966 & 1410 \\
\hline \hline
\end{tabular}

Notes: This table reports the results from estimating equation (11) of the main paper separately for salaried and hourly workers. Each regression contains the following controls measured in the base year: work experience, work experience squared, sex, age, number of children, marital status, education, local unemployment (municipality), region fixed effects, firm size, exporter status, share of high- and low-skilled workers in the firm and 5 component splines of income at $t-1$ and income change between $t-1$ and $t$. Low-coordination firms (columns 2 and 4 ) are defined as being in the top half of the distribution of the standard deviation of hours across skill groups in 2008. First-stage results are available from the authors upon request. Observations are weighted by labor income. Standard errors in parentheses are clustered at the firm level. ${ }^{*} p<0.10$, $* * p<0.05, *^{* *} p<0.01$. 
Table D.9: Spillovers and peer effects

\begin{tabular}{|c|c|c|c|c|c|c|}
\hline & $\begin{array}{c}(1) \\
\text { Baseline } \\
\text { Specification }\end{array}$ & 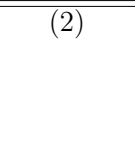 & $\begin{array}{c}(3) \\
5 \text { percent } \\
\text { most repetitive } \\
\text { occupations }\end{array}$ & $\begin{array}{c}(4) \\
\text { Remaining } \\
\text { Occupations }\end{array}$ & $\begin{array}{c}(5) \\
\text { Occupations } \\
\text { with low } \\
\text { learning content }\end{array}$ & $\begin{array}{c}(6) \\
\text { Remaining } \\
\text { Occupations }\end{array}$ \\
\hline Dependent Variable & $\Delta \log h^{L}$ & $\Delta \log h^{L}$ & $\Delta \log h^{L}$ & $\Delta \log h^{L}$ & $\Delta \log h^{L}$ & $\Delta \log h^{L}$ \\
\hline$\Delta \log \overline{h^{H}}$ & $\begin{array}{c}0.878^{* * *} \\
(0.301)\end{array}$ & & $\begin{array}{c}-0.697 \\
(3.897)\end{array}$ & $\begin{array}{c}0.867^{* * *} \\
(0.299)\end{array}$ & $\begin{array}{c}0.362 \\
(0.987)\end{array}$ & $\begin{array}{c}0.866^{* * *} \\
(0.302)\end{array}$ \\
\hline$\Delta \log {\overline{h^{H}}}_{\text {same occupation }}$ & & $\begin{array}{c}0.384 \\
(0.664)\end{array}$ & & & & \\
\hline$\Delta \log {\overline{h^{H}}}_{\text {different occupation }}$ & & $\begin{array}{c}0.874 \\
(1.416)\end{array}$ & & & & \\
\hline IV & YES & YES & YES & YES & YES & YES \\
\hline $\begin{array}{l}\text { Splines of } \log t-1 \text { Inc. } \\
\text { and } \Delta \log \text { inc. } t-1-t\end{array}$ & YES & YES & YES & YES & YES & YES \\
\hline Overtime Hours & NO & $\mathrm{NO}$ & $\mathrm{NO}$ & NO & NO & $\mathrm{NO}$ \\
\hline F-stat Excl. Inst. & & $2.40,1.77$ & 0.28 & 14.91 & 2.67 & 14.13 \\
\hline P-value Excl. Inst. & & $0.12,0.18$ & 0.6 & 0.00 & 0.11 & 0.00 \\
\hline Mean Hours Low Sk. & 1812.51 & 1807.17 & 1758.18 & 1814.89 & 1855.84 & 1811.87 \\
\hline Mean Hours High Sk. & 1875.00 & 1869.94 & 1841.98 & 1876.44 & 1877.18 & 1874.97 \\
\hline N Firms & 968 & 723 & 101 & 958 & 66 & 962 \\
\hline $\mathrm{N}$ & 10091 & 8001 & 422 & 9669 & 148 & 9943 \\
\hline
\end{tabular}

Notes: This table reports the results from estimating equation (11) in the main paper. It shows the elasticity of low-skilled hours to the average hours worked by high-skilled coworkers. The specification in column 2 separates between the elasticity to the average hours worked by high-skilled coworkers in the same 3 digit occupation and the elasticity to the average hours worked by high-skilled coworkers in different occupations. In columns 3 and 4 . we estimate the elasticity separately for workers in the $5 \%$ most repetitive occupations and for workers in other occupations. In columns 5 and 6 , we estimate the elasticity separately cupations with low learning content can rate among high-skilled workers in a firm as an instrument for the average change in hours. We also control for changes in marginal net-of-tax rate of lowskilled workers $\Delta \log \left(1-\tau^{L}\right)$, and we use the mechanical change in the net-of-tax rate of low-skilled workers as an instrument for observed changes of $1-\tau^{L}$ (Section 5.5). First-stage results are available on request. Each regression contains the following controls measured in the base year (2008): work experience, work experience squared, sex, age, number of children, marital status, education, local unemployment (municipality), region fixed effects, firm size, exporter status, and the shares of high and low-skilled workers in the firm (the residual group is omitted). "Splines" refer to a flexible piecewise linear functional form with 5 conents. We consider only 
Table D.10: The spillover effects on the hourly wages of low-skilled workers

\begin{tabular}{|c|c|c|c|c|c|c|}
\hline & (1) & (2) & (3) & $\begin{array}{c}(4) \\
\text { Low Coord. }\end{array}$ & $(5)$ & $\begin{array}{c}(6) \\
\text { Low Coord }\end{array}$ \\
\hline & $\Delta \log w^{L}$ & $\Delta \log w^{L}$ & $\Delta \log w^{L}$ & $\Delta \log w^{L}$ & $\Delta \log w^{L}$ & $\Delta \log w^{L}$ \\
\hline$\Delta \log {\overline{h^{H}}}_{\text {normal }}$ & $\begin{array}{l}-0.248 \\
(0.217)\end{array}$ & $\begin{array}{l}-1.528 \\
(1.228)\end{array}$ & $\begin{array}{l}-1.019 \\
(1.125)\end{array}$ & $\begin{array}{l}-0.497 \\
(0.958)\end{array}$ & & \\
\hline$\Delta \log {\overline{h^{H}}}_{\text {total }}$ & & & & & $\begin{array}{c}-1.556 \\
(1.972)\end{array}$ & $\begin{array}{l}-0.557 \\
(1.086)\end{array}$ \\
\hline$\Delta \log \left(1-\tau^{L}\right)$ & $\begin{array}{c}-0.504^{* * *} \\
(0.060)\end{array}$ & $\begin{array}{c}1.322^{* * *} \\
(0.350)\end{array}$ & $\begin{array}{c}0.606 \\
(0.499)\end{array}$ & $\begin{array}{c}0.400 \\
(0.444)\end{array}$ & $\begin{array}{c}0.618 \\
(0.511)\end{array}$ & $\begin{array}{c}0.417 \\
(0.442)\end{array}$ \\
\hline IV & $\mathrm{NO}$ & YES & YES & YES & YES & YES \\
\hline Region F.E. & YES & YES & YES & YES & YES & YES \\
\hline $\begin{array}{l}\text { Splines of } \log t-1 \text { Inc. } \\
\text { and } \Delta \log \text { inc. } t-1-t\end{array}$ & $\mathrm{NO}$ & $\mathrm{NO}$ & YES & YES & YES & YES \\
\hline Overtime Hours & $\mathrm{NO}$ & $\mathrm{NO}$ & $\mathrm{NO}$ & $\mathrm{NO}$ & YES & YES \\
\hline F-stat Excl. Instr. & & $12.65,163.45$ & $14.94,77.89$ & $11.34,48.34$ & $3.97,77.72$ & $7.46,51.25$ \\
\hline P-value Excl. Instr. & & $0.00,0.00$ & $0.00,0.00$ & $0.00,0.00$ & $0.05,0.00$ & $0.01,0.00$ \\
\hline Mean Hours Low Sk. & 1812.88 & 1812.88 & 1812.88 & 1742.40 & 1831.72 & 1763.13 \\
\hline Mean Hours High Sk. & 1875.10 & 1875.10 & 1875.10 & 1846.59 & 1910.16 & 1882.25 \\
\hline N Firms & 967.00 & 967.00 & 967.00 & 484.00 & 967.00 & 484.00 \\
\hline $\mathrm{N}$ & 10043 & 10043 & 10043 & 4066 & 10043 & 4066 \\
\hline
\end{tabular}

Notes: This table reports the results of estimating a model equivalent to equation (11) and using changes in wages rather than changes in hours as the dependent variable. It shows the elasticity of low-skilled wages to the average hours worked by high-skilled coworkers. We consider both regular (normal) hours (columns 1 to 5 ) and total (regular and overtime) hours (columns 6 and 7 ) worked by high-skilled workers. Specifications in columns 2 to 7 use mechanical changes in the average net-of-tax rate among high-skilled workers in a firm as an instrument for the average change in hours and the mechanical change in the net-of-tax rate of low-skilled workers as an instrument for observed changes of 1- $\tau^{L}$ (Section 5.5). First-stage results are available from the authors on request. Low-coordination firms (columns 5 and 7) are defined as being in the top half of the distribution of the standard deviation of hours across skill groups in 2008. Each regression contains the following controls measured in the base year: work experience, work experience squared, sex, age, number of children, marital status, education, local unemployment (municipality), region fixed effects, firm size, exporter status, and the shares of high- and low-skilled workers in the firm (the residual group is omitted). "Splines" refer to a flexible piecewise linear functional form with 5 components. We consider only low-skilled workers who are at the same firm between 2008 and 2011 . We estimate this regression on changes between 2008 and 2011. Observations are weighted by labor income. Standard errors in parentheses are clustered at the firm level.* $p<0.10$, ** $p<0.05$, *** $p<0.01$. 
Table D.11: Summary statistics of the AKM regression

\begin{tabular}{lcc}
\hline & All Sample & $\begin{array}{c}\text { Largest group } \\
\text { of connected firms }\end{array}$ \\
\hline & & \\
Person and estabilishment parameters & & \\
Number of person effects & 1205295 & 1195884 \\
Number of firm effects & 26227 & 26121 \\
& & \\
Summary of parameters estimates & 0.962 & 0.960 \\
Std. dev. of person effects & 0.141 & 0.137 \\
Std. dev. of firm effects & 0.829 & 0.828 \\
Std. dev. Of Xb & 0.913 & \\
Adjusted R-squared & & \\
& 0.451 & 0.450 \\
Std. dev. of log wages & 4466655 & 4445484 \\
Number of person-year observations & & \\
\hline
\end{tabular}

Notes: Controls in first step (AKM) regressions: year dummies interacted with education dummies, quadratic and cubic terms in age interacted with education dummies, VA per employee, capital per employee, sales per employee, exporter status, and the fraction of salaried workers.

Table D.12: Mobility and wage changes: males

\begin{tabular}{lccccc}
\hline & & \multicolumn{2}{c}{ Log wages of movers (mean) } & \multicolumn{2}{c}{ Log wage change } \\
Origin to destination quartile & Number of moves & 2 years before & 2 years after & Raw & Adjusted \\
\hline 1 to 1 & 2895 & 5.14 & 5.25 & 0.11 & 0.00 \\
1 to 2 & 1515 & 5.16 & 5.28 & 0.12 & 0.03 \\
1 to 3 & 965 & 5.21 & 5.36 & 0.15 & 0.05 \\
1 to 4 & 500 & 5.29 & 5.48 & 0.19 & 0.09 \\
& & & & & \\
2 to 1 & 960 & 5.22 & 5.25 & 0.03 & -0.06 \\
2 to 2 & 2443 & 5.29 & 5.35 & 0.06 & -0.02 \\
2 to 3 & 1824 & 5.33 & 5.43 & 0.10 & 0.02 \\
2 to 4 & 925 & 5.39 & 5.51 & 0.13 & 0.04 \\
& & & & & \\
3 to 1 & 612 & 5.37 & 5.37 & 0.00 & -0.07 \\
3 to 2 & 2110 & 5.39 & 5.43 & 0.05 & -0.03 \\
3 to 3 & 6217 & 5.40 & 5.46 & 0.06 & 0.00 \\
3 to 4 & 2120 & 5.49 & 5.59 & 0.10 & 0.02 \\
4 to 1 & & & & & \\
4 to 2 & 304 & 5.43 & 5.41 & -0.02 & -0.10 \\
4 to 3 & 760 & 5.51 & 5.55 & 0.03 & -0.05 \\
4 to 4 & 2354 & 5.55 & 5.60 & 0.05 & -0.02 \\
\hline
\end{tabular}

Notes: Entries are observed mean log real hourly wages in the 2003-2011 period for job changers with at least 2 years of wages at the old job and the new job. Job refers to the firm of main occupation in the year. Origin/destination quartiles are based on mean wages of coworkers in the year before (origin) or year after (destination) a job move. Four-year wage changes in adjusted regressions include controls for age, age squared and cubed, education dummies, and quadratics of age fully interacted with education. 
Table D.13: Mobility and wage changes: females

\begin{tabular}{|c|c|c|c|c|c|}
\hline \multirow[b]{2}{*}{ Origin to destination quartile } & \multirow[b]{2}{*}{ Number of moves } & \multicolumn{2}{|c|}{ Log wages of movers (mean) } & \multicolumn{2}{|c|}{ Log wage change } \\
\hline & & 2 years before & 2 years after & Raw & Adjusted \\
\hline 1 to 1 & 2869 & 4.94 & 5.04 & 0.10 & 0.00 \\
\hline 1 to 2 & 759 & 5.01 & 5.12 & 0.11 & 0.02 \\
\hline 1 to 3 & 496 & 5.04 & 5.17 & 0.13 & 0.03 \\
\hline 1 to 4 & 240 & 5.12 & 5.24 & 0.12 & 0.03 \\
\hline 2 to 1 & 511 & 5.08 & 5.12 & 0.04 & -0.05 \\
\hline 2 to 2 & 1128 & 5.11 & 5.18 & 0.07 & -0.01 \\
\hline 2 to 3 & 869 & 5.13 & 5.23 & 0.10 & 0.01 \\
\hline 2 to 4 & 465 & 5.19 & 5.29 & 0.10 & 0.01 \\
\hline 3 to 1 & 324 & 5.15 & 5.17 & 0.03 & -0.06 \\
\hline 3 to 2 & 873 & 5.18 & 5.24 & 0.06 & -0.02 \\
\hline 3 to 3 & 2934 & 5.24 & 5.30 & 0.06 & 0.00 \\
\hline 3 to 4 & 1064 & 5.29 & 5.40 & 0.11 & 0.02 \\
\hline 4 to 1 & 195 & 5.27 & 5.27 & 0.00 & -0.08 \\
\hline 4 to 2 & 419 & 5.24 & 5.28 & 0.04 & -0.05 \\
\hline 4 to 3 & 1371 & 5.34 & 5.39 & 0.05 & -0.01 \\
\hline 4 to 4 & 3177 & 5.41 & 5.49 & 0.07 & -0.01 \\
\hline
\end{tabular}


Table D.14: Dynamics in the hours of movers

\begin{tabular}{ccccc}
\hline \multicolumn{2}{c}{$\begin{array}{c}\text { Average change in annual hours worked by movers (\%) } \\
\text { Breakdown by quartiles of the coworkers wage distribution }\end{array}$} \\
Type of origin firm & \multicolumn{3}{c}{$\begin{array}{c}\text { Males } \\
\text { Obs. }\end{array}$} & \multicolumn{2}{c}{$\begin{array}{c}\text { Females } \\
\text { Mean change (\%) }\end{array}$} & $\begin{array}{c}\text { Obs. } \\
\text { Meange (\%) }\end{array}$ \\
1st Quartile & 6709 & 0.05 & 4920 & -0.25 \\
2nd Quartile & 7182 & 0.01 & 3444 & -0.31 \\
3rd Quartile & 12924 & 0.27 & 5952 & 0.06 \\
4th Quartile & 11549 & 0.04 & 5913 & -0.39 \\
\hline
\end{tabular}

Mean change (\%) in annual hours worked by movers Detailed Breakdown for movers in the 1st and 4th quartile

\begin{tabular}{ccccc}
\hline Sending to Receiving firm & \multicolumn{2}{c}{$\begin{array}{c}\text { Males } \\
\text { Obs. }\end{array}$} & $\begin{array}{c}\text { Females } \\
\text { Mean change (\%) }\end{array}$ & Obs. \\
1st to 1st & 3284 & 0.02 & 3202 & 0.43 \\
1st to 2nd & 1775 & 0.04 & 853 & -1.06 \\
1st to 3rd & 1084 & 0.08 & 575 & -0.40 \\
1st to 4th & 566 & 0.24 & 290 & 0.04 \\
4th to 1st & 351 & 0.01 & 220 & -0.52 \\
4th to 2nd & 995 & 0.00 & 502 & -0.70 \\
4th to 3rd & 2709 & 0.23 & 1541 & 0.10 \\
4th to 4th & 7494 & 0.07 & 3650 & -0.45 \\
Mean Hours & & 1935 & & 1930 \\
\hline
\end{tabular}

Notes: Panel A in the table shows the average percentage change in hours worked by movers broken down the quartile of the coworkers wage distribution of the sending firm. In Panel b we then further break down the hours change within the 1 st and 4 th of the sending firm depending on the quartile of the coworkers wage distribution of the receiving firm. We do this in each interthe sending firm depending on the quartile of the coworkers wage distribution of the receiving firm. We
val 2003-2007, 2004-2008, 2005-2009, 2006-2010 and 2007-2011. In the table we show the average change across these periods. 
Table D.15: Coordination index by sector using TUS data

Coordination index

\begin{tabular}{lc}
\hline Agriculture, forestry and fishing, mining and quarrying & 0.833 \\
Manufacturing & 0.978 \\
Construction & 0.956 \\
Electricity, gas, steam and air conditioning supply, trade and transport & 0.982 \\
Financial and insurance, Real estate, Other business & 0.986 \\
Public administration, education, health, arts & 0.929 \\
\hline Observations & 748 \\
\hline
\end{tabular}


Table D.16: Coordination and wage differentials: measurement error and regular hours

\begin{tabular}{|c|c|c|c|c|c|}
\hline & $\begin{array}{c}(1) \\
\text { Firm f.e. }\end{array}$ & $\begin{array}{c}(2) \\
\text { Firm f.e. }\end{array}$ & $\begin{array}{c}(3) \\
\text { Firm f.e. }\end{array}$ & $\begin{array}{c}(4) \\
\text { Firm f.e. }\end{array}$ & $\begin{array}{c}(5) \\
\text { Firm f.e. }\end{array}$ \\
\hline Stand. Dev. Tot. Hours & $\begin{array}{c}-0.342^{* *} \\
(0.172)\end{array}$ & & $\begin{array}{c}-0.069^{* * *} \\
(0.018)\end{array}$ & $\begin{array}{c}-0.072^{* * *} \\
(0.018)\end{array}$ & $\begin{array}{c}-0.061^{* * *} \\
(0.017)\end{array}$ \\
\hline Median Abs. Dev. Tot. Hours & & $\begin{array}{c}-0.085^{* * *} \\
(0.015)\end{array}$ & & & \\
\hline Firm size & $\begin{array}{c}0.003 \\
(0.006)\end{array}$ & $\begin{array}{c}0.010 \\
(0.007)\end{array}$ & $\begin{array}{c}0.009 \\
(0.007)\end{array}$ & $\begin{array}{l}0.148^{*} \\
(0.075)\end{array}$ & $\begin{array}{c}0.004 \\
(0.004)\end{array}$ \\
\hline Exporter status & $\begin{array}{c}0.023 \\
(0.029)\end{array}$ & $\begin{array}{c}0.072^{* * *} \\
(0.018)\end{array}$ & $\begin{array}{c}0.065^{* * *} \\
(0.016)\end{array}$ & $\begin{array}{c}0.059^{* * *} \\
(0.019)\end{array}$ & $\begin{array}{c}0.051^{* * *} \\
(0.015)\end{array}$ \\
\hline Union. Rate & $\begin{array}{c}0.068 * * \\
(0.029)\end{array}$ & $\begin{array}{c}0.035 \\
(0.023)\end{array}$ & $\begin{array}{c}0.030 \\
(0.023)\end{array}$ & $\begin{array}{c}0.030 \\
(0.022)\end{array}$ & $\begin{array}{c}0.020 \\
(0.023)\end{array}$ \\
\hline Female Share & $\begin{array}{c}-0.113^{* * *} \\
(0.038)\end{array}$ & $\begin{array}{c}-0.108^{* *} \\
(0.042)\end{array}$ & $\begin{array}{c}-0.104^{* *} \\
(0.044)\end{array}$ & $\begin{array}{c}-0.087^{* *} \\
(0.040)\end{array}$ & $\begin{array}{c}-0.111^{* *} \\
(0.044)\end{array}$ \\
\hline Average Hours & $\begin{array}{c}0.024 \\
(0.043)\end{array}$ & $\begin{array}{l}-0.001 \\
(0.025)\end{array}$ & $\begin{array}{c}0.008 \\
(0.026)\end{array}$ & $\begin{array}{c}0.006 \\
(0.027)\end{array}$ & $\begin{array}{c}0.002 \\
(0.025)\end{array}$ \\
\hline $\log (\mathrm{Cap} / \mathrm{empl})$ & $\begin{array}{c}0.019 \\
(0.015)\end{array}$ & $\begin{array}{c}0.029 * * \\
(0.013)\end{array}$ & $\begin{array}{l}0.025^{*} \\
(0.013)\end{array}$ & $\begin{array}{c}0.038^{* * *} \\
(0.014)\end{array}$ & $\begin{array}{c}0.028 * * \\
(0.013)\end{array}$ \\
\hline Numb. of skill groups & & & & & $\begin{array}{c}0.072^{* * *} \\
(0.012)\end{array}$ \\
\hline (Intang. Assets)/empl & & & $\begin{array}{c}0.019 * * \\
(0.009)\end{array}$ & & \\
\hline O*NET IV & YES & NO & $\mathrm{NO}$ & $\mathrm{NO}$ & $\mathrm{NO}$ \\
\hline Multi-plant firms & YES & YES & YES & $\mathrm{NO}$ & YES \\
\hline Coordination Share & & 0.279 & 0.256 & 0.273 & 0.200 \\
\hline F-stat excl. instr. & 8.942 & & & & \\
\hline R-sq & 0.020 & 0.118 & 0.101 & 0.101 & 0.105 \\
\hline $\mathrm{N}$ & 6089 & 7374 & 7312 & 5695 & 7312 \\
\hline
\end{tabular}

Notes: The stand. dev. of total hours is the standard deviation of the average hours worked across skill groups within a firm. The median abs. dev. is the the median absolute deviation of median hours across each skill group within a firm. Skill groups are defined as deciles of the distribution of $\hat{\alpha_{i}}+\hat{\beta} X_{i j t}$ from the AKM model. O*NET IV refers to a vector composed of the average importance of the Contact, Teamwork and Communication in the firm (Section 4.3). All regressions show standardized coefficients. Exporter and industry dummies are based on the median Colue between 2003 and 2011 . indicates intangible assets per employee. All regression include a vector of controls for the share of workers in each skill group and for the average value of the individual fixed effects $\hat{\alpha}_{i}$ in each quartile of the distribution of $\hat{\alpha_{i}}$ within a firm. Coordination share is derived as the ratio of "Part. R-sq SD Hours" and "Part. R-sq $V A$ and Sales". Standard errors are clustered at the 2-digit industry level. *, ** and *** are 10, 5 and 1 percent significance levels, respectively. 
Table D.17: Wage differentials and coordination: additional robustness

\begin{tabular}{|c|c|c|c|c|c|c|}
\hline & $\begin{array}{c}(1) \\
\text { Firm f.e. }\end{array}$ & $\begin{array}{c}(2) \\
\text { Firm f.e. }\end{array}$ & $\begin{array}{c}(3) \\
\text { Firm f.e. }\end{array}$ & $\begin{array}{c}(4) \\
\text { Firm f.e. }\end{array}$ & $\begin{array}{c}(5) \\
\text { Firm f.e. }\end{array}$ & $\begin{array}{c}(6) \\
\text { Firm f.e. }\end{array}$ \\
\hline Stand. Dev. Def. 1 & $\begin{array}{c}-0.041^{* * *} \\
(0.011)\end{array}$ & $\begin{array}{c}-0.021^{* *} \\
(0.010)\end{array}$ & $\begin{array}{c}-0.051^{* * *} \\
(0.018)\end{array}$ & & $\begin{array}{c}-0.030^{*} \\
(0.016)\end{array}$ & \\
\hline Median Abs. Dev. Def. 1 & & & & $\begin{array}{c}-0.069^{* * *} \\
(0.016)\end{array}$ & & $\begin{array}{c}-0.034^{* * *} \\
(0.012)\end{array}$ \\
\hline Firm size & $\begin{array}{c}0.007^{* * *} \\
(0.002)\end{array}$ & $\begin{array}{c}0.011^{* * *} \\
(0.002)\end{array}$ & $\begin{array}{c}0.010 \\
(0.007)\end{array}$ & $\begin{array}{c}0.011 \\
(0.008)\end{array}$ & $\begin{array}{c}0.009 \\
(0.007)\end{array}$ & $\begin{array}{c}0.010 \\
(0.008)\end{array}$ \\
\hline Exporter status & $\begin{array}{c}0.048^{* * *} \\
(0.011)\end{array}$ & $\begin{array}{c}0.022^{* *} \\
(0.009)\end{array}$ & $\begin{array}{c}0.044^{* * *} \\
(0.015)\end{array}$ & $\begin{array}{c}0.042^{* * * *} \\
(0.016)\end{array}$ & $\begin{array}{c}0.013 \\
(0.009)\end{array}$ & $\begin{array}{c}0.012 \\
(0.009)\end{array}$ \\
\hline Union. Rate & $\begin{array}{c}0.041^{* * *} \\
(0.015)\end{array}$ & $\begin{array}{c}0.040^{* * *} \\
(0.013)\end{array}$ & $\begin{array}{c}0.038 \\
(0.026)\end{array}$ & $\begin{array}{c}0.042 \\
(0.026)\end{array}$ & $\begin{array}{c}0.027 \\
(0.018)\end{array}$ & $\begin{array}{c}0.029 \\
(0.018)\end{array}$ \\
\hline Female Share & $\begin{array}{c}-0.150^{* * *} \\
(0.039)\end{array}$ & $\begin{array}{c}-0.089^{* * *} \\
(0.020)\end{array}$ & $\begin{array}{c}-0.131^{* * *} \\
(0.044)\end{array}$ & $\begin{array}{c}-0.134^{* * *} \\
(0.042)\end{array}$ & $\begin{array}{c}-0.055^{* *} \\
(0.027)\end{array}$ & $\begin{array}{c}-0.057^{* *} \\
(0.026)\end{array}$ \\
\hline Average Hours & $\begin{array}{c}-0.021^{* *} \\
(0.010)\end{array}$ & $\begin{array}{c}-0.045^{* * *} \\
(0.010)\end{array}$ & $\begin{array}{l}-0.015 \\
(0.024)\end{array}$ & $\begin{array}{l}-0.028 \\
(0.022)\end{array}$ & $\begin{array}{c}-0.045^{* *} \\
(0.022)\end{array}$ & $\begin{array}{c}-0.055^{* *} \\
(0.021)\end{array}$ \\
\hline $\log (\mathrm{Cap} / \mathrm{empl})$ & $\begin{array}{l}0.022^{*} \\
(0.013)\end{array}$ & $\begin{array}{c}0.036^{* * *} \\
(0.010)\end{array}$ & $\begin{array}{c}0.026 * * \\
(0.012)\end{array}$ & $\begin{array}{c}0.026^{* *} \\
(0.012)\end{array}$ & $\begin{array}{c}0.017 \\
(0.012)\end{array}$ & $\begin{array}{c}0.017 \\
(0.012)\end{array}$ \\
\hline Connected set sample & YES & YES & $\mathrm{NO}$ & $\mathrm{NO}$ & $\mathrm{NO}$ & $\mathrm{NO}$ \\
\hline 3 digits Sector f.e. & $\mathrm{NO}$ & YES & $\mathrm{NO}$ & $\mathrm{NO}$ & $\mathrm{NO}$ & NO \\
\hline 3-year sub-period f.e. & $\mathrm{NO}$ & $\mathrm{NO}$ & $\mathrm{NO}$ & $\mathrm{NO}$ & YES & YES \\
\hline AKM individual controls & $\mathrm{NO}$ & $\mathrm{NO}$ & YES & YES & $\mathrm{NO}$ & NO \\
\hline Part. R-sq SD Hours & 0.002 & 0.001 & 0.003 & 0.003 & 0.001 & 0.001 \\
\hline Part. R-sq VA and Sales & 0.022 & 0.008 & 0.014 & 0.014 & 0.004 & 0.004 \\
\hline Coordination Share & 0.084 & 0.074 & 0.182 & 0.209 & 0.198 & 0.190 \\
\hline R-sq & 0.153 & 0.200 & 0.092 & 0.094 & 0.380 & 0.380 \\
\hline $\mathrm{N}$ & 20766 & 20766 & 7305 & 7305 & 8487 & 8487 \\
\hline
\end{tabular}

Notes: The stand. dev. of total hours is the standard deviation of the average hours worked across skill groups within a firm. The median abs. dev. is the the median absolute deviation of median hours across each skill group within a firm. Skill groups are defined as deciles of the distribution of $\hat{\alpha_{i}}+\hat{\beta} X_{i j t}$ from the AKM model. All regressions show standardized coefficients. Exporter and industry dummies are based on the median value between 2003 and 2011. (Cap/empl) stands for physical capital over the number of full-time equivalent employees. Specifications (7) also include quadratic and cubic terms of value added per employee. All regression include a vector of controls for the share of workers in each skill group and for the average value of the individual fixed effects $\hat{\alpha}$ in "Part. R-sq VA and Sales". Standard errors are clustered at the 2-digit industry level. *, ** and *** are 10,5 and 1 percent significance levels, respectively. 
Table D.18: Value added, sales and and wage premiums relative to Table 2

\begin{tabular}{|c|c|c|c|c|c|c|}
\hline & $\begin{array}{c}(1) \\
\text { Firm f.e. }\end{array}$ & $\begin{array}{c}(2) \\
\text { Firm f.e. }\end{array}$ & $\begin{array}{c}(3) \\
\text { Firm f.e. }\end{array}$ & $\begin{array}{c}(4) \\
\text { Firm f.e. }\end{array}$ & $\begin{array}{c}(5) \\
\text { Firm f.e. }\end{array}$ & $\begin{array}{c}(6) \\
\text { Firm f.e. }\end{array}$ \\
\hline $\log (\mathrm{VA} / \mathrm{empl})$ & $\begin{array}{c}0.122^{* * *} \\
(0.020)\end{array}$ & $\begin{array}{c}0.095^{* * *} \\
(0.019)\end{array}$ & $\begin{array}{c}0.168^{* * *} \\
(0.020)\end{array}$ & $\begin{array}{c}0.168^{* * *} \\
(0.025)\end{array}$ & $\begin{array}{c}0.166^{* * *} \\
(0.021)\end{array}$ & $\begin{array}{c}0.157^{* * *} \\
(0.022)\end{array}$ \\
\hline TFP & $\begin{array}{c}0.049 \\
(0.034)\end{array}$ & $\begin{array}{c}0.031 \\
(0.024)\end{array}$ & $\begin{array}{c}0.097^{* * *} \\
(0.029)\end{array}$ & $\begin{array}{c}0.113^{* * *} \\
(0.029)\end{array}$ & $\begin{array}{c}0.096^{* * *} \\
(0.029)\end{array}$ & $\begin{array}{c}0.059 * * \\
(0.023)\end{array}$ \\
\hline Firm size & & $\begin{array}{c}0.016^{* *} \\
(0.007)\end{array}$ & $\begin{array}{l}0.013^{*} \\
(0.007)\end{array}$ & $\begin{array}{c}0.041^{* * *} \\
(0.012)\end{array}$ & $\begin{array}{l}0.013^{*} \\
(0.007)\end{array}$ & $\begin{array}{c}0.013^{* *} \\
(0.006)\end{array}$ \\
\hline Exporter status & & $\begin{array}{c}0.062^{* * *} \\
(0.017)\end{array}$ & $\begin{array}{c}0.046^{* * *} \\
(0.015)\end{array}$ & $\begin{array}{c}0.047^{* *} \\
(0.020)\end{array}$ & $\begin{array}{c}0.047^{* * *} \\
(0.015)\end{array}$ & $\begin{array}{c}0.037^{* * *} \\
(0.013)\end{array}$ \\
\hline Union. Rate & & $\begin{array}{l}-0.001 \\
(0.026)\end{array}$ & $\begin{array}{c}0.038 \\
(0.024)\end{array}$ & $\begin{array}{c}0.045 \\
(0.031)\end{array}$ & $\begin{array}{c}0.039 \\
(0.024)\end{array}$ & $\begin{array}{c}0.067 * * * \\
(0.025)\end{array}$ \\
\hline Female Share & & $\begin{array}{l}-0.058 \\
(0.040)\end{array}$ & $\begin{array}{c}-0.107^{* * *} \\
(0.035)\end{array}$ & $\begin{array}{c}-0.111^{* * *} \\
(0.035)\end{array}$ & $\begin{array}{c}-0.105^{* * *} \\
(0.035)\end{array}$ & $\begin{array}{c}-0.098 * * * \\
(0.020)\end{array}$ \\
\hline Average Hours & & $\begin{array}{l}-0.020 \\
(0.022)\end{array}$ & $\begin{array}{l}-0.031 \\
(0.021)\end{array}$ & $\begin{array}{c}-0.030 * \\
(0.018)\end{array}$ & $\begin{array}{l}-0.030 \\
(0.021)\end{array}$ & $\begin{array}{c}-0.063^{* * *} \\
(0.023)\end{array}$ \\
\hline $\log (\mathrm{Cap} / \mathrm{empl})$ & & $\begin{array}{c}0.019 \\
(0.012)\end{array}$ & $\begin{array}{l}-0.008 \\
(0.013)\end{array}$ & $\begin{array}{c}0.023 \\
(0.016)\end{array}$ & $\begin{array}{c}-0.007 \\
(0.013)\end{array}$ & $\begin{array}{l}-0.007 \\
(0.015)\end{array}$ \\
\hline Persuasion & & & & & & $\begin{array}{c}-0.188^{* *} \\
(0.074)\end{array}$ \\
\hline Social Perceptiveness & & & & & & $\begin{array}{c}0.025 \\
(0.044)\end{array}$ \\
\hline Adjust Actions to others & & & & & & $\begin{array}{c}0.005 \\
(0.017)\end{array}$ \\
\hline Negotiation & & & & & & $\begin{array}{c}0.254^{* *} \\
(0.097)\end{array}$ \\
\hline Region F.E. & $\mathrm{NO}$ & YES & YES & YES & YES & YES \\
\hline Compos. cntr & $\mathrm{NO}$ & $\mathrm{NO}$ & YES & YES & YES & YES \\
\hline Ability Measures & $\mathrm{NO}$ & $\mathrm{NO}$ & YES & YES & YES & YES \\
\hline Av. Hours b/w 36.5 and 37.5 & YES & YES & YES & $\mathrm{NO}$ & YES & YES \\
\hline Part. R-sq VA and Sales & 0.022 & 0.010 & 0.032 & 0.038 & 0.032 & 0.020 \\
\hline R-sq & 0.022 & 0.041 & 0.148 & 0.153 & 0.147 & 0.165 \\
\hline $\mathrm{N}$ & 7117 & 7117 & 7060 & 4279 & 7047 & 5904 \\
\hline
\end{tabular}

Notes: All regressions show standardized coefficients. Exporter and industry dummies are based on the median value between 2003 and 2011. (Cap/empl) stands for physical capital over the number of full-time-equivalent employees. All specifications control for quadratic and cubic functions of value added per employee and TFP. TFP is obtained as described in Appendix B.4. "Compos. cntr" refers to a vector of controls for the share of workers in each skill group. "Ability Measures" indicate a vector containing the average value of the individual fixed effects $\hat{\alpha_{i}}$ in each quartile of the distribution of $\hat{\alpha}_{i}$ within a firm. Coordination share is derived as the ratio of "Part. R-sq SD Hours" and "Part. R-sq VA and Sales". Standard errors are clustered at the 2-digit industry level. *, ** and *** are 10, 5 and 1 percent significance levels, respectively. 
Table D.19: Value added, sales and and wage premiums relative to Table 3

\begin{tabular}{|c|c|c|c|}
\hline & $\begin{array}{c}(1) \\
\text { Firm f.e. }\end{array}$ & $\begin{array}{c}(2) \\
\text { Firm f.e. }\end{array}$ & $\begin{array}{c}(3) \\
\text { Firm f.e. }\end{array}$ \\
\hline $\log (\mathrm{VA} / \mathrm{empl})$ & $\begin{array}{c}0.159^{* * *} \\
(0.019)\end{array}$ & $\begin{array}{c}0.148^{* * *} \\
(0.020)\end{array}$ & $\begin{array}{c}0.142^{* * *} \\
(0.019)\end{array}$ \\
\hline TFP & $\begin{array}{c}0.122^{* * *} \\
(0.029)\end{array}$ & $\begin{array}{c}0.083^{* * *} \\
(0.021)\end{array}$ & $\begin{array}{c}0.084^{* * *} \\
(0.021)\end{array}$ \\
\hline Firm size & $\begin{array}{c}0.012^{* *} \\
(0.005)\end{array}$ & $\begin{array}{l}0.007^{*} \\
(0.004)\end{array}$ & $\begin{array}{l}0.018^{*} \\
(0.010)\end{array}$ \\
\hline Exporter status & $\begin{array}{c}0.034^{* *} \\
(0.013)\end{array}$ & $\begin{array}{c}0.018 \\
(0.012)\end{array}$ & $\begin{array}{c}0.010 \\
(0.012)\end{array}$ \\
\hline Union. Rate & $\begin{array}{l}0.044^{*} \\
(0.026)\end{array}$ & $\begin{array}{c}0.042 \\
(0.028)\end{array}$ & $\begin{array}{c}0.043 \\
(0.028)\end{array}$ \\
\hline Female Share & $\begin{array}{c}-0.136^{* * *} \\
(0.030)\end{array}$ & $\begin{array}{c}-0.083^{* * * *} \\
(0.023)\end{array}$ & $\begin{array}{c}-0.066^{* * * *} \\
(0.025)\end{array}$ \\
\hline Average Hours & $\begin{array}{c}-0.041^{* *} \\
(0.017)\end{array}$ & $\begin{array}{c}-0.052^{* * *} \\
(0.018)\end{array}$ & $\begin{array}{c}-0.057^{* * * *} \\
(0.017)\end{array}$ \\
\hline $\log (\mathrm{Cap} / \mathrm{empl})$ & $\begin{array}{c}-0.005 \\
(0.013)\end{array}$ & $\begin{array}{l}-0.001 \\
(0.013)\end{array}$ & $\begin{array}{c}0.006 \\
(0.011)\end{array}$ \\
\hline Region f.e. & YES & YES & YES \\
\hline Compos. and Ability cntr. & YES & YES & YES \\
\hline 1 digit Sector f.e. & YES & NO & NO \\
\hline 2 digits Sector f.e. & NO & YES & NO \\
\hline 3 digits Sector f.e. & NO & NO & YES \\
\hline Part. R-sq VA and Sales & 0.033 & 0.016 & 0.014 \\
\hline R-sq & 0.156 & 0.183 & 0.188 \\
\hline $\mathrm{N}$ & 7055 & 7055 & 7055 \\
\hline
\end{tabular}

Notes: All regressions show standardized coefficients. Exporter and industry dummies are based on the median value between 2003 and 2011. All specifications control for quadratic and cubic functions of value added per employee and TFP. TFP is obtained as described in Appendix B.4. "Compos. cntr" refers to a vector of controls for the share of workers in each skill group. "Ability Measures" indicate a vector containing the average value of the individual fixed effects $\hat{\alpha_{i}}$ in each quartile of the distribution of $\hat{\alpha_{i}}$ within a firm. Coordination share is derived as the ratio of "Part. R-sq SD Hours" and "Part. R-sq VA and Sales". Standard errors are clustered at the 2-digit industry level. *, ** and *** are 10, 5 and 1 percent significance levels, respectively.

\section{Table D.20: Income types in the Danish tax system}

\begin{tabular}{lll}
\hline Acronym & Income Type & \multicolumn{1}{c}{ Main Intems Included } \\
LI & Labor income & Salary, wages, honoraria, fees, bonuses, fringe benefits, business earnings \\
PI & Personal income & $\begin{array}{l}\text { LI t transfers, grants, awards, gifts, received alimony } \\
\text {-Labor market contribution, certain pension contributions }\end{array}$ \\
CI & Capital income & $\begin{array}{l}\text { Interest income, rental income, business capital income } \\
\text {-interest on debt (mortgage, bank loan, credit cards, student loans) }\end{array}$ \\
D & Deductions & $\begin{array}{l}\text { Commuting costs, union fees, UI contribution, other work expenditures, } \\
\text { charity, paid alimony }\end{array}$ \\
PCP & & Private capital pension contribution \\
ECP & & Employer paid capital pension contribution \\
TI & Taxable income & PI+CI-D \\
SI & Stock Income & Dividends and realized capital gains from shares \\
\hline
\end{tabular}


Table D.21: Personal income tax system in Denmark

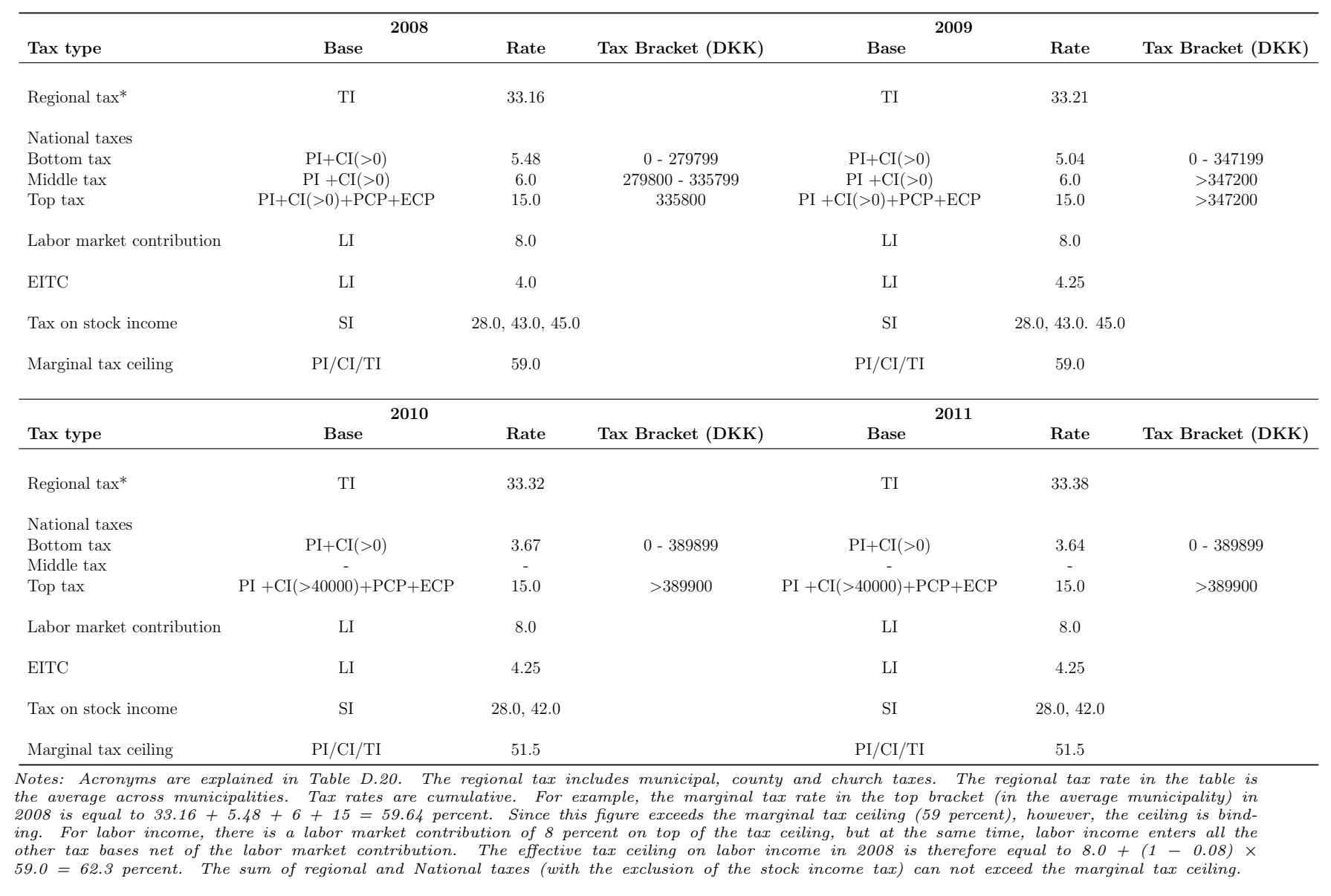


Table D.22: Elasticity of high-skilled hours: normal hours worked

\begin{tabular}{cccc}
\hline \hline & $(1)$ & $(2)$ & $(3)$ \\
& $\Delta \log h^{H}$ & $\Delta \log h^{H}$ & $\Delta \log h^{H}$ \\
\hline$\Delta \log \left(1-\tau^{H}\right)$ & $-0.022^{* * *}$ & $-0.050^{* * *}$ & $-0.028^{* *}$ \\
& $(0.007)$ & $(0.016)$ & $(0.013)$
\end{tabular}

Log base-year income $\quad-0.008^{* * *}$

$(0.002)$

\begin{tabular}{lccc}
\hline IV & NO & YES & YES \\
Region F.E. & YES & YES & YES \\
Overtime Hours & NO & NO & NO \\
Mean Hours & 1888.27 & 1888.27 & 1888.27 \\
F-stat Excl. Inst. & & 1355.00 & 754.53 \\
P-value Excl. Inst. & & 0.00 & 0.00 \\
N Firms & 1166 & 1166 & 1166 \\
N & 26489 & 26489 & 26489 \\
\hline
\end{tabular}

Notes: Each regression contains the following controls measured in the base year: work experience, work experience squared, sex, age, number of children, marital status, education, local unemployment (municipality), region fixed effects, firm size, exporter status, and the shares of high- and low-skilled workers in the firm (the residual group is omitted). We consider only regular hours worked. Observations are weighted by labor income. Standard errors in parentheses are clustered at the firm level. First-stage regressions are available from the authors upon request. $* p<0.10$, $* * p<0.05$, *** $p<0.01$.

Table D.23: Elasticity of hours of workers in the residual group

\begin{tabular}{|c|c|c|c|c|c|c|}
\hline & $\begin{array}{c}(1) \\
\Delta \log h^{H}\end{array}$ & $\begin{array}{c}(2) \\
\Delta \log h^{H}\end{array}$ & $\begin{array}{c}(3) \\
\Delta \log h^{H}\end{array}$ & $\begin{array}{c}(4) \\
\Delta \log h^{H}\end{array}$ & $\begin{array}{c}(5) \\
\Delta \log h^{H}\end{array}$ & $\begin{array}{c}(6) \\
\Delta \log h^{H}\end{array}$ \\
\hline$\Delta \log \left(1-\tau^{\text {Residual }}\right)$ & $\begin{array}{c}-0.014^{* *} \\
(0.006)\end{array}$ & $\begin{array}{c}0.007 \\
(0.020)\end{array}$ & $\begin{array}{c}0.007 \\
(0.019)\end{array}$ & $\begin{array}{c}0.011 \\
(0.020)\end{array}$ & & $\begin{array}{c}0.017 \\
(0.026)\end{array}$ \\
\hline$\Delta \log \left(1-\tau_{5 t h}^{\text {Residual }}\right)$ & & & & & $\begin{array}{c}0.011 \\
(0.024)\end{array}$ & \\
\hline IV & $\mathrm{NO}$ & YES & YES & YES & YES & YES \\
\hline Splines of inc. at $\mathrm{t}$ & $\mathrm{NO}$ & $\mathrm{NO}$ & YES & NO & NO & YES \\
\hline Splines of $\log \mathrm{t}-1$ inc. and $\Delta \log$ inc. $\mathrm{t}-1-\mathrm{t}$ & NO & NO & NO & YES & NO & NO \\
\hline 5th ord. polynomial inc. $\mathrm{t}$ & $\mathrm{NO}$ & $\mathrm{NO}$ & NO & NO & YES & $\mathrm{NO}$ \\
\hline Base-year inc. above median only & NO & NO & NO & NO & $\mathrm{NO}$ & YES \\
\hline Mean Hours & 1876.15 & 1876.15 & 1876.15 & 1879.48 & 1870.05 & 1878.65 \\
\hline F-stat Excl. Inst. & & 407.80 & 476.59 & 348.64 & 377.72 & 291.47 \\
\hline P-value Excl. Inst. & & 0.00 & 0.00 & 0.00 & 0.00 & 0.00 \\
\hline N Firms & 932 & 932 & 932 & 792 & 965 & 742 \\
\hline $\mathrm{N}$ & 6246 & 6246 & 6246 & 4962 & 4958 & 3123 \\
\hline
\end{tabular}

Notes: Each regression contains the following controls measured in the base year: work experience, work experience squared, sex, age, number of children, marital status, education, local unemployment (municipality), region fixed effects, firm size, exporter status, and the shares of high- and low-skilled workers in the firm (the residual group is omitted). We consider only regular hours worked. Observations are weighted by labor income. Standard errors in parentheses are clustered at the firm level. First-stage regressions are available from the authors on request. ${ }^{*} p<0.10$, $* * p<0.05, * * * p<0.01$. 
Table D.24: Elasticity of hours and labor income: extra specifications

\begin{tabular}{lcccc}
\hline \hline & $(1)$ & $(2)$ & $(3)$ & $(4)$ \\
& $\Delta \operatorname{logh} h^{H}$ & $\Delta \operatorname{logh} h^{H}$ & $\Delta \operatorname{logh} h^{H}$ & $\Delta \log \left(\right.$ Labor income $\left.{ }^{H}\right)$ \\
\hline \multirow{4}{*}{$\log \left(1-\tau^{H}\right)$} & & & & \\
& $0.071^{* *}$ & $-0.063^{*}$ & $-0.045^{* * *}$ & $0.0336^{* * *}$ \\
& $(0.035)$ & $(0.037)$ & $(0.015)$ & $(0.0087)$ \\
Log base-year income & -0.012 & -0.003 & $-0.008^{* * *}$ & $-0.1988^{* * *}$ \\
& $(0.012)$ & $(0.005)$ & $(0.003)$ & $(0.0063)$ \\
& & & & \\
\hline Women with kids only & YES & NO & NO & NO \\
Workers at kinks & YES & YES & NO & YES \\
Top 10\\
% income only & NO & YES & NO & NO \\
Mean Hours & 1888.72 & 1951.85 & 1927.68 & \\
F-stat Excl. Inst. & 189.17 & 14.46 & 678.35 & $5.66 \mathrm{e}+04$ \\
P-value Excl. Inst. & 0.00 & 0.00 & 0.00 & 0.00 \\
N & 2998 & 2648 & 24736 & 1865067 \\
\hline \hline
\end{tabular}

Notes: The regression in columns 1 to 3 contains the following controls measured in the base year: work experience, work experience squared, sex, age, number of children, marital status, education, local unemployment (municipality), region fixed effects, firm size, exporter status, and the shares of high- and low-skilled workers in the firm (the residual group is omitted). We consider both regular and overtime hours worked. To be consistent with Kleven and Schultz (2014), we include the following controls in column 4: labor market experience, experience, squared, age, gender, marital status, number of children aged 0-18 years, educational degree, industry, municipality, local unemployment rate, and base-year fixed effects. Observations are weighted by labor income. Standard years, educational degree, industry, municipality, local unemployment rate, and base-year fixed effects. Observations are weighted by labor income. Standard
errors in parentheses are clustered at the firm level. First-stage regressions are available from the authors on request. * ${ }^{*}<0.10, * * p<0.05, * * *<<0.01$.

Table D.25: Elasticity of high-skilled hours: income controls

\begin{tabular}{|c|c|c|c|c|c|c|}
\hline & $\begin{array}{c}(1) \\
\text { High Coord. } \\
\text { Top 50\% }\end{array}$ & $\begin{array}{c}(2) \\
\text { Low Coord. } \\
\text { Bottom } 50 \%\end{array}$ & $\begin{array}{c}(3) \\
\text { High Coord. } \\
\text { Top 50\% }\end{array}$ & $\begin{array}{c}(4) \\
\text { Low Coord. } \\
\text { Bottom } 50 \%\end{array}$ & $\begin{array}{c}(5) \\
\text { High Coord. } \\
\text { Top } 50 \%\end{array}$ & $\begin{array}{c}(6) \\
\text { Low Coord. } \\
\text { Bottom } 50 \%\end{array}$ \\
\hline Dependent Variable & $\Delta \log h^{H}$ & $\Delta \log h^{H}$ & $\Delta \log h^{H}$ & $\Delta \log h^{H}$ & $\Delta \log h^{H}$ & $\Delta \log h^{H}$ \\
\hline$\Delta \log \left(1-\tau^{H}\right)$ & $\begin{array}{l}-0.020 \\
(0.014)\end{array}$ & $\begin{array}{c}-0.082^{* * *} \\
(0.027)\end{array}$ & & & $\begin{array}{c}-0.024^{* *} \\
(0.012)\end{array}$ & $\begin{array}{c}-0.072^{* *} \\
(0.029)\end{array}$ \\
\hline$\Delta \log \left(1-\tau_{-} 5 t h^{H}\right)$ & & & $\begin{array}{l}-0.023 \\
(0.022)\end{array}$ & $\begin{array}{c}-0.115^{* * *} \\
(0.031)\end{array}$ & & \\
\hline IV & YES & YES & YES & YES & YES & YES \\
\hline Region F.E. & YES & YES & YES & YES & YES & YES \\
\hline Splines of inc. at $t$ & YES & YES & $\mathrm{NO}$ & $\mathrm{NO}$ & $\mathrm{NO}$ & $\mathrm{NO}$ \\
\hline 5th ord. polynomial inc. $t$ & $\mathrm{NO}$ & $\mathrm{NO}$ & YES & YES & $\mathrm{NO}$ & $\mathrm{NO}$ \\
\hline $\begin{array}{l}\text { Splines of log t- } 1 \text { inc. } \\
\text { and } \Delta \text { log inc. t-1-t } \\
\text { Pvalue High=Low }\end{array}$ & $\begin{array}{l}\mathrm{NO} \\
0.05\end{array}$ & $\mathrm{NO}$ & $\begin{array}{l}\mathrm{NO} \\
0.02\end{array}$ & NO & $\begin{array}{l}\text { YES } \\
0.02\end{array}$ & YES \\
\hline Mean Hours & 1904.10 & 1847.66 & 1904.29 & 1850.89 & 1907.00 & 1853.11 \\
\hline F-stat Excl. Inst. & 1298.25 & 461.91 & 307.72 & 79.46 & 857.62 & 250.09 \\
\hline P-value Excl. Inst. & 0.00 & 0.00 & 0.00 & 0.00 & 0.00 & 0.00 \\
\hline N Firms & 584 & 583 & 584 & 581 & 537 & 519 \\
\hline $\mathrm{N}$ & 19067 & 7421 & 17852 & 6814 & 15619 & 5649 \\
\hline
\end{tabular}

Notes: Each regression contains the following controls measured in the base year: work experience, work experience squared, sex, age, number of children, marital status, education, local unemployment (municipality), region fixed effects, firm size, exporter status, and the shares of high- and low-skilled workers in the firm (the residual group is omitted). "Splines" refer to a flexible piecewise linear functional form with 5 components. $\tau_{5}$ th refers to marginal tax rates obtained as in Dahl and Lochner (2012). "P-value High=Low" refers to the p-value of the null hypothesis that the coefficient attached to $\Delta$ log $\left(1-\tau^{H}\right)$ is equal in low- and high-coordination firms. Observations are weighted by labor income. Coordination is measured using Std. Dev. Definition 1. Standard errors in parentheses are clustered at the firm level. First-stage regressions are available from the authors on request. $* p<0.10$, ** $p<0.05, * * * p<0.01$. 
Table D.26: Spillover effects: income controls

\begin{tabular}{|c|c|c|c|}
\hline & $\begin{array}{c}(1) \\
\Delta \log h^{L}\end{array}$ & $\begin{array}{c}(2) \\
\Delta \log h^{L}\end{array}$ & $\begin{array}{c}(3) \\
\Delta \log h^{L}\end{array}$ \\
\hline$\Delta \log \overline{h^{H}}$ & $\begin{array}{c}1.152^{* * *} \\
(0.373)\end{array}$ & $\begin{array}{c}1.160^{* * * *} \\
(0.365)\end{array}$ & $\begin{array}{c}1.115^{* *} \\
(0.464)\end{array}$ \\
\hline$\Delta \log \left(1-\tau^{L}\right)$ & $\begin{array}{c}0.050 \\
(0.105)\end{array}$ & $\begin{array}{c}0.044 \\
(0.123)\end{array}$ & \\
\hline$\Delta \log \left(1-\tau_{5 t h}^{L}\right)$ & & & $\begin{array}{c}0.030^{* *} \\
(0.015)\end{array}$ \\
\hline Log base-year income & YES & $\mathrm{NO}$ & NO \\
\hline Splines of inc. at $t$ & NO & YES & NO \\
\hline 5th ord. polynomial inc. $\mathrm{t}$ & NO & NO & YES \\
\hline F-stat Excl. Inst. 13.65, 105.11 & $17.17,62.25$ & $3.91,459.04$ & \\
\hline P-value Excl. Inst. & $0.00,0.00$ & $0.00,0.00$ & $0.05,0.00$ \\
\hline Mean Hours Low Sk. & 1809.02 & 1809.02 & 1809.49 \\
\hline Mean Hours High Sk. & 1877.51 & 1877.51 & 1877.50 \\
\hline N Firms & 1157 & 1157 & 1151 \\
\hline $\mathrm{N}$ & 14402 & 14402 & 13654 \\
\hline
\end{tabular}

Notes: Each regression contains the following controls measured in the base year: work experience, work experience squared, sex, age, number of children, marital status, education, local unemployment (municipality), region fixed effects, firm size, exporter status, and the shares of high- and low-skilled workers in the firm. "Splines" refer to a flexible piecewise linear functional form with 5 components. $\tau_{5}$ th refers to marginal tax rates obtained as in Dahl and Lochner (2012). Observations are weighted by labor income. First-stage regressions are available from the authors on request. Standard errors in parentheses are clustered at the firm level. $* \quad p<0.10, * * \quad p<0.05, * * * \quad p<0.01$. 
Table D.27: The spillover effects on low-skilled hours: additional specifications

\begin{tabular}{|c|c|c|c|c|c|}
\hline & 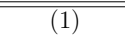 & 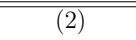 & 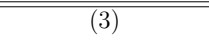 & $\overline{(4)}$ & (5) \\
\hline & $\Delta \log h^{L}$ & $\Delta \log h^{L}$ & $\Delta \log h^{L}$ & $\Delta \log h^{L}$ & $\Delta \log h^{L}$ \\
\hline$\Delta \log \bar{h}_{\text {normal }}^{H}$ & $\begin{array}{c}0.888^{* * *} \\
(0.333)\end{array}$ & & $\begin{array}{c}1.763 \\
(1.214)\end{array}$ & $\begin{array}{c}0.983^{* *} \\
(0.445)\end{array}$ & $\begin{array}{c}0.893^{* * *} \\
(0.303)\end{array}$ \\
\hline$\Delta \log \overline{h^{H}} \times$ High Union Share & & & $\begin{array}{l}-1.200 \\
(1.394)\end{array}$ & & \\
\hline$\Delta \log \bar{h}_{\text {total }}^{H}$ & & $\begin{array}{l}1.217^{* *} \\
(0.576)\end{array}$ & & & \\
\hline$\Delta \log \bar{h}_{\text {normal }}^{\text {Residual }}$ & & & & $\begin{array}{l}-0.179 \\
(0.567)\end{array}$ & \\
\hline High Union Share & & & $\begin{array}{c}0.012 \\
(0.008)\end{array}$ & & \\
\hline$\Delta \log \left(1-\tau^{L}\right)$ & $\begin{array}{l}0.163^{*} \\
(0.088)\end{array}$ & $\begin{array}{c}0.151 \\
(0.094)\end{array}$ & $\begin{array}{c}0.006 \\
(0.066)\end{array}$ & $\begin{array}{c}0.026 \\
(0.069)\end{array}$ & $\begin{array}{c}0.064 \\
(0.116)\end{array}$ \\
\hline Overtime hours & $\mathrm{NO}$ & YES & NO & $\mathrm{NO}$ & $\mathrm{NO}$ \\
\hline Firm f.e. & YES & YES & NO & $\mathrm{NO}$ & NO \\
\hline Base-year f.e. & YES & YES & NO & NO & NO \\
\hline Workers at kinks & YES & YES & YES & YES & $\mathrm{NO}$ \\
\hline Mean Hours Low Sk. & 1815.25 & 1833.23 & 1813.05 & 1811.60 & 1811.95 \\
\hline Mean Hours High Sk. & 1873.63 & 1906.57 & 1875.14 & 1877.83 & 1874.93 \\
\hline F-stat Excl. Inst. & $6.23,24.55$ & $2.45,25.57$ & $1.81,8.57,133.48$ & $4.41,12.16,122.94$ & $13.97,77.48$ \\
\hline P-value Excl. Inst. & $0.01,0.00$ & $0.12,0.00$ & $0.18,0.00,0.00$ & $0.04,0.00,0.00$ & $0.00,0.00$ \\
\hline N Firms & 835 & 835 & 977 & 799 & 958 \\
\hline $\mathrm{N}$ & 15985 & 15985 & 10196 & 9606 & 9979 \\
\hline
\end{tabular}

Notes: This table reports the results from estimating alternative specifications of equation (11) in Section 5.4. We consider both regular (normal) hours (columns 1, 3, 4 and 5) and total hours (column 2). All specifications use mechanical changes of the average net-of-tax rate among high-skilled workers in a firm as an instrument for the average change in hours, and the mechanical change of the net-of-tax rate of low-skilled workers as an instrument for observed changes of $1-\tau^{L}$ (Section 5.5). The dummy variable "High Union Share" in column 3 takes a value of 1 if the firm had a share of unionized workers above the median in 2008. In column 4, we also consider change in average hours among workers in the residual group within the same firm. We instrument for the average change in hours in this group using the average mechanical change of the net-of-tax rate among workers in the residual group. Each regression contains the following controls measured in the base year: work experience, work experience squared, sex, age, number of children, marital status, education, local unemployment (municipality), region fixed effects, firm size, exporter status, the shares of high-and low-skilled workers in the firm, 5 component splines of income at t-1 and income change between $t-1$ and $t$. Workers close to the kink points (column 5) are defined as having taxable income within 5,000 DKK of the top kink or 2,000 $D K K$ of the bottom kink (Kleven and Schultz, 2014). In evaluating the closeness of workers to kinks, base year income is measured in 2005 DKK (6 DKK $\simeq$ 1 USD in 2005). Observations are weighted by labor income. Standard errors in parentheses are clustered at the firm level.* $p<0.10, * * p<0.05, * * * p<0.01$. 
Table D.28: Elasticity of high-skilled hours: alternative definitions of coordination and data on hours

\begin{tabular}{|c|c|c|c|c|c|c|c|}
\hline & $\begin{array}{c}(1) \\
\text { High Coord. } \\
\text { Top } 50 \% \\
\text { Def. } 2\end{array}$ & $\begin{array}{c}(2) \\
\text { Low Coord. } \\
\text { Bottom } 50 \% \\
\text { Def. } 2\end{array}$ & $\begin{array}{c}(3) \\
\text { Low Coord. } \\
\text { Bottom } 50 \% \\
\text { Def. } 2\end{array}$ & $\begin{array}{c}(4) \\
\text { Low Coord. } \\
\text { Bottom } 50 \% \\
\text { Def. } 2\end{array}$ & $\begin{array}{c}(5) \\
\text { High Coord. } \\
\text { Top 50\% } \\
\text { BFL Hours }\end{array}$ & $\begin{array}{c}(6) \\
\text { Low Coord. } \\
\text { Bottom 50\% } \\
\text { BFL Hours }\end{array}$ & BFL Hours \\
\hline Dependent variable & $\Delta \log h^{H}$ & $\Delta \log h^{H}$ & $\Delta \log h^{L}$ & $\Delta \log h^{L}$ & $\Delta \log h^{H}$ & $\Delta \log h^{H}$ & $\Delta \log h^{L}$ \\
\hline$\Delta \log \left(1-\tau^{H}\right)$ & $\begin{array}{c}-0.001 \\
(0.012)\end{array}$ & $\begin{array}{c}-0.092^{* * *} \\
(0.022)\end{array}$ & & & $\begin{array}{c}-0.008 \\
(0.041)\end{array}$ & $\begin{array}{c}-0.091^{* *} \\
(0.042)\end{array}$ & \\
\hline$\Delta \log \overline{h_{\text {normal }}^{H}}$ & & & $\begin{array}{c}0.684^{* *} \\
(0.307)\end{array}$ & & & & \\
\hline$\Delta \log \overline{h_{\text {total }}^{H}}$ & & & & $\begin{array}{c}0.760^{* *} \\
(0.319)\end{array}$ & & & \\
\hline$\Delta \log \overline{h_{b l f}^{H}}$ & & & & & & & $\begin{array}{c}1.015^{* *} \\
(0.400)\end{array}$ \\
\hline$\Delta \log \left(1-\tau^{L}\right)$ & & & $\begin{array}{l}-0.016 \\
(0.107)\end{array}$ & $\begin{array}{l}-0.077 \\
(0.113)\end{array}$ & & & $\begin{array}{c}0.187 \\
(0.291)\end{array}$ \\
\hline Log base-year income & $\begin{array}{l}-0.001 \\
(0.002)\end{array}$ & $\begin{array}{c}-0.022^{* * * *} \\
(0.007)\end{array}$ & & & $\begin{array}{c}-0.022^{* *} \\
(0.009) \\
\end{array}$ & $\begin{array}{c}-0.010 \\
(0.010)\end{array}$ & \\
\hline Overtime hours & YES & YES & $\mathrm{NO}$ & YES & $\mathrm{NO}$ & $\mathrm{NO}$ & $\mathrm{NO}$ \\
\hline BFL hours & $\mathrm{NO}$ & NO & NO & $\mathrm{NO}$ & YES & YES & YES \\
\hline Mean Hours & 1905.27 & 1863.52 & 1760.44 & 1783.84 & 1901.01 & 1854.16 & 1851.93 \\
\hline $\begin{array}{l}\text { Pvalue High=Low } \\
\text { F-stat Excl. Inst. }\end{array}$ & 0.00 & & & & 0.15 & & \\
\hline F-stat Excl. Inst. & 1034.04 & 282.28 & $5.43,35.78$ & $9.88,35.78$ & 962.85 & 179.52 & $1.37,33.69$ \\
\hline P-value Excl. Inst. & 0.00 & 0.00 & $0.00,0.00$ & $0.00,0.00$ & 0.00 & 0.00 & $0.26,33.69$ \\
\hline N Firms & 583 & 583 & 489 & 489 & 477 & 521 & 802 \\
\hline $\mathrm{N}$ & 15701 & 10788 & 4749 & 4749 & 15521 & 6330 & 8562 \\
\hline
\end{tabular}

Notes: Each regression contains the following controls measured in the base year: work experience, work experience squared, sex, age, number of children, marital status, education, local unemployment (municipality), region fixed effects, firm size, exporter status, and the shares of high- and low-skilled workers in the firm (the residual group is omitted). Columns 3, 4 and 7 contain controls for flexible piecewise linear functions with 5 components of income at $t$ - 1 and the change in income between $t-1$ and $t$. BFL hours refer to hours from E-indkomst. Total hours refer to the sum of normal and overtime hours. Coordination is measured using the St. Dev. Definition 2 in columns 1 to 4 and the St. Dev. Definition 1 in column 5 to 7.065 . Orvations are weighted by labor income. Standard errors in parentheses are clustered at the firm level. First-stage regressions are available from the authors on request. $* p<0.10, * * p<0.05$, $* * * 0<0.01$. 
Table D.29: Uncompensated elasticity and virtual income

\begin{tabular}{|c|c|c|c|}
\hline Dependent variable & $\begin{array}{c}(1) \\
\text { High Coord. } \\
\text { Top } 50 \% \\
\Delta \log h^{H}\end{array}$ & $\begin{array}{c}(2) \\
\text { Low Coord. } \\
\text { Bottom } 50 \% \\
\Delta \log h^{H}\end{array}$ & $\Delta \log h^{L}$ \\
\hline$\Delta \log \left(1-\tau^{H}\right)$ & $\begin{array}{c}-0.028^{* *} \\
(0.014)\end{array}$ & $\begin{array}{c}-0.552 \\
(6.212)\end{array}$ & \\
\hline$\Delta \log v y^{H}$ & $\begin{array}{l}-0.013 \\
(0.017)\end{array}$ & $\begin{array}{c}-1.154 \\
(15.801)\end{array}$ & \\
\hline$\Delta \log \overline{h^{H}}$ & & & $\begin{array}{c}0.957^{* * *} \\
(0.283)\end{array}$ \\
\hline$\Delta \log \left(1-\tau^{L}\right)$ & & & $\begin{array}{l}-0.008 \\
(0.065)\end{array}$ \\
\hline$\Delta \log v y^{L}$ & & & $\begin{array}{l}-0.008 \\
(0.020)\end{array}$ \\
\hline Log base-year income & $\begin{array}{c}0.002 \\
(0.007)\end{array}$ & $\begin{array}{c}0.429 \\
(6.200)\end{array}$ & $\begin{array}{c}0.010 \\
(0.013)\end{array}$ \\
\hline Overtime hours & YES & YES & $\mathrm{NO}$ \\
\hline Mean Hours & 1924.91 & 1907.33 & 1812.58 \\
\hline $\begin{array}{l}\text { Pvalue } \Delta \log \left(1-\tau^{H}\right) \text { High=Low } \\
\text { Pvalue } \Delta \log v y^{H} \text { High=Low }\end{array}$ & $\begin{array}{l}0.98 \\
0.98\end{array}$ & & \\
\hline F-stat Excl. Inst. & $2049,43.8$ & $0.65,0.01$ & $23.84,5,78,29.7$ \\
\hline N Firms & 583 & 584 & 968 \\
\hline $\mathrm{N}$ & 18824 & 7618 & 10066 \\
\hline
\end{tabular}

Notes: Each regression contains the following controls measured in the base year: work experience, work experience squared, sex, age, number of children, marital status, education, local unemployment (municipality), region fixed effects, firm size, exporter status, and the shares of high- and low-skilled workers in the firm (the residual group is omitted). In column 3 , we consider only regular hours worked. Observations are weighted by labor income. "P-value $\Delta \log \left(1-\tau^{H}\right)$ High=Low" refers to the p-value of the null hypothesis that the coefficient attached to $\Delta \log \left(1-\tau^{H}\right)$ in low- and high-coordination firms is equal. "P-value $\Delta \log \left(1-v y^{H}\right)$ High=Low" refers to the p-value of the null hypothesis that the coefficient attached to $\Delta \log \left(1-v y^{H}\right)$ in low-and high-coordination firms is equal. First-stage regressions are available from the authors on request. Standard errors in parentheses are clustered at the firm level. $*$ p<0.10, $* * \quad p<0.05, * * * \quad p<0.01$. 
Table D.30: The effects of the tax reform on firm characteristics

\begin{tabular}{|c|c|c|c|c|}
\hline & 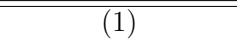 & 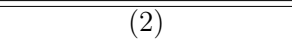 & 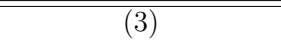 & (4) \\
\hline & $\Delta \log ($ FirmSize $)$ & $\Delta \log ($ ShareHighSk. $)$ & $\Delta \log ($ ShareLowSk.) & $\Delta \log ($ PhysicalCapital $)$ \\
\hline$\Delta \log \left(\overline{1-\tau^{H}}\right)$ & $\begin{array}{c}-0.204 \\
(0.398)\end{array}$ & $\begin{array}{c}0.161 \\
(0.349)\end{array}$ & $\begin{array}{c}-0.466 \\
(0.357)\end{array}$ & $\begin{array}{c}0.063 \\
(1.481)\end{array}$ \\
\hline Firm Size & $\begin{array}{l}-0.000 \\
(0.000)\end{array}$ & $\begin{array}{c}0.000 \\
(0.000)\end{array}$ & $\begin{array}{l}-0.000^{*} \\
(0.000)\end{array}$ & $\begin{array}{c}0.000 \\
(0.000)\end{array}$ \\
\hline Ind. Exp. & $\begin{array}{c}-0.055^{* * *} \\
(0.020)\end{array}$ & $\begin{array}{c}0.034^{* *} \\
(0.016)\end{array}$ & $\begin{array}{c}-0.071^{* * *} \\
(0.022)\end{array}$ & $\begin{array}{c}0.251^{* *} \\
(0.101)\end{array}$ \\
\hline Ind. Mupltiplant & $\begin{array}{l}-0.036^{*} \\
(0.021)\end{array}$ & $\begin{array}{l}-0.011 \\
(0.014)\end{array}$ & $\begin{array}{c}0.025 \\
(0.020)\end{array}$ & $\begin{array}{c}0.003 \\
(0.106)\end{array}$ \\
\hline Share of Low Sk. & $\begin{array}{c}0.053 \\
(0.100)\end{array}$ & $\begin{array}{c}-0.527^{* * *} \\
(0.089)\end{array}$ & $\begin{array}{c}-0.214 \\
(0.141)\end{array}$ & $\begin{array}{l}-0.599 \\
(0.567)\end{array}$ \\
\hline Share of High Sk. & $\begin{array}{c}0.042 \\
(0.095)\end{array}$ & $\begin{array}{l}-0.128 \\
(0.081)\end{array}$ & $\begin{array}{c}-0.800^{* * *} \\
(0.125)\end{array}$ & $\begin{array}{l}-0.315 \\
(0.542)\end{array}$ \\
\hline Mean Log base year (t) income & $\begin{array}{l}-0.047 \\
(0.116)\end{array}$ & $\begin{array}{l}-0.011 \\
(0.068)\end{array}$ & $\begin{array}{c}0.243^{* *} \\
(0.111)\end{array}$ & $\begin{array}{c}0.299 \\
(0.455)\end{array}$ \\
\hline IV & YES & YES & YES & YES \\
\hline Region F.E. & YES & YES & YES & YES \\
\hline F-stat Excl. Inst. & 116.04 & 116.04 & 116.04 & 117.07 \\
\hline P-value Excl. Inst. & 0.00 & 0.00 & 0.00 & 0.00 \\
\hline N Firms & 968 & 968 & 968 & 963 \\
\hline
\end{tabular}

Notes: Each regression contains the following additional controls measured in the base year: average work experience, average work experience squared, share of males, share of married workers, average worker age, average number of children per worker, local unemployment (firm municipality), share of primary, secondary and tertiary educated workers, and region fixed effects. "Mech." stands for mechanical change. First-stage regressions are available from the authors on request. F-stat Excl. Inst. refers to the

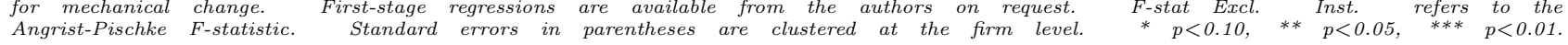




\section{D.2 First-stage regressions}

Table D.31: First-stage regression relative to Table 4

\begin{tabular}{|c|c|c|c|c|c|c|}
\hline & (1) & $(2)$ & $\begin{array}{c}(3) \\
\text { High Coord. }\end{array}$ & $\begin{array}{c}(4) \\
\text { Low Coord. }\end{array}$ & $\begin{array}{c}(5) \\
\text { High Coord. } \\
\text { Top } 25 \%\end{array}$ & $\begin{array}{c}(6) \\
\text { Low Coord. } \\
\text { Bottom } 25 \%\end{array}$ \\
\hline Dependent Variable & $\Delta \log h^{H}$ & $\Delta \log h^{H}$ & $\Delta \log h^{H}$ & $\Delta \log h^{H}$ & $\Delta \log h^{H}$ & $\Delta \log h^{H}$ \\
\hline$\Delta \log \left(1-\tau^{H}\right)$ Mech. & $\begin{array}{c}1.935^{* * * *} \\
(0.053)\end{array}$ & $\begin{array}{c}2.086^{* * *} \\
(0.076)\end{array}$ & $\begin{array}{c}1.942^{* * *} \\
(0.054)\end{array}$ & $\begin{array}{c}2.429 * * * \\
(0.175)\end{array}$ & $\begin{array}{c}1.952^{* * *} \\
(0.082)\end{array}$ & $\begin{array}{c}2.499^{* * *} \\
(0.216)\end{array}$ \\
\hline Log base-year income & & $\begin{array}{c}-0.030 * * * \\
(0.007)\end{array}$ & $\begin{array}{c}-0.016^{* * *} \\
(0.004)\end{array}$ & $\begin{array}{c}-0.056^{* * *} \\
(0.016)\end{array}$ & $\begin{array}{l}-0.010 \\
(0.006)\end{array}$ & $\begin{array}{c}-0.057^{* * *} \\
(0.014)\end{array}$ \\
\hline IV & YES & YES & YES & YES & YES & YES \\
\hline Region fe & YES & YES & YES & YES & YES & YES \\
\hline Overtime Hours & YES & YES & YES & YES & YES & YES \\
\hline F-stat & $1.36 \mathrm{e}+03$ & $7.55 \mathrm{e}+02$ & $1.29 \mathrm{e}+03$ & $1.93 \mathrm{e}+02$ & $5.66 \mathrm{e}+02$ & $1.34 \mathrm{e}+02$ \\
\hline p-value & 0.00 & 0.00 & 0.00 & 0.00 & 0.00 & 0.00 \\
\hline N Firms & 1167 & 1167 & 584 & 583 & 293 & 291 \\
\hline $\mathrm{N}$ & 26488 & 26488 & 18875 & 7613 & 8307 & 2371 \\
\hline
\end{tabular}

Notes: Each regression contains the following controls measured in the base year: work experience, work experience squared, sex, age, number of children, marital status, education, local unemployment (municipality), region fixed effects, firm size, exporter status, and the shares of high- and low-skilled workers in the firm (the residual group is omitted). The abbreviation "Mech." stands for mechanical changes. Ob-

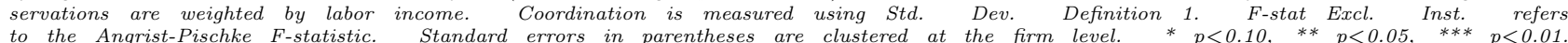

Table D.32: First-stage regression relative to Table 5

\begin{tabular}{|c|c|c|c|c|c|c|c|c|c|c|}
\hline & $\begin{array}{c}\stackrel{(1)}{\Delta l o g}\left(1-\tau^{H}\right) \\
\text { (n) }\end{array}$ & $\begin{array}{c}\stackrel{(2)}{\Delta l o g}\left(1-\tau^{H}\right) \\
\end{array}$ & $\begin{array}{c}\stackrel{(3)}{\Delta l o g}\left(1-\tau^{H}\right) \\
\text { (1) }\end{array}$ & $\begin{array}{c}\operatorname{cog}\left(1-\tau^{H}\right) \times \text { Size } \\
\end{array}$ & $\begin{array}{c}\sin \left(1-\tau^{H}\right) \\
\Delta \log ()^{\prime}\end{array}$ & $\begin{array}{c}(6) \\
\Delta \log \left(1-\tau^{H}\right) \times \text { Size }\end{array}$ & $\begin{array}{c}(7) \\
\Delta \log \left(1-\tau^{H}\right)\end{array}$ & 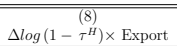 & $\begin{array}{c}(9) \\
\Delta \log \left(1-\tau^{H}\right)\end{array}$ & $\begin{array}{c}\log \left(1-\tau^{H}\right) \times \text { Export } \\
\Delta \log \end{array}$ \\
\hline$\Delta \log \left(1-\tau^{H}\right)$ Mech. & $\begin{array}{c}1.835^{* * *} \\
(0.047)\end{array}$ & $\begin{array}{c}2.182^{* * *} \\
(0.116)\end{array}$ & $\begin{array}{c}1.946^{* * *} \\
(0.067)\end{array}$ & $\begin{array}{l}136.367^{* * * *} \\
(44.471)\end{array}$ & $\begin{array}{c}2.494^{* * *} \\
(0.195)\end{array}$ & $\begin{array}{l}93.787^{* * *} \\
(21.641)\end{array}$ & $\begin{array}{c}2.086^{* * *} \\
(0.132)\end{array}$ & $\begin{array}{c}0.202^{* * * *} \\
(0.026)\end{array}$ & $\begin{array}{c}2.529^{* * *} \\
(0.266)\end{array}$ & $\begin{array}{c}.197^{* * *} \\
(0.066)\end{array}$ \\
\hline$\Delta \log \left(1-\tau^{H}\right)$ Mech. $\times$ Mech. Size & & & $\begin{array}{l}-0.000 \\
(0.000)\end{array}$ & $\begin{array}{c}1.684^{* * *} \\
(0.021)\end{array}$ & $\begin{array}{l}-0.000 \\
(0.000)\end{array}$ & $\begin{array}{c}1.710^{* * *} \\
(0.101)\end{array}$ & & & & \\
\hline$\Delta \log \left(1-\tau^{H}\right)$ Mech. $\times$ Export & & & & & & & $\begin{array}{l}-0.167 \\
(0.138)\end{array}$ & $\begin{array}{c}1.685^{* * *} \\
(0.050)\end{array}$ & $\begin{array}{l}-0.159 \\
(0.213)\end{array}$ & $\begin{array}{c}1.888^{* * *} \\
(0.102)\end{array}$ \\
\hline Log base-year income & $\begin{array}{c}-0.012^{* * *} \\
(0.004)\end{array}$ & $\begin{array}{c}-0.038^{* * *} \\
(0.008)\end{array}$ & $\begin{array}{c}-0.016 * * * \\
(0.004)\end{array}$ & $\begin{array}{c}-7.925 * * \\
(3.299)\end{array}$ & $\begin{array}{c}-0.056^{* * *} \\
(0.016)\end{array}$ & $\begin{array}{c}-7.290^{* * *} \\
(1.894)\end{array}$ & $\begin{array}{c}-0.016^{* * *} \\
(0.004)\end{array}$ & $\begin{array}{c}-0.015 * * * \\
(0.003)\end{array}$ & $\begin{array}{c}-0.056^{* * *} \\
(0.016)\end{array}$ & $\begin{array}{c}-0.025^{* * *} \\
(0.006)\end{array}$ \\
\hline $\begin{array}{l}\text { Firm F.E. } \\
\text { Base-year F.E. }\end{array}$ & $\begin{array}{l}\text { YES } \\
\text { YES }\end{array}$ & $\begin{array}{l}\text { YES } \\
\text { YES }\end{array}$ & $\begin{array}{l}\text { NO } \\
\text { NO }\end{array}$ & $\begin{array}{l}\text { NO } \\
\text { NO }\end{array}$ & $\begin{array}{l}\text { NO } \\
\text { NO }\end{array}$ & $\begin{array}{l}\text { NO } \\
\text { NO }\end{array}$ & $\begin{array}{l}\text { NO } \\
\text { NO }\end{array}$ & $\begin{array}{l}\text { NO } \\
\text { NO }\end{array}$ & $\begin{array}{l}\text { NO } \\
\text { NO }\end{array}$ & $\begin{array}{l}\text { NO } \\
\text { NO }\end{array}$ \\
\hline $\begin{array}{l}\text { Base-year F.E. } \\
\text { F-stat }\end{array}$ & $\begin{array}{c}\text { YES } \\
1542.40\end{array}$ & $\begin{array}{l}\text { YES } \\
353.25\end{array}$ & $\begin{array}{c}\mathrm{NO} \\
1033.24\end{array}$ & $\begin{array}{c}\text { No } \\
6991.11\end{array}$ & $\begin{array}{c}\text { No } \\
291.82\end{array}$ & $\begin{array}{l}N 0 \\
605.65\end{array}$ & $\begin{array}{c}N 0 \\
204.80\end{array}$ & $\begin{array}{l}\text { NO } \\
4583.96\end{array}$ & $\begin{array}{l}\text { NO } \\
113.01\end{array}$ & $\begin{array}{c}\mathrm{NO} \\
658.43\end{array}$ \\
\hline p-value & 0.00 & 0.00 & 0.00 & 0.00 & 0.00 & 0.00 & 0.00 & 0.00 & 0.00 & 0.00 \\
\hline N Firms & 78.5 & 675 & 584 & 584 & 583 & 583 & 584 & 584 & 583 & 583 \\
\hline $\mathrm{N}$ & 26497 & 10267 & 18875 & 18875 & 7613 & 7613 & 18875 & 18875 & 7613 & 7613 \\
\hline
\end{tabular}

Notes: Each regression contains the following controls measured in the base year: work experience, work experience squared, sex, age, number of children, marital status, education, local unemployment (municipality), region fixed effects, firm size, exporter status, and the shares of high and low-skilled workers in the firm (the residual group is omitted). "Mech." stands for mechanical changes. Observations are weighted by labor income. F-stat Excl.

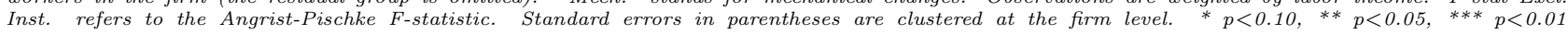


Table D.33: First-stage regression relative to Table 5

\begin{tabular}{|c|c|c|c|c|c|c|c|c|}
\hline$\Delta \log \left(1-\tau^{H}\right)$ Mech. & $\begin{array}{c}(1) \\
\Delta \log \left(1-\tau^{H}\right) \\
1.966^{* * *} \\
(0.082)\end{array}$ & $\begin{array}{c}\Delta \log \left(1-\tau^{H}\right) \times \stackrel{(2)}{\text { High Union. Share }} \\
0.126^{* * *} \\
(0.020)\end{array}$ & $\begin{array}{c}(3) \\
\Delta \log \left(1-\tau^{H}\right) \\
2.612^{* * *} \\
(0.192)\end{array}$ & $\begin{array}{c}\Delta \log \left(1-\tau^{H}\right) \times \text { High Union. Share } \\
0.397^{* * *} \\
(0.136)\end{array}$ & $\begin{array}{c}(5) \\
\Delta \log \left(1-\tau^{H}\right) \\
2.058^{* * *} \\
(0.061)\end{array}$ & \begin{tabular}{c}
\multicolumn{1}{c}{$(6)$} \\
$\Delta \log \left(1-\tau^{H}\right) \times$ High TFP \\
$0.164^{* * *}$ \\
$(0.025)$
\end{tabular} & $\begin{array}{c}(7) \\
\Delta \log \left(1-\tau^{H}\right) \\
2.480^{* * *} \\
(0.222)\end{array}$ & $\begin{array}{c}(8) \\
\Delta \log \left(1-\tau^{H}\right) \times \operatorname{High} \text { TFP } \\
0.193^{* * *} \\
(0.038)\end{array}$ \\
\hline$\Delta \log \left(1-\tau^{H}\right)$ Mech. $\times$ High Union. Share & $\begin{array}{c}-0.029 \\
(0.096)\end{array}$ & $\begin{array}{c}1.696^{* * *} \\
(0.056)\end{array}$ & $\begin{array}{l}-0.255 \\
(0.179)\end{array}$ & $\begin{array}{c}1.794 * * * \\
(0.120)\end{array}$ & & & & \\
\hline$\Delta \log \left(1-\tau^{H}\right)$ Mech. $\times$ High TFP & & & & & $\begin{array}{c}-0.190 * * \\
(0.082)\end{array}$ & $\begin{array}{c}1.625 * * * \\
(0.062)\end{array}$ & $\begin{array}{l}-0.105 \\
(0.183)\end{array}$ & $\begin{array}{c}1.843^{* * *} \\
(0.107)\end{array}$ \\
\hline Log base-year income & $\begin{array}{c}-0.016^{* * *} \\
(0.004)\end{array}$ & $\begin{array}{c}-0.009^{* * *} \\
(0.003)\end{array}$ & $\begin{array}{c}-0.057^{* * *} \\
(0.016)\end{array}$ & $\begin{array}{c}-0.039^{* *} \\
(0.019)\end{array}$ & $\begin{array}{c}-0.017^{* * * *} \\
(0.004)\end{array}$ & $\begin{array}{c}-0.010^{* * *} \\
(0.003)\end{array}$ & $\begin{array}{c}-0.056^{* * *} \\
(0.016)\end{array}$ & $\begin{array}{c}-0.013^{* * *} \\
(0.004)\end{array}$ \\
\hline $\begin{array}{l}\text { Firm F.E. } \\
\text { Base-year F E. }\end{array}$ & $\begin{array}{l}\text { NO } \\
\text { NO }\end{array}$ & $\begin{array}{l}\text { NO } \\
\text { NO }\end{array}$ & $\begin{array}{l}\text { NO } \\
\text { NO }\end{array}$ & $\begin{array}{l}\text { NO } \\
\text { NO }\end{array}$ & $\begin{array}{l}\text { NO } \\
\text { NO }\end{array}$ & $\begin{array}{l}\text { NO } \\
\text { NO }\end{array}$ & $\begin{array}{l}\text { NO } \\
\text { nO }\end{array}$ & $\begin{array}{l}\text { NO } \\
\text { NO }\end{array}$ \\
\hline p-value & 0.00 & 0.00 & 0.00 & 0.00 & 0.00 & 0.00 & 0.00 & 0.00 \\
\hline N Firms & 584 & 584 & 583 & 583 & 584 & 584 & 583 & 583 \\
\hline $\mathrm{N}$ & 18875 & 18875 & 7613 & 7613 & 18875 & 18875 & 7613 & 7613 \\
\hline
\end{tabular}

Notes: Each regression contains the following controls measured in the base year: work experience, work experience squared, sex, age, number of children, marital status, education, local unemployment (municipality), region fixed effects, firm size, exporter status, and the shares of high- and lowskilled workers in the firm (the residual group is omitted). "Mech." stands for mechanical changes. Observations are weighted by labor income. F-stat Excl. Inst. refers to the Angrist-Pischke F-statistic. Standard errors in parentheses are clustered at the firm level. * $p<0.10$, ** $p<0.05, * * * p<0.01$

Table D.34: First-stage regression relative to Table 6

\begin{tabular}{|c|c|c|c|c|c|c|c|c|c|c|c|c|}
\hline & $\begin{array}{c}(1) \\
\Delta \log \overline{h^{H}} \\
\end{array}$ & $\begin{array}{c}(2) \\
\Delta \log \left(1-\tau^{L}\right) \\
\end{array}$ & $\begin{array}{c}(3) \\
\Delta \log \overline{h^{H}}\end{array}$ & $\begin{array}{c}(4) \\
\Delta \log \left(1-\tau^{L}\right) \\
\end{array}$ & $\begin{array}{c}(5) \\
\Delta \log \overline{h^{H}}\end{array}$ & $\begin{array}{c}(6) \\
\Delta \log \left(1-\tau^{L}\right) \\
\end{array}$ & $\begin{array}{c}(7) \overline{ } \\
\Delta \log \overline{h^{H}}\end{array}$ & $\begin{array}{c}(8) \\
\Delta \log \left(1-\tau^{L}\right) \\
\end{array}$ & $\begin{array}{c}(9) \\
\Delta \log \overline{h_{\text {total }}^{H}}\end{array}$ & $\begin{array}{c}(10) \\
\Delta \log \left(1-\tau^{L}\right) \\
\end{array}$ & $\begin{array}{c}(11) \\
\Delta \log \overline{h_{\text {total }}^{H}}\end{array}$ & $\begin{array}{c}(12) \\
\Delta \log \left(1-\tau^{L}\right)\end{array}$ \\
\hline$\Delta \log \left(\overline{1-\tau^{H}}\right)$ Mech. & $\begin{array}{c}-0.432^{* * * *} \\
(0.163)\end{array}$ & $\begin{array}{l}-0.185^{*} \\
(0.111)\end{array}$ & $\begin{array}{c}-0.432^{* * * *} \\
(0.163)\end{array}$ & $\begin{array}{l}-0.178^{*} \\
(0.097)\end{array}$ & $\begin{array}{c}-0.438^{* *} \\
(0.193)\end{array}$ & $\begin{array}{c}0.139 \\
(0.118)\end{array}$ & $\begin{array}{c}-0.545^{* * * *} \\
(0.192)\end{array}$ & $\begin{array}{l}-0.187 \\
(0.152)\end{array}$ & $\begin{array}{l}-0.277 \\
(0.178)\end{array}$ & $\begin{array}{l}-0.178^{*} \\
(0.097)\end{array}$ & $\begin{array}{c}-0.495^{* * *} \\
(0.194)\end{array}$ & $\begin{array}{l}-0.187 \\
(0.152)\end{array}$ \\
\hline$\Delta \log \left(1-\tau^{L}\right)$ & $\begin{array}{l}-0.063^{*} \\
(0.036) \\
\end{array}$ & $\begin{array}{c}0.649^{* * * *} \\
(0.051) \\
\end{array}$ & $\begin{array}{l}-0.061 \\
(0.037) \\
\end{array}$ & $\begin{array}{c}0.492^{* * *} \\
(0.060) \\
\end{array}$ & $\begin{array}{l}-0.061 \\
(0.037) \\
\end{array}$ & $\begin{array}{c}0.478 * * * \\
(0.059) \\
\end{array}$ & $\begin{array}{c}-0.143^{* *} \\
(0.056) \\
\end{array}$ & $\begin{array}{c}0.858 * * * \\
(0.113) \\
\end{array}$ & $\begin{array}{l}-0.038 \\
(0.037) \\
\end{array}$ & $\begin{array}{c}0.492^{* * *} \\
(0.060) \\
\end{array}$ & $\begin{array}{l}-0.107^{*} \\
(0.061) \\
\end{array}$ & $\begin{array}{c}0.858^{* * * *} \\
(0.113) \\
\end{array}$ \\
\hline $\begin{array}{l}\text { Region F.E. } \\
\text { Splines of log t-1 Inc. and }\end{array}$ & YES & YES & YES & YES & YES & YES & YES & YES & YES & YES & YES & YES \\
\hline$\Delta \log$ inc. $t-1-t$ & NO & NO & YES & YES & YES & YES & YES & YES & YES & YES & YES & YES \\
\hline Log Mean Inc. High Sk. & NO & NO & NO & NO & YES & YES & NO & NO & NO & NO & NO & NO \\
\hline Overtime Hours & NO & NO & NO & NO & NO & NO & NO & NO & YES & YES & YES & YES \\
\hline F-stat Excl. Inst. & 13.09 & 160.40 & 15.45 & 76.76 & 4.66 & 55.84 & 11.90 & 48.55 & 4.43 & 76.72 & 8.39 & 50.92 \\
\hline P-value Excl. Inst. & 0.00 & 0.00 & 0.00 & 0.00 & 0.03 & 0.00 & 0.00 & 0.00 & 0.04 & 0.00 & 0.00 & 0.00 \\
\hline N Firms & 968 & 968 & 968 & 968 & 968 & 968 & 484 & 484 & 968 & 968 & 484 & 484 \\
\hline $\mathrm{N}$ & 10091 & 10091 & 10091 & 10091 & 10091 & 10091 & 4100 & 4100 & 10091 & 10091 & 4100 & 4100 \\
\hline
\end{tabular}

Notes: Each regression contains the following controls measured in the base year: work experience, work experience squared, sex, age, number of children, marital status, education, local unemployment (municipality), region fixed effects, firm size, exporter status, and the shares of high- and low-skilled workers in the firm (the residual group is omitted). Observations are weighted by labor income. "Mech." stands for mechanical change. F-stat Excl. Inst. refers to the Angrist-Pischke F-statistic. Standard errors in parentheses are clustered at the firm level. * $p<0.10$, ** $p<0.05$, *** $p<0.01$. 


\section{D.3 Standard deviation of hours definition 2: tables and graphs}

In this section, we present the results of a parallel analysis performed using the standard deviation of hours across skill groups, where skill groups are defined at the the intersection of 3 educational groups (i.e., primary, secondary and tertiary education) and 3 broad occupational categories (i.e., manager, middle manager and blue collar) (Section 4.3).

Figure D.7: Tasks and coordination of hours (Def. 2 education-occupation)
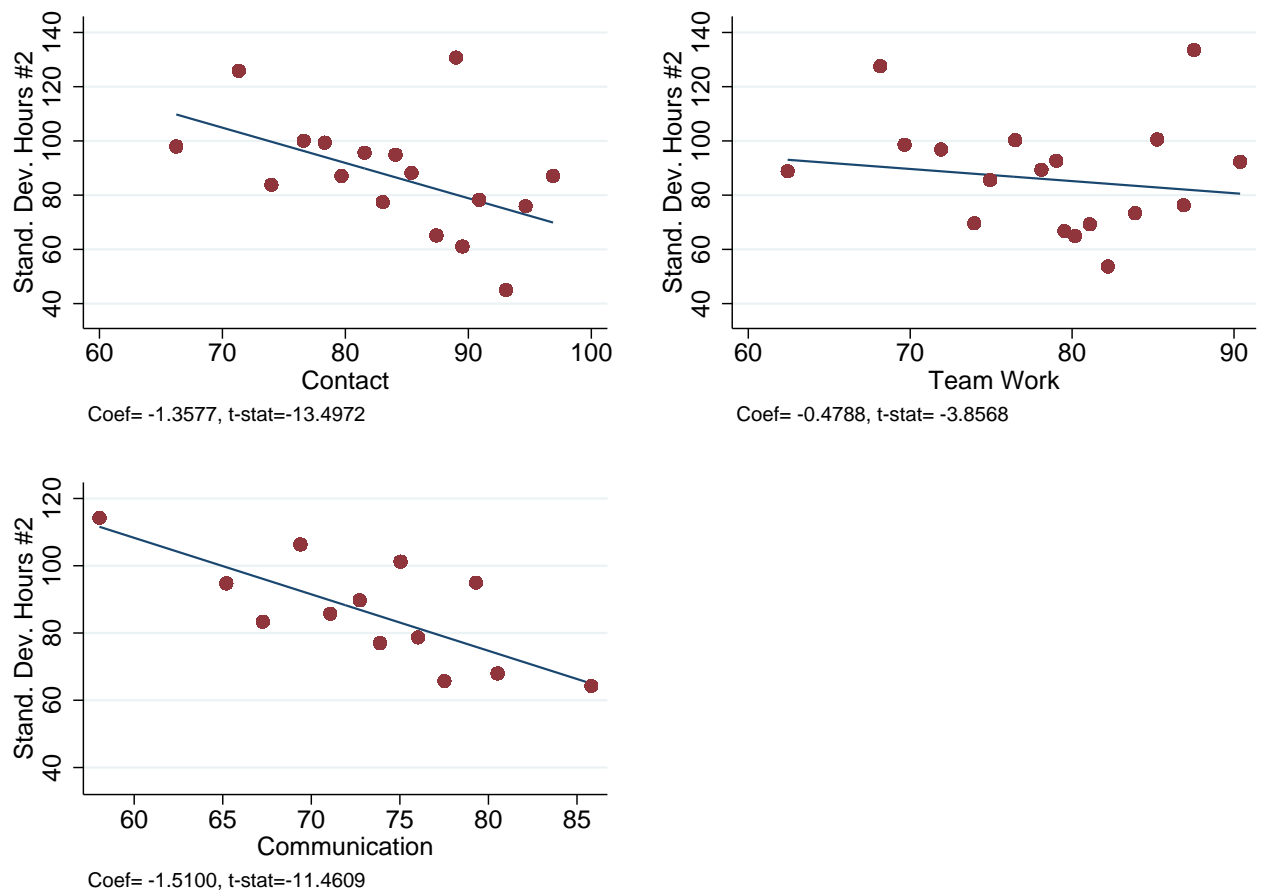

Notes: We group firms into 20 equally sized bins based on the variable on the $\mathrm{x}$-axis. 
Figure D.8: PIAAC validation exercise coordination (Def. 2)
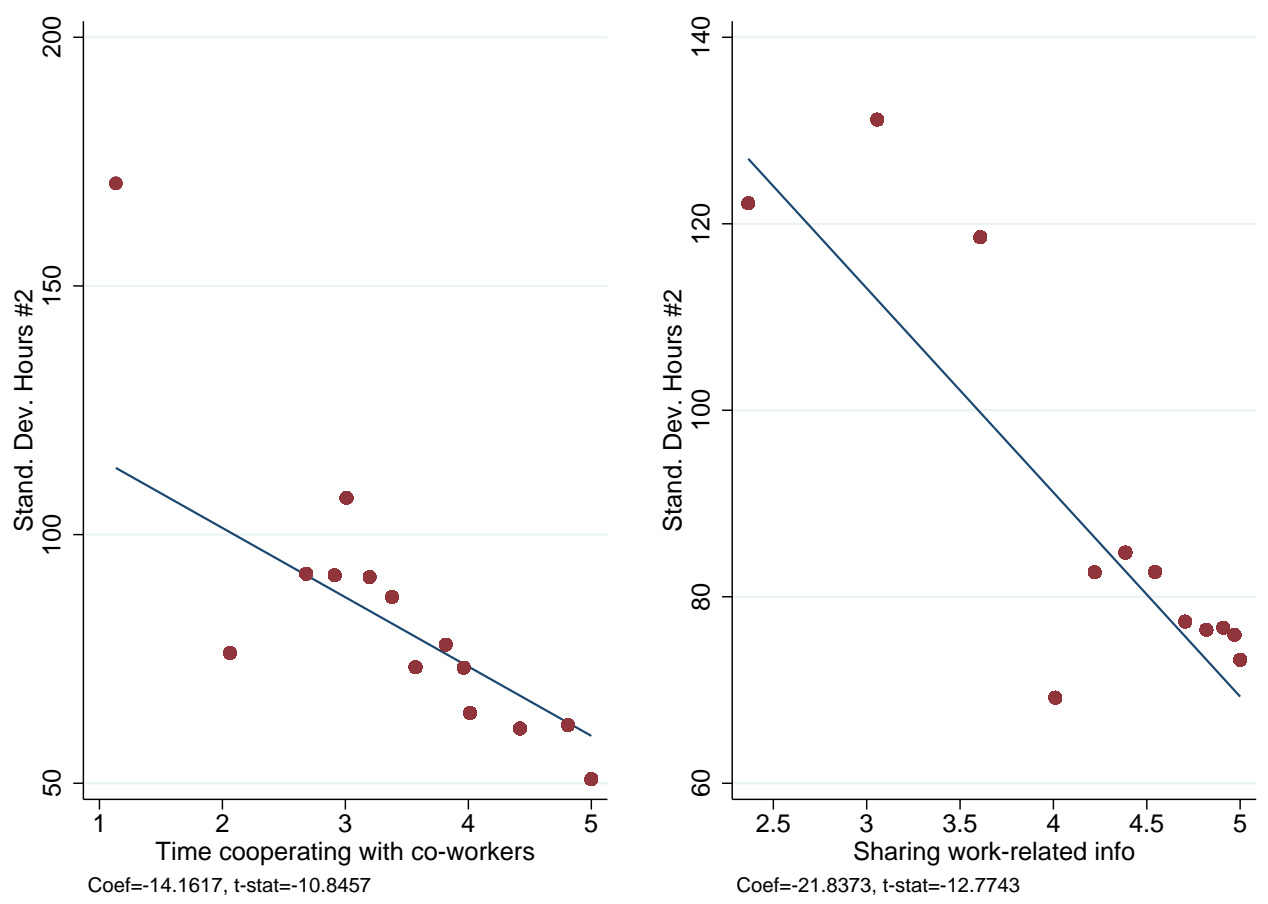

Notes: We group firms into 20 equally sized bins based on the variable on the $\mathrm{x}$-axis

Table D.35: Coordination by sector (def. 2)

Std. Dev. hours Def. 2

(education occupation)

\section{Coordination by Industry (2003-2011)}

Mean Std. Dev.

Agriculture, forestry and fishing, mining and quarrying $\quad 112.25 \quad 101.70$

Manufacturing

$98.55 \quad 80.31$

Constructions

$129.04 \quad 96.06$

Electricity, gas, steam and air conditioning supply,

Trade and transport

$68.15 \quad 86.97$

Financial and insurance, Real estate, Other business $\quad 79.00 \quad 80.38$

Public administration, education, health,

arts, entertainment and other services

$67.41 \quad 65.92$

Overall sectors

87.79

89.60

Observations

8182

Notes: 
Table D.36: Coordination and firm characteristics (Def. 2)

\begin{tabular}{|c|c|c|c|}
\hline & \multicolumn{2}{|c|}{$\begin{array}{c}\text { Stand. Dev. Def. } 2 \\
\text { (education-occupation) }\end{array}$} & \multirow[t]{2}{*}{ Obs. } \\
\hline & (1) & $(2)$ & \\
\hline V.A. /employee & $\begin{array}{c}-0.037^{* * *} \\
(0.008)\end{array}$ & $\begin{array}{l}-0.014^{*} \\
(0.007)\end{array}$ & 17714 \\
\hline Capital/employee & $\begin{array}{l}-0.006 \\
(0.007)\end{array}$ & $\begin{array}{c}-0.005^{* * *} \\
(0.001)\end{array}$ & 17714 \\
\hline Sales/employee & $\begin{array}{c}-0.042^{* * *} \\
(0.009)\end{array}$ & $\begin{array}{l}-0.004 \\
(0.020)\end{array}$ & 17714 \\
\hline TFP & $\begin{array}{c}-0.112^{* * *} \\
(0.008)\end{array}$ & $\begin{array}{c}-0.061^{* * *} \\
(0.013)\end{array}$ & 16148 \\
\hline Firm size & $\begin{array}{c}-0.018^{* *} \\
(0.007)\end{array}$ & $\begin{array}{c}-0.050 * * * \\
(0.015)\end{array}$ & 17714 \\
\hline Share of tertiary educ. & $\begin{array}{c}-0.139 * * * \\
(0.008)\end{array}$ & $\begin{array}{c}-0.061^{* * *} \\
(0.014)\end{array}$ & 17714 \\
\hline Number of plants & $\begin{array}{c}-0.022^{* * *} \\
(0.007)\end{array}$ & $\begin{array}{l}-0.027 \\
(0.017)\end{array}$ & 17714 \\
\hline Exporter status & $\begin{array}{c}-0.133^{* * *} \\
(0.007)\end{array}$ & $\begin{array}{l}-0.009 \\
(0.010)\end{array}$ & 17714 \\
\hline Fraction of hourly work. & $\begin{array}{c}0.317^{* * *} \\
(0.007)\end{array}$ & $\begin{array}{c}0.235^{* * *} \\
(0.017)\end{array}$ & 17714 \\
\hline Fraction of Unionized work. & $\begin{array}{c}0.095^{* * *} \\
(0.008)\end{array}$ & $\begin{array}{l}0.025^{* *} \\
(0.012)\end{array}$ & 17714 \\
\hline Fraction of Females & $\begin{array}{c}-0.019 * * \\
(0.008)\end{array}$ & $\begin{array}{c}0.061^{* * *} \\
(0.016)\end{array}$ & 17714 \\
\hline Fraction of Part-Time work & $\begin{array}{c}0.207^{* * *} \\
(0.008)\end{array}$ & $\begin{array}{c}0.121^{* * *} \\
(0.014)\end{array}$ & 17714 \\
\hline Mean Managerial Ability & $\begin{array}{c}-0.055^{* * *} \\
(0.008)\end{array}$ & $\begin{array}{c}-0.022^{* *} \\
(0.011)\end{array}$ & 17714 \\
\hline Negotiation & $\begin{array}{c}-0.291^{* * *} \\
(0.009)\end{array}$ & $\begin{array}{c}-0.128^{* * *} \\
(0.015)\end{array}$ & 16401 \\
\hline Persuasion & $\begin{array}{c}-0.298^{* * *} \\
(0.009)\end{array}$ & $\begin{array}{c}-0.134^{* * *} \\
(0.015)\end{array}$ & 13353 \\
\hline Social Perceptiveness & $\begin{array}{c}-0.277^{* * *} \\
(0.009)\end{array}$ & $\begin{array}{c}-0.099 * * * \\
(0.015)\end{array}$ & 13353 \\
\hline Adjust Actions to others & $\begin{array}{c}-0.146^{* * *} \\
(0.009)\end{array}$ & $\begin{array}{c}-0.063^{* * *} \\
(0.013)\end{array}$ & 13353 \\
\hline 5 digits industry f.e. & NO & YES & \\
\hline
\end{tabular}

Notes: The table shows standardized coefficients from a regression of the standard deviation of hours across skill groups on firm characteristics. Each cell is a different regression. TFP is obtained from the procedure described in Appendix B.4. To avoid confusion, we label the $O * N E T$ descriptor "Coordination" as "Adjust Actions to Others". Standard errors in parentheses are clustered at the firm level. * ${ }^{*}<0.10$, ** $p<0.05$, *** $p<0.01$. 
Table D.37: Coordination and wage premiums

\begin{tabular}{|c|c|c|c|c|c|c|}
\hline Stand. Dev. Def. 2 & $\begin{array}{c}(1) \\
\text { Firm f.e. } \\
-0.070^{* * *} \\
(0.019)\end{array}$ & $\begin{array}{c}(2) \\
\text { Firm f.e. } \\
-0.047^{* *} \\
(0.018)\end{array}$ & $\begin{array}{c}(3) \\
\text { Firm f.e. } \\
-0.042^{* *} \\
(0.018)\end{array}$ & $\begin{array}{c}(4) \\
\text { Firm f.e. } \\
-0.077^{* * *} \\
(0.016)\end{array}$ & $\begin{array}{c}(5) \\
\text { Firm f.e. }\end{array}$ & $\begin{array}{c}(6) \\
\text { Firm f.e. } \\
-0.038^{* *} \\
(0.016)\end{array}$ \\
\hline Stand. Dev. Normal Hours & & & & & $\begin{array}{c}-0.044^{* *} \\
(0.019)\end{array}$ & \\
\hline Firm size & & $\begin{array}{l}0.015^{*} \\
(0.007)\end{array}$ & $\begin{array}{c}0.014^{* *} \\
(0.006)\end{array}$ & $\begin{array}{c}0.038^{* * *} \\
(0.014)\end{array}$ & $\begin{array}{c}0.014^{* *} \\
(0.007)\end{array}$ & $\begin{array}{c}0.012^{* *} \\
(0.005)\end{array}$ \\
\hline Exporter status & & $\begin{array}{c}0.069^{* * *} \\
(0.015)\end{array}$ & $\begin{array}{c}0.083^{* * *} \\
(0.017)\end{array}$ & $\begin{array}{c}0.085^{* * *} \\
(0.025)\end{array}$ & $\begin{array}{c}0.084^{* * * *} \\
(0.018)\end{array}$ & $\begin{array}{c}0.081^{* * *} \\
(0.016)\end{array}$ \\
\hline Union. Rate & & $\begin{array}{l}-0.003 \\
(0.025)\end{array}$ & $\begin{array}{c}0.047^{*} \\
(0.026)\end{array}$ & $\begin{array}{c}0.038 \\
(0.029)\end{array}$ & $\begin{array}{l}0.046^{*} \\
(0.026)\end{array}$ & $\begin{array}{c}0.053^{* *} \\
(0.025)\end{array}$ \\
\hline Female Share & & $\begin{array}{l}-0.055 \\
(0.045)\end{array}$ & $\begin{array}{c}-0.070^{* *} \\
(0.034)\end{array}$ & $\begin{array}{c}-0.077^{* * * *} \\
(0.028)\end{array}$ & $\begin{array}{c}-0.067^{*} \\
(0.035)\end{array}$ & $\begin{array}{c}-0.049^{* *} \\
(0.019)\end{array}$ \\
\hline Average Hours & & $\begin{array}{c}0.003 \\
(0.025)\end{array}$ & $\begin{array}{l}-0.011 \\
(0.025)\end{array}$ & $\begin{array}{c}0.002 \\
(0.023)\end{array}$ & $\begin{array}{l}-0.012 \\
(0.025)\end{array}$ & $\begin{array}{l}-0.039 \\
(0.026)\end{array}$ \\
\hline $\log (\mathrm{Cap} / \mathrm{empl})$ & & $\begin{array}{c}0.038^{* * *} \\
(0.012)\end{array}$ & $\begin{array}{c}0.067^{* * * *} \\
(0.013)\end{array}$ & $\begin{array}{c}0.083^{* * *} \\
(0.017)\end{array}$ & $\begin{array}{c}0.067^{* * *} \\
(0.013)\end{array}$ & $\begin{array}{c}0.064^{* * *} \\
(0.014)\end{array}$ \\
\hline Negotiation & & & & & & $\begin{array}{c}0.201 \\
(0.123)\end{array}$ \\
\hline Persuasion & & & & & & $\begin{array}{c}-0.151^{* * *} \\
(0.056)\end{array}$ \\
\hline Social Perceptiveness & & & & & & $\begin{array}{c}0.017 \\
(0.068)\end{array}$ \\
\hline Adjust Actions to others & & & & & & $\begin{array}{c}-0.034^{*} \\
(0.017)\end{array}$ \\
\hline Region F.E. & $\mathrm{NO}$ & YES & YES & YES & $\mathrm{NO}$ & YES \\
\hline Compos. cntr & $\mathrm{NO}$ & $\mathrm{NO}$ & YES & YES & $\mathrm{NO}$ & YES \\
\hline Ability Measures & $\mathrm{NO}$ & $\mathrm{NO}$ & YES & YES & & YES \\
\hline Av. Hours b/w 36.5 and 37.5 & YES & YES & YES & $\mathrm{NO}$ & NO & YES \\
\hline Part. R-sq SD Hours & 0.006 & 0.002 & 0.002 & 0.002 & 0.002 & 0.001 \\
\hline Part. R-sq VA and Sales & 0.022 & 0.010 & 0.006 & 0.006 & 0.008 & 0.005 \\
\hline Coordination Share & 0.276 & 0.251 & 0.280 & 0.260 & 0.255 & 0.227 \\
\hline R-sq & 0.006 & 0.031 & 0.072 & 0.073 & 0.072 & 0.079 \\
\hline $\mathrm{N}$ & 7285 & 7285 & 7285 & 4392 & 7271 & 6067 \\
\hline
\end{tabular}

Notes: The "Stand. Dev." is the standard deviation of the average total hours worked across skill groups within a firm. The Stand. Dev. of normal hours is the standard deviation of the average normal hours worked across skill groups within a firm. Skill groups are defined as deciles of the distribution of $\hat{\alpha_{i}}+\hat{\beta} X_{i j t}$ from the AKM model. All regressions show standardized coefficients. The exporter dummy is derived as the modal exporter status between 2003 and 2011. (Cap/empl) stands for physical capital over the number of full-time equivalent employees. "Compos. citr" - refers to betwe "Ability Measures" indicate a vector containing the aver-

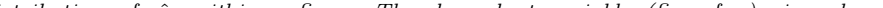
(5) is based on the wage rate from normal hours. To avoid confusion, we label the O*NET descriptor "Coordination" as "Adjust Actions to Oth-

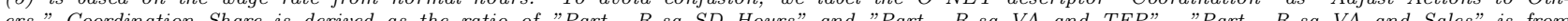
ers." Coordination Share is derived as the ratio of "Part. R-sq SD Hours" and "Part. R-sq VA and TFP". "Part. R-sq VA and Sales" is from Table D.18. Standard errors are clustered at the 2-digit industry level. *, ** and *** are 10, 5 and 1 percent significance levels, respectively. 
Table D.38: Coordination and wage differentials within sectors

\begin{tabular}{|c|c|c|c|c|c|c|c|c|}
\hline & $\begin{array}{c}(1) \\
\text { Firm f.e. }\end{array}$ & $\begin{array}{c}(2) \\
\text { Firm f.e. }\end{array}$ & $\begin{array}{c}(3) \\
\text { Firm f.e. }\end{array}$ & $\begin{array}{c}(4) \\
\text { Firm f.e. }\end{array}$ & $\begin{array}{c}(5) \\
\text { Firm f.e. }\end{array}$ & $\begin{array}{c}(6) \\
\text { Firm f.e. }\end{array}$ & $\begin{array}{c}(7) \\
\text { Firm f.e. }\end{array}$ & $\begin{array}{c}(8) \\
\text { Firm f.e. }\end{array}$ \\
\hline Stand. Dev. Def. 2 & $\begin{array}{c}-0.038^{* *} \\
(0.016)\end{array}$ & $\begin{array}{c}-0.031^{*} \\
(0.017)\end{array}$ & $\begin{array}{l}-0.028 \\
(0.017)\end{array}$ & & & & $\begin{array}{c}-0.038^{* *} \\
(0.019)\end{array}$ & $\begin{array}{c}-0.032^{*} \\
(0.019)\end{array}$ \\
\hline Median Abs. Dev. Def. 2 & & & & $\begin{array}{c}-0.049^{* * *} \\
(0.015)\end{array}$ & $\begin{array}{c}-0.037^{* *} \\
(0.015)\end{array}$ & $\begin{array}{c}-0.034^{* *} \\
(0.015)\end{array}$ & & \\
\hline Firm size & $\begin{array}{c}0.013^{* *} \\
(0.006)\end{array}$ & $\begin{array}{l}0.009 * \\
(0.005)\end{array}$ & $\begin{array}{l}0.021^{*} \\
(0.011)\end{array}$ & $\begin{array}{c}0.013^{* *} \\
(0.005)\end{array}$ & $\begin{array}{l}0.009^{*} \\
(0.005)\end{array}$ & $\begin{array}{l}0.020^{*} \\
(0.010)\end{array}$ & $\begin{array}{c}0.015^{* *} \\
(0.007)\end{array}$ & $\begin{array}{c}0.014^{* *} \\
(0.006)\end{array}$ \\
\hline Exporter status & $\begin{array}{c}0.058^{* * *} \\
(0.017)\end{array}$ & $\begin{array}{c}0.039^{* * *} \\
(0.013)\end{array}$ & $\begin{array}{c}0.031^{* *} \\
(0.013)\end{array}$ & $\begin{array}{c}0.054^{* * *} \\
(0.017)\end{array}$ & $\begin{array}{c}0.037^{* * *} \\
(0.013)\end{array}$ & $\begin{array}{c}0.029 * * \\
(0.013)\end{array}$ & $\begin{array}{c}0.086^{* * *} \\
(0.017)\end{array}$ & $\begin{array}{c}0.077^{* * * *} \\
(0.018)\end{array}$ \\
\hline Union. Rate & $\begin{array}{c}0.038 \\
(0.028)\end{array}$ & $\begin{array}{c}0.035 \\
(0.031)\end{array}$ & $\begin{array}{c}0.033 \\
(0.031)\end{array}$ & $\begin{array}{c}0.038 \\
(0.029)\end{array}$ & $\begin{array}{c}0.035 \\
(0.032)\end{array}$ & $\begin{array}{c}0.033 \\
(0.032)\end{array}$ & $\begin{array}{c}0.050 * * \\
(0.025)\end{array}$ & $\begin{array}{c}0.058^{* * * *} \\
(0.022)\end{array}$ \\
\hline Female Share & $\begin{array}{c}-0.085^{* *} \\
(0.036)\end{array}$ & $\begin{array}{l}-0.037 \\
(0.024)\end{array}$ & $\begin{array}{c}-0.016 \\
(0.021)\end{array}$ & $\begin{array}{c}-0.085^{* *} \\
(0.036)\end{array}$ & $\begin{array}{c}-0.037 \\
(0.025)\end{array}$ & $\begin{array}{l}-0.017 \\
(0.023)\end{array}$ & $\begin{array}{c}-0.078^{* *} \\
(0.033)\end{array}$ & $\begin{array}{c}-0.063^{* *} \\
(0.025)\end{array}$ \\
\hline Average Hours & $\begin{array}{l}-0.019 \\
(0.023)\end{array}$ & $\begin{array}{l}-0.030 \\
(0.024)\end{array}$ & $\begin{array}{c}-0.036 \\
(0.023)\end{array}$ & $\begin{array}{l}-0.022 \\
(0.021)\end{array}$ & $\begin{array}{c}-0.033 \\
(0.022)\end{array}$ & $\begin{array}{c}-0.038^{*} \\
(0.021)\end{array}$ & $\begin{array}{l}-0.013 \\
(0.025)\end{array}$ & $\begin{array}{l}-0.019 \\
(0.025)\end{array}$ \\
\hline $\log (\mathrm{Cap} / \mathrm{empl})$ & $\begin{array}{c}0.057^{* * *} \\
(0.010)\end{array}$ & $\begin{array}{c}0.043^{* * *} \\
(0.010)\end{array}$ & $\begin{array}{c}0.044^{* * * *} \\
(0.010)\end{array}$ & $\begin{array}{c}0.058^{* * *} \\
(0.011)\end{array}$ & $\begin{array}{c}0.045^{* * *} \\
(0.010)\end{array}$ & $\begin{array}{c}0.047^{* * * *} \\
(0.011)\end{array}$ & $\begin{array}{c}0.067 * * * \\
(0.013)\end{array}$ & $\begin{array}{c}0.021 \\
(0.029)\end{array}$ \\
\hline $\log (\mathrm{VA} / \mathrm{empl})$ & & & & & & & & $\begin{array}{c}0.145^{* *} \\
(0.071)\end{array}$ \\
\hline Region f.e. & YES & YES & YES & YES & YES & YES & YES & YES \\
\hline Compos. and Ability cntr. & YES & YES & YES & YES & YES & YES & YES & YES \\
\hline 1 digit Sector f.e. & YES & NO & NO & YES & NO & NO & NO & NO \\
\hline 2 digits Sector f.e. & $\mathrm{NO}$ & YES & $\mathrm{NO}$ & NO & YES & NO & NO & NO \\
\hline 3 digits Sector f.e. & $\mathrm{NO}$ & $\mathrm{NO}$ & YES & $\mathrm{NO}$ & $\mathrm{NO}$ & YES & YES & YES \\
\hline Part. R-sq SD Hours & 0.001 & 0.001 & 0.001 & 0.002 & 0.001 & 0.001 & 0.002 & \\
\hline Part. R-sq VA and Sales & 0.009 & 0.005 & 0.004 & 0.009 & 0.005 & 0.004 & & \\
\hline Coordination Share & 0.163 & 0.171 & 0.150 & 0.113 & 0.276 & 0.237 & & \\
\hline R-sq & 0.065 & 0.087 & 0.091 & 0.066 & 0.088 & 0.092 & 0.076 & 0.083 \\
\hline $\mathrm{N}$ & 7240 & 7240 & 7240 & 7306 & 7306 & 7306 & 7035 & 7035 \\
\hline
\end{tabular}

Notes: The "Stand. Dev." is the standard deviation of the average total hours worked across skill groups within a firm. The Median Abs. Dev. is the the median absolute deviation of median hours across all skill groups within a firm. Skill groups are defined as deciles of the distribution of $\hat{\alpha}_{i}+\hat{\beta} X_{i j t}$ from the AKM model. All regressions show standardized coefficients. Exporter and industry dummies are based on the median value between 2003 and 2011. (Cap/empl) stands for physical capital over the number of full-time equivalent employees. In column (8), TFP is used as an instrument for valued added per employee $(\log (V . A . / e m p l))$. TFP is obtained as described in Appendix B.4. "Compos. cntr" refers to a vector of controls for the share of workers in each skill group. "Ability Measures" indicate a vector containing the average value of the individual fixed effects $\hat{\alpha}_{i}$ in each quartile of the distribution of $\hat{\alpha}_{i}$ within a firm . Coordination share is derived as the ratio of "Part. $R$-sq SD Hours" and "Part. R-sq VA and TFP". "Part. R-sq VA and Sales" is from Table D.19. Standard errors are clustered at the 2-digit industry level. *, ** and *** are 10, 5 and 1 percent significance levels, respectively. 


\section{References}

Abowd, J. M., Creecy, R. H., and Kramarz, F. (2002). Computing person and firm effects using linked longitudinal employeremployee data. Cornell University. Working paper.

Ackerberg, D. A., Caves, K., and Frazer., G. (2015). Identification properties of recent production function estimators. Econometrica., 83 (6):2411 - 2451.

Arizo, K., Hotz, J., and Per, J. (2016). Family friendly firms? Worker mobility, firm attributes, and wage trajectories of women and men. working paper.

Borjas, G. (1980). The relationship between wages and weekly hours of work: The role of division bias. Journal of Human Resources, 15:409-423.

Card, D., Cardoso, A., and Kline, P. (2016). Bargaining, sorting, and the gender wage gap: Quantifying the impact of firms on the relative pay of women. Quarterly Journal of Economics, 131 (2):633-686.

Card, D., Heining, J., and Kline, P. (2013). Workplace heterogeneity and the rise of west german wage inequality. The Quarterly Journal of Economics, 128 (3):967-1015.

Cornelissen, T., Dustmann, C., and Schnberg, U. (2017). Peer effects in the workplace. American Economic Review, 107(2):425-56.

Dahl, G. B. and Lochner, L. (2012). The impact of family income on child achievement: Evidence from the earned income tax credit. American Economic Review, 102(5):1927-56.

Gruber, J. and Saez, E. (2002). Elasticity of taxable income: Evidence and implications. Journal of Public Economics, 84:1-32.

Kleven, H. J. and Schultz, E. (2014). Estimating taxable income responses using danish tax reforms. American Economic Journal: Economic Policy, 6(4):271-301.

Kopczuk, W. (2005). Tax bases, tax rates and the elasticity of reported income. Journal of Public Economics, 89:2093-2119.

Lavetti, K. and Schmutte, I. (2016). Estimating compensating wage differentials with endogenous job mobility. working paper.

Olley, G. S. and Pakes, A. (1996). The dynamics of productivity in the telecommunications equipment industry. Econometrica, 64 (6):1263-1297.

Song, J., Price, D. J., Guvenen, F., Bloom, N., and von Watcher, T. (2016). Firming up wage inequality. work in progress.

Van Reenen, J. (1996). Wages and innovation in a panel of u.k. companies. The Quarterly Journal of Economics, 111:195-226. 